NIST GCR 17-013

\title{
Further Development of a Conceptual Framework for Assessing Resilience at the Community Scale
}

\author{
Alexis Kwasinski \\ University of Pittsburgh \\ Joseph Trainor \\ University of Delaware \\ Royce Francis \\ George Washington University \\ Cynthia Chen \\ University of Washington \\ Francis M. Lavelle \\ Applied Research Associates, Inc.
}


NIST GCR 17-013

\title{
Further Development of a Conceptual Framework for Assessing Resilience at the Community Scale
}

\author{
Prepared for \\ U.S. Department of Commerce \\ Engineering Laboratory \\ National Institute of Standards and Technology \\ Gaithersburg, MD 20899 \\ By \\ Alexis Kwasinski \\ University of Pittsburgh \\ Joseph Trainor \\ University of Delaware \\ Royce Francis \\ George Washington University \\ Cynthia Chen \\ University of Washington \\ Francis M. Lavelle \\ Applied Research Associates, Inc.
}

This publication is available free of charge from:

https://doi.org/10.6028/NIST.GCR.17-013

July 2017

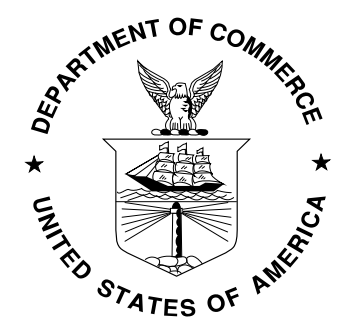

U.S. Department of Commerce Wilbur L. Ross, Jr., Secretary

National Institute of Standards and Technology Kent Rochford, Acting NIST Director and Under Secretary of Commerce for Standards and Technology 


\section{Disclaimer}

This publication was produced as part of contract SB1341-12-CQ-0014, Task Order 15-369 with the National Institute of Standards and Technology. The contents of this publication do not necessarily reflect the views or policies of the National Institute of Standards and Technology or the US Government. 


\section{Acknowledgments}

This report documents research conducted by the authors under the Community Resilience Assessment Methodology task order of the Disaster and Failure Studies Program (NIST contract SB1341-12-CQ-0014, Task Order 15-369).

The NIST Project Manager and Technical Point of Contact for this Task Order was Mr. Stephen A. Cauffman. The authors would like to express our gratitude to Mr. Cauffman for his guidance and feedback throughout the course of the project. 
This Page Intentionally Left Blank 


\section{Contents}

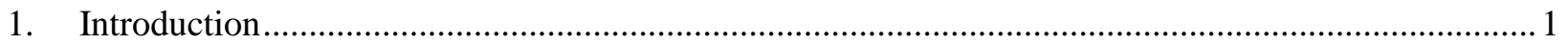

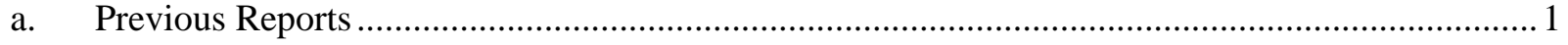

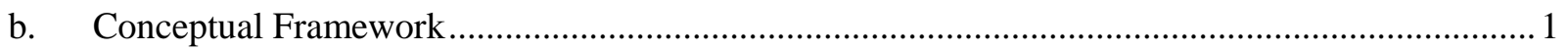

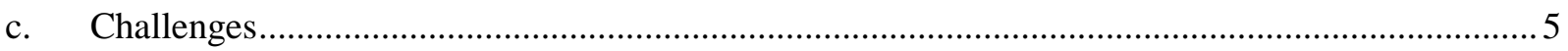

d. Conclusions from the Community Health Dimension Assessment .............................................. 6

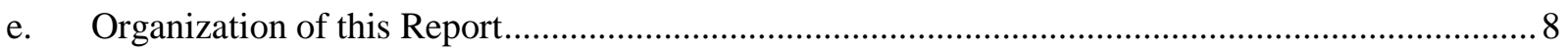

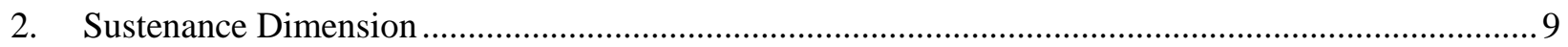

a. Definition and Overview of the Community Sustenance Dimension............................................ 9

b. Description of the Infrastructure Systems Involved in the Community Sustenance Dimension ... 10

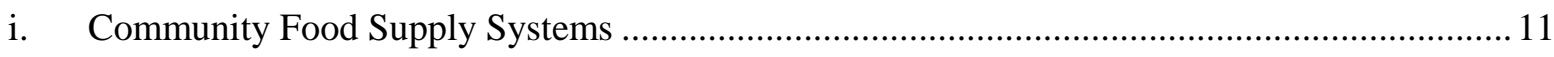

ii. Community Water Distribution Networks....................................................................... 11

c. Notable Features of the Community Sustenance Dimension..................................................... 11

d. Community Services, Systems and Resources Supporting the Sustenance Dimension ................ 12

i. Community Services Supporting the Community Sustenance Dimension................................. 13

ii. Community Systems and Resources Supporting the Community Sustenance Dimension.......... 14

e. What Should Be Measured to Characterize the Community Sustenance Dimension? ................... 16

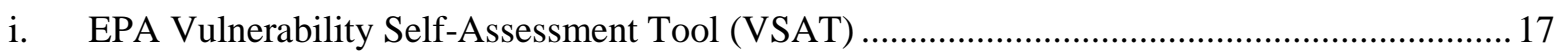

ii. EPA Water Health and Economic Analysis Tool (WHEAT) .................................................. 17

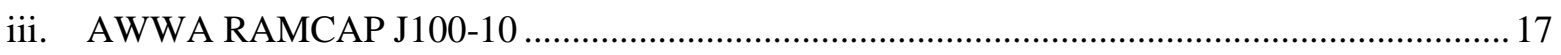

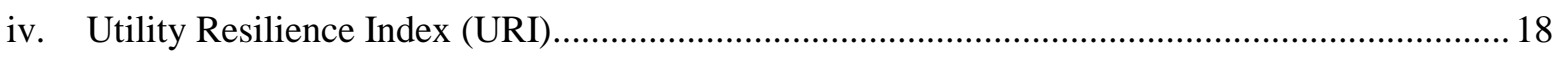

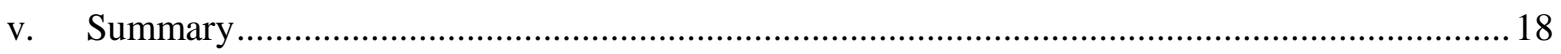

f. Other Efforts Relevant to the Community Sustenance Dimension............................................. 19

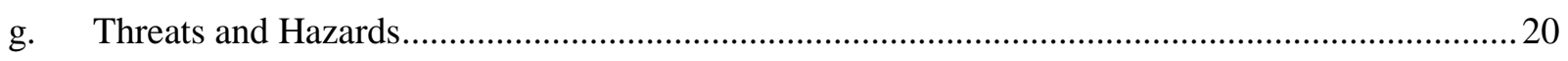

h. Impact of Routine Maintenance and Financial Operations on Community Function....................23

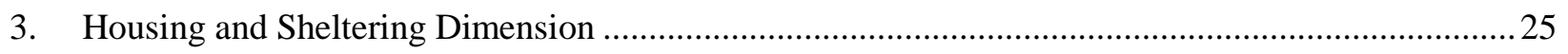

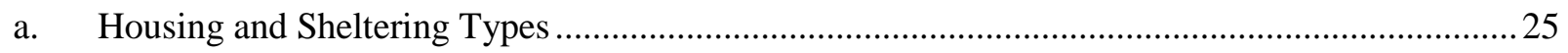

b. Attributes of the Housing and Shelter Dimension and its Related Services and Systems .............29

c. $\quad$ Meaning of Resilience for the H\&S Dimension and Services .................................................... 32

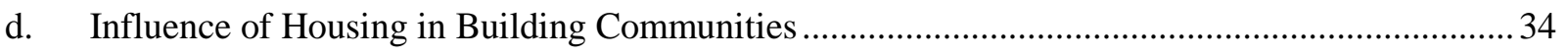

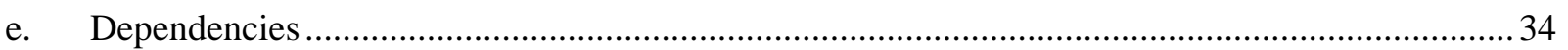

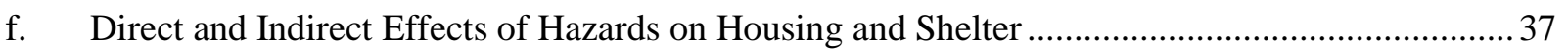

g. Relationships between Housing and Sheltering and other Community Dimensions..................... 38

h. Resilience Assessment of the Housing and Shelter Dimension.................................................. 40

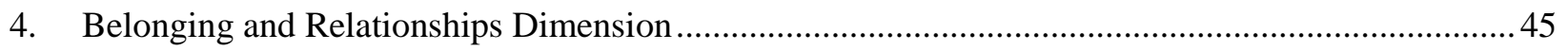




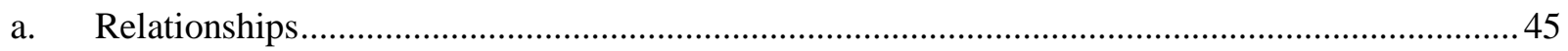

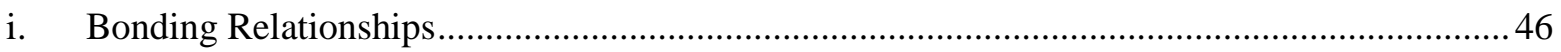

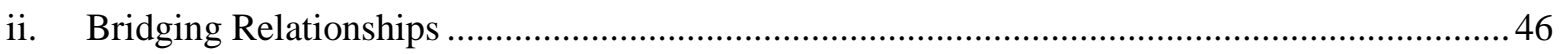

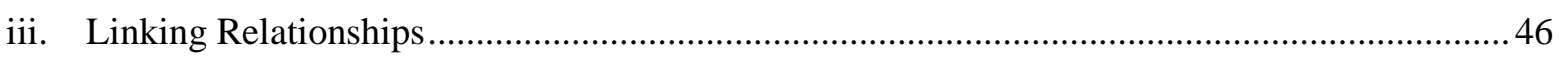

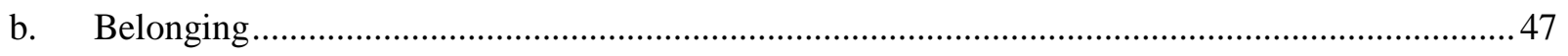

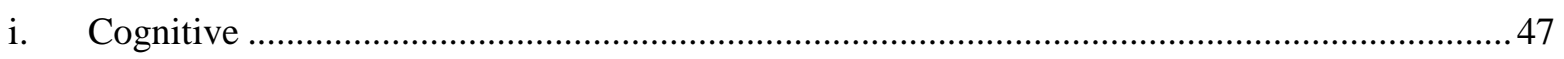

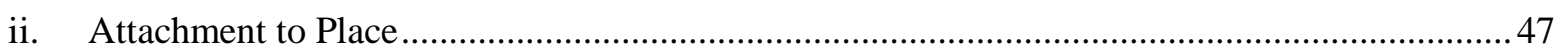

c. Attributes of the Belonging and Relationships Dimension and its Related Services and Systems 48

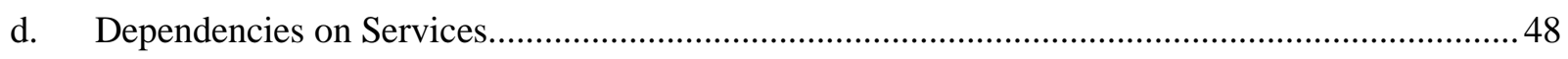

e. Measurement of Belonging and Relationships .................................................................... 50

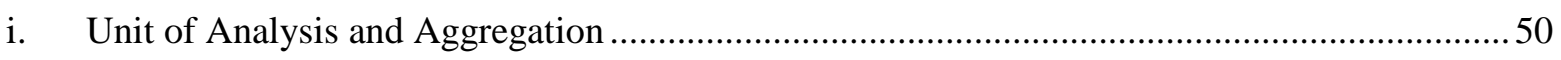

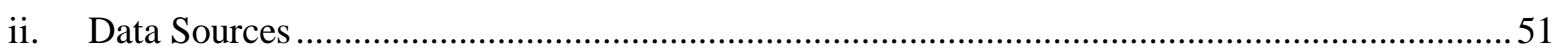

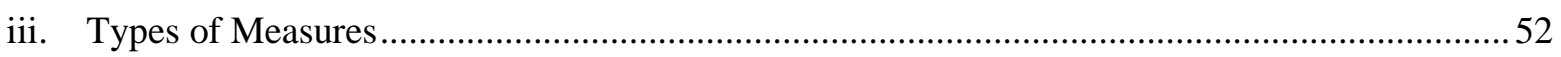

f. Belonging and Relationship Community Program Examples ................................................... 53

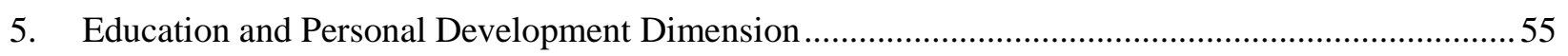

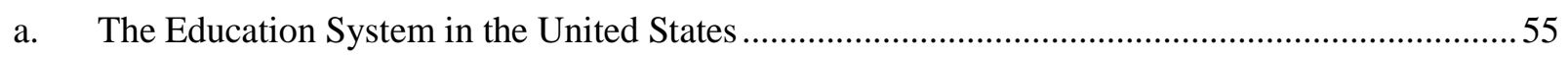

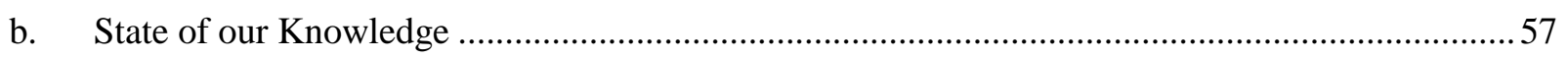

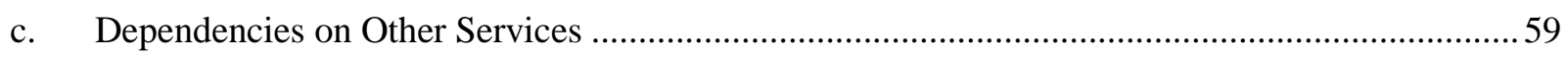

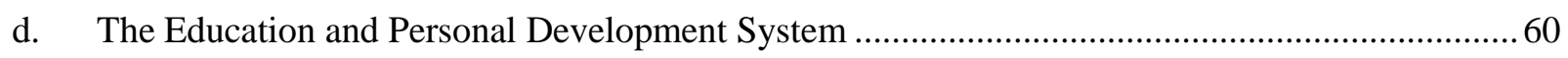

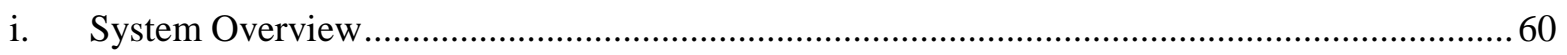

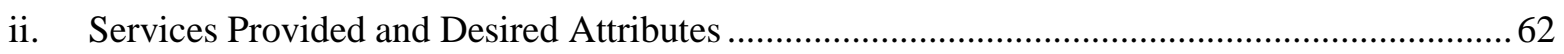

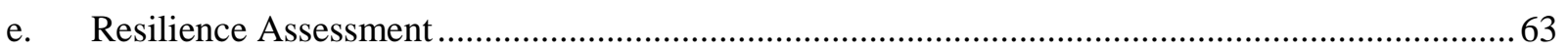

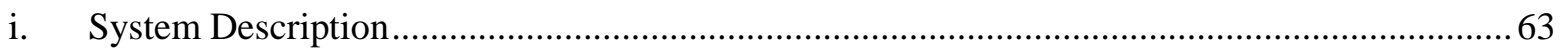

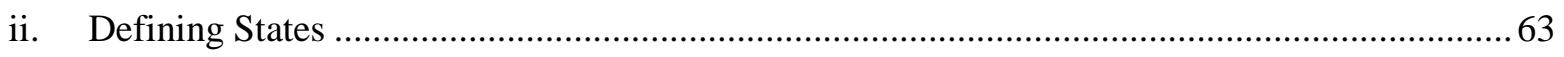

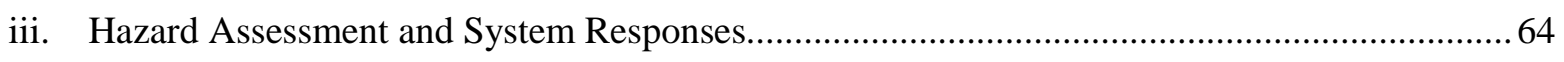

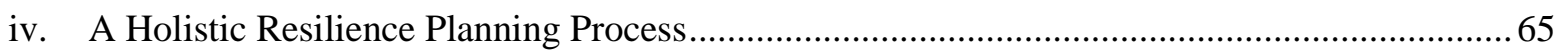

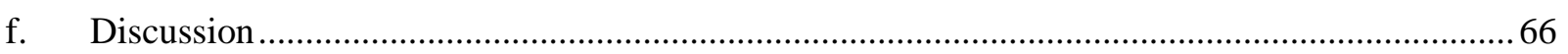

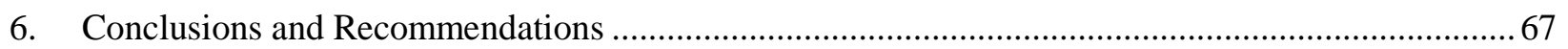

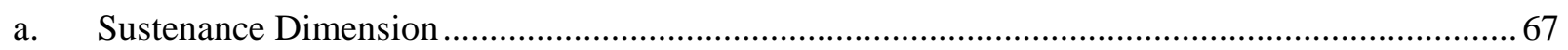

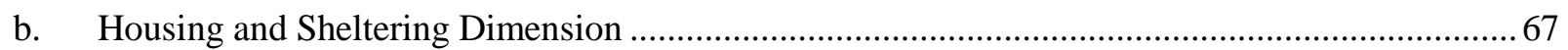

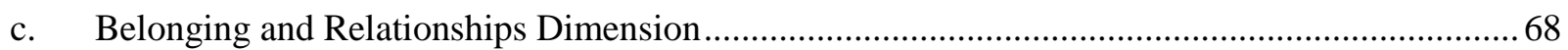

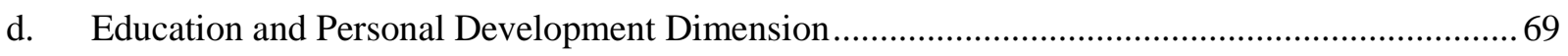

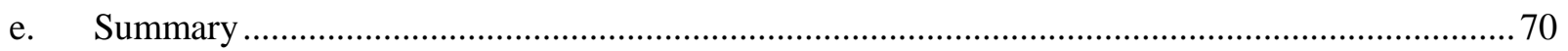

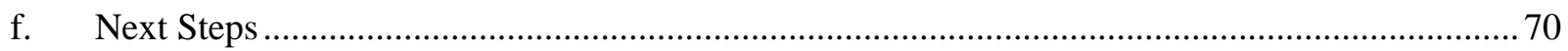

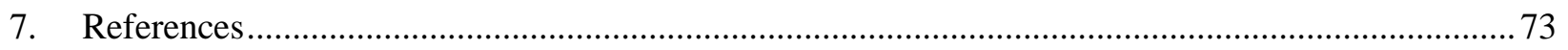




\section{Introduction}

As part of its community resilience program, the National Institute of Standards and Technology (NIST) is sponsoring the Community Resilience Assessment Methodology (CRAM) project. The CRAM project team is working in parallel with several other NIST initiatives, including: the Community Resilience Planning Guide for Buildings and Infrastructure Systems (https://www.nist.gov/el/resilience/communityresilience-planning-guides), the Center for Risk-Based Community Resilience Planning (http://resilience.colostate.edu/), and the Community Resilience Panel for Buildings and Infrastructure Systems (https://www.crpanel.org/).

The objective of the CRAM project is to develop a foundation for assessing resilience at the community scale. For the purposes of this project, community resilience is defined as "the ability to prepare for and adapt to changing conditions and to withstand and recover rapidly from disruptions" (PPD-21 2013), and a community is defined as "a place designated by geographical boundaries that functions under the jurisdiction of a governance structure, such as a town, city, or county” (NIST 2015).

\section{a. Previous Reports}

This is the third report produced under the CRAM project. The primary objective of the first report (Lavelle et al. 2015) was to review and critically assess a set of nine existing tools and methodologies that could be helpful in assessing community resilience. Each identified tool or methodology was found to address one or more important aspects of community resilience assessment, but each had important limitations, such as little or no treatment of interdependencies or recovery times, inability to assess both physical and social systems, or applicable only to specific types of hazards. The authors recommended that an attempt be made to combine the best features of several existing and emerging methodologies to produce a new community resilience assessment methodology that would address the community planning needs identified in the NIST Guide (NIST 2015).

The objective of the second CRAM report (Kwasinski et al. 2016) was to build upon the strengths of 2015).existing approaches, identify gaps or needs, and recommend a conceptual framework for filling those gaps. The second report introduced the concepts of community dimensions and community services, and it examined the dependencies of infrastructure systems on the services produced by other systems. A specific community dimension, health, was selected to illustrate the spectrum of services and systems required to support it.

\section{b. Conceptual Framework}

The conceptual framework developed in the second CRAM report (Kwasinski et al. 2016) is illustrated in Figure 1. Central to the framework is the concept of an essential set of community dimensions, developed from the insights of Maslow (1943) and the NIST Guide (2015). Much of the way we structure ourselves, the way we design buildings and infrastructure, and the way we utilize natural resources is determined by our desire to provide these essential dimensions within a community. They are, in essence, the purpose of communities. Understanding and assessing these fundamental community dimensions, both under normal circumstances and in the wake of disruptive events, should be the ultimate goal of any resiliency assessment. By thinking about dimensions first, we can see a broader purpose for communities and start to assess the degree to which services, infrastructure systems, social systems, resources, policies, and practices help people within a community achieve and maintain these dimensions over time. The essential community dimensions listed in Figure 1 are not necessarily exhaustive, but they do capture the most fundamental 
purposes of a community. At the same time, the dimensions are intentionally broad and abstract. This choice keeps the number of dimensions to a minimum without unduly constraining the types or sizes of communities to which they can be applied.

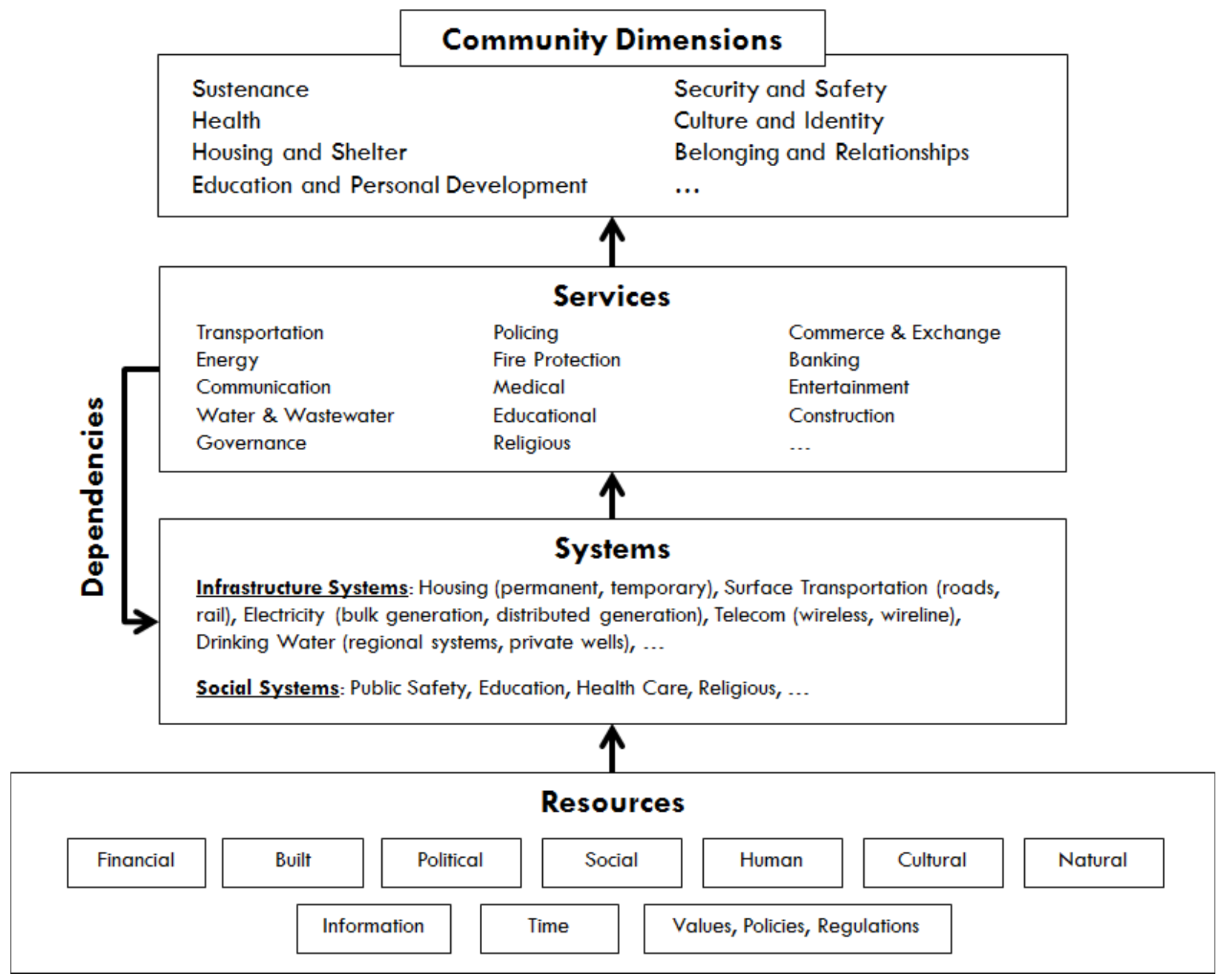

Community Dimensions are the broad purposes or desires of the community.

Services are the provision of specific activities, supplies or goods that support community dimensions.

Infrastructure Systems are specific combinations of resources and human actions organized to deliver services primarily through the built environment and cybernetic sub-systems. Infrastructure systems comprise three primary domains: physical, human, and cybernetic.

Social Systems are specific combinations of resources and human actions organized to deliver services primarily through human interactions. Social systems are formed by the same three primary domains as infrastructure systems, but with an emphasis on the human domain over the physical and cybernetic domains.

Resources are inputs to systems that are used, and in some instances consumed, in order to deliver services.

Dependencies are the reliance of infrastructure or social systems on services provided by other infrastructure or social systems. The services may be provided by permanent or temporary systems.

Figure 1. Conceptual framework of community dimensions, services, systems and resources (adapted from Kwasinski et al. 2016). 
The hierarchical structure of the framework is intended to bridge a significant gap found in some previously suggested community resilience assessment frameworks by more explicitly considering the integration of social systems and infrastructure systems and by differentiating these systems from the services that they provide. Some community services are directly aligned with a single community dimension (e.g., policing and fire protection services support the security and safety dimension), whereas other community services support multiple community dimensions (e.g., energy, communication, transportation, and commerce and exchange services each support multiple community dimensions). Once again, it is recognized that the list of community services shown in Figure 1 is not exhaustive, but it does capture many of the most fundamental services for communities.

There are a number of resources and systems within any community that support the delivery of community services. Resources are the inputs (e.g., fuel, people, buildings, and equipment) that can be utilized by systems (e.g., electric power generation, transmission, and distribution) to provide services (e.g., electric power at an outlet). This is an important distinction because many equate systems with services. For example, the provision of power is often equated with the quality of the electric wires, grid, switches, repair crews, etc. The difficulty with equating the two is that if systems are seen as services, then the only options we have are to repair, replace, and/or strengthen individual systems. If, however, we think about the traditional systems as an important way, but not the only way, of ensuring the delivery of the key community services, many alternatives emerge. For example, if the power grid goes down, all available resources can be allocated to repairing power lines to get a hospital up and running, or, instead, resources can be allocated to providing access to fuel that allows the facility to run an on-site generator and continue to provide critical health care. Ultimately, this view emphasizes the delivery of services and the support of essential community dimensions as the goal of any resilience system, plan, or policy alternative.

The framework identifies two types of systems: infrastructure systems and social systems. These systems use their resources and other elements to provide the services to the community dimensions that they support. As illustrated below in Figure 2, both types of systems can be thought of as combinations of human, physical, and cybernetic resources and components. Social systems tend to serve people, primarily through human-to-human interactions, whereas infrastructure systems may serve people or other physical systems.

Infrastructure systems are specific combinations of resources and processes developed to deliver services primarily through a physical built environment or a cybernetic sub-system. A public transportation system is one example of an infrastructure system. Its physical domain includes, for example, buses, terminals, garages, roads, and bridges. Its cybernetic domain includes data about schedules and routes as well as the database of drivers. The human and social domain includes employees, riders, mechanics, and the personnel and processes to hire and train drivers or to conduct inspections and repairs of buses.

Social systems, on the other hand, are specific combinations of resources and processes developed to deliver services primarily through human interactions. Like infrastructure systems they are also formed by human, physical, and cybernetic domains. Examples of social systems include public safety, education, health, and religious systems. An education system includes administrators, teachers, students, curricula, rules, and laws as part of its human and social domain; school buildings and supplies as part of its physical domain; and school records and payroll systems as part of its cybernetic domain. 


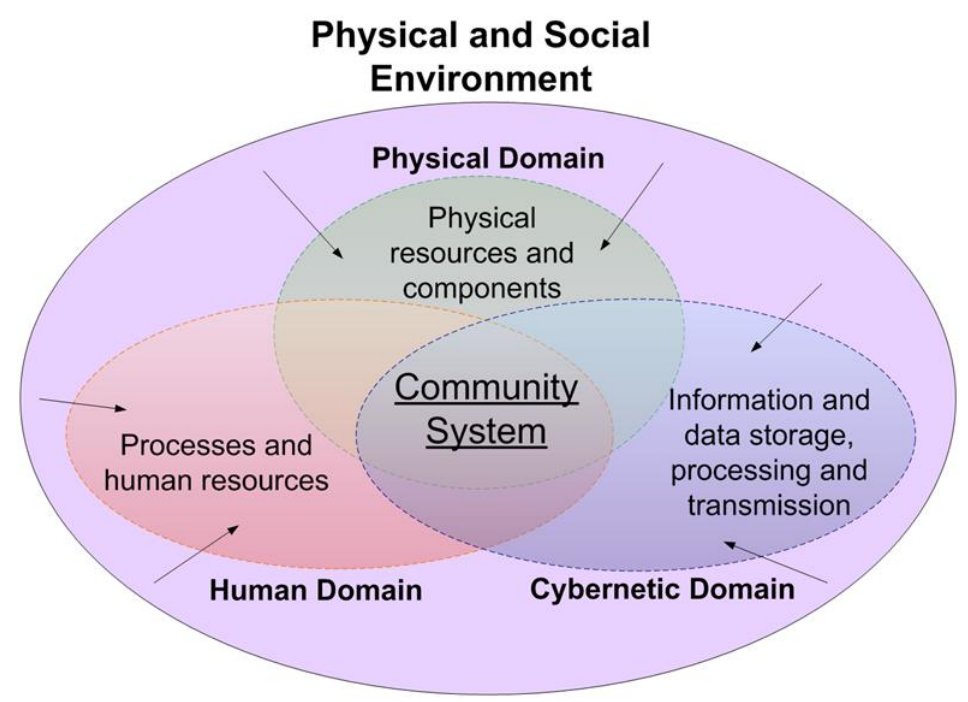

Figure 2. Representation of a community (social or physical) system and its three component domains: physical, human, and cybernetic (Kwasinski et al. 2016).

The conceptual framework can be used to characterize a community resilience assessment methodology by evaluating which systems are considered, whether each of the three component domains (human, cyber and physical) is considered for each of those systems, and which dependencies between systems are considered. As an example, consider Figure 3, which depicts a reduced set of five interacting community systems. In this figure, the arrows represent the provision of a service from one system to another system. Each system depends on other systems to generate services that, in turn, support one or more community dimensions. For example, the arrow going from the physical domain of the power grid infrastructure system to the physical domain of the health system represents the need for electric energy in health care facilities in order to deliver health services. The arrow going from the physical domain of the communications systems to the cybernetic domain of the health systems represents the communication services used by health systems in order to coordinate their activities when delivering health services. The arrows going from the human domain of the health system to the human domains of the power grid system and the communication networks systems represent the health care services needed by these infrastructure systems to allow their workers to maintain a level of health that is sufficient to operate their systems and deliver their corresponding services.

As discussed by Kwasinski et al. (2016), dependencies can be characterized by degree (e.g., fully dependent, partially dependent, or conditionally dependent). Dependencies can also be regulated by maintaining a local reserve or buffer within the dependent system or by temporarily reducing the demand for the services produced by the dependent system. Thus, the characterization of dependencies may change over time or may also change when considering different resilience time scales.

In some cases, two-way dependencies exist. In the simplified example shown in Figure 3, the physical domain of the communications system is dependent upon the physical domain of the power grid system, and the human domain of the power grid system is dependent upon the cybernetic domain of the communications system. We refer to such two-way dependencies as interdependencies. At a community level, interdependencies among systems exist in a very complex meshed structure, in which services provided by one system influence and are influenced by other community services. The potential for a cascading series of failures must also be considered. 


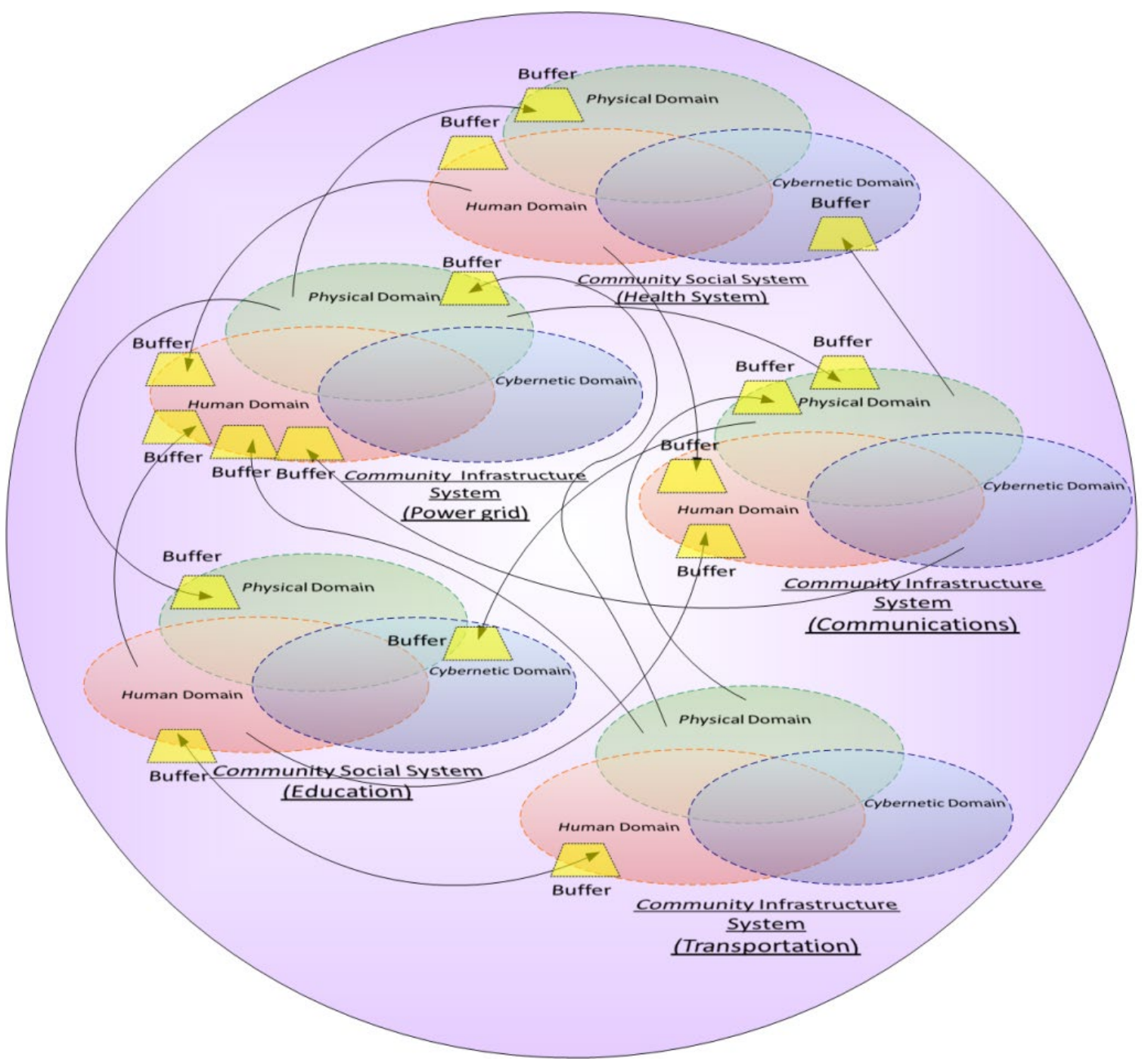

Figure 3. Representation of a community with a reduced number of systems, showing the interactions among these systems (Kwasinski et al. 2016).

In summary, the conceptual framework treats people, buildings, infrastructure, and information systems as the pieces that communities organize in order to produce services that support essential community dimensions.

\section{c. Challenges}

A number of important challenges were identified in the second report (Kwasinski et al. 2016), including:

- Selecting metrics or indicators for evaluating resilience (whether these indicators are quantitative or qualitative) and determining how to evaluate them.

- Projecting social benefits or impacts under different planning scenarios. These include benefits or impacts that cannot be expressed in monetary terms or that the community may not wish to express in monetary terms, such as: deaths, injuries or illnesses avoided; community disruptions avoided; or any other net negative social effects that are reduced or avoided through the implementation of community resilience measures. This could also include less tangible 
effects that can be difficult to measure, such as loss of community cohesion or culture. The assessment of social factors should also consider how social impacts and benefits are distributed within the community.

- Dealing with multiple metrics or indicators. In general, some combination of social indicators and economic metrics will be required. These, in turn, will depend on system performance levels and associated recovery times.

- Developing a focused set of dynamic resilience metrics that are applicable to the short-term (days), medium-term (weeks), and long-term (months) assessment time frames recommended in the NIST Guide (NIST 2015).

- Representing and accurately accounting for external effects on the community. It is quite uncommon for a community to be internally self-sufficient or self-contained. Activities of one community can have significant impacts on another. This relationship can also work in a positive way. For example, in our health care example, we focused on the provision of services within the community; however, in modern medicine, it is common for providers to be part of large and complex networks that dictate policy, but also bring significant negotiating power and connectivity to resources. We have not fully explored the potential of mutual aid agreements and other external influences, both direct and indirect, on resilience.

- Allowing resilience assessments to be performed at different levels in the framework. Depending on the time and resources available, one could target individual dimensions, services or systems, certain combinations of these, or the entire community. This decision will clearly influence the scope of the resilience planning decisions that can be assessed and the metrics selected.

- Treating the effects of dependencies and interdependencies within community systems and services. Community systems typically depend on services that are provided by other community systems. As illustrated previously in Figure 3, some dependencies can be mitigated through buffers (i.e., local storage). The buffer capacity required to achieve a given level of resilience can serve to characterize the degree of dependence. It is also possible to identify different levels of dependencies, some more critical than others, although this can change depending on the recovery time frame being considered. Through dependencies and interdependencies, all community dimensions are interrelated. Therefore, resilience improvements focused on one community dimension are likely to affect all other dimensions to varying degrees. As a result of such complex interactions, characterization of dependencies may need to be simplified or considered on a limited basis in order to simplify the analysis to a practical level.

- Balancing assessment accuracy and comprehensiveness with implementation practicality and simplicity. This challenge encapsulates the more specific challenges described above and is perhaps the most significant challenge we encountered.

These challenges were identified and illustrated by Kwasinski et al. (2016) within the context of the community health dimension. One objective of this report is to reassess these challenges in the context of four additional community dimensions: sustenance, housing and shelter, belonging and relationships, and education and personal development.

\section{d. Conclusions from the Community Health Dimension Assessment}

The assessment of the community health dimension by Kwasinski et al. (2016) clearly demonstrated the dynamic notion of resilience as it changes over time and the many dependencies and interdependencies that 
can be found among systems and services and the community dimensions they support. One of the lessons learned from the discussion of the community health dimension was that it is difficult, if not impossible, to treat resilience of a given community in isolation because of the influence and interactions with neighboring communities and the broader political and social environment. Still, it is important to identify local resources as well as resources that may be available from outside of the community.

A practical community resilience assessment methodology must be adaptable to communities of different types and sizes. Through the study of the community health dimension, it was possible to describe a general structure for a community resilience assessment, beginning with a pre-assessment with the goals of determining what to measure and what approach to follow. The pre-assessment is then followed by the proper assessment, in which it is recommended that service performance be evaluated in terms of the four resilience components described in the PPD-21 (2013): (1) withstanding capability, (2) restoration speed, (3) planning capacity, and (4) adaptation. The assessment should provide an understanding of the subgroups within the community and project the expected levels of service provision under each of the relevant hazard scenarios. In many cases, it will be important to assess not only whether a service can be provided but also the quality of service delivery. Definitions of the community dimensions and services may also lead to additional challenges. For example, the definition of community health with respect to social wellbeing may introduce a subjective component to the assessment.

One important research objective relates to the need for measuring resilience by identifying attributes, dependencies, and other influencing factors and integrating these notions in a simple-to-understand output. Since dependencies and interdependencies play a critical role, their characterization and identification also represent important research needs. Analysis of scaling approaches to determine resilience by considering assessments at an individual level and aggregating them into a community indicator is a complex problem that also needs to be further explored. All these studies need to be made within a context of resilience as a dynamic indicator that may change for different time scales. Ultimately, it is important to accept that any assessment will require significant simplifications in order to find a balance between practicality and comprehensiveness. Hence, every assessment methodology will include tradeoffs and will need to accept certain margins of error or uncertainty.

The infrastructure systems that support essential community dimensions are fundamentally linked, and their dependencies and interdependencies extend beyond community boundaries. This is certainly the case over longer time scales where it is necessary to have educational, health, and financial systems that support the people that are responsible for the operation of infrastructure systems.

It is critical that future community resilience assessment methodologies include guidance for:

- Identifying common dependency and interdependency linkages;

- Encouraging planners to look for and identify other important linkages; and

- Evaluating the resilience of the linkages between systems and community dimensions in addition to the systems themselves.

Resilience must be evaluated not only in terms of the physical components of infrastructure systems, but also in terms of the resilience of plans, policies, and people. Evaluation methods must include mechanisms to assess whether those elements are also resilient.

A simultaneous objective should be to begin building a catalog of tools and methodologies for estimating recovery times, economic impacts, and social impacts that is applicable to a broad range of possible hazard 
scenarios, community types, and recovery time scales. The selection and/or development of these tools and methods should focus on the needs and capabilities of end-users. Any guidance, methods, information, and expectations should encompass a range of experience, expertise, staff availability, and budgetary resources and should allow for local practices and customs. For example, the assessment methodology should provide enough flexibility so that it could be adapted for use by a municipality as large as New York or a small rural community whose challenges, manpower, experience, and budgetary constraints are completely different.

Finally, it was recommended that a set of pilot community resilience assessments be conducted and documented for a broad range of real-world case studies. A key focus of the pilot studies should be the selection of metrics or indicators that are appropriate to the pilot communities and the development and evaluation of methods for displaying and interpreting multiple disparate measures.

\section{e. Organization of this Report}

This report expands upon our second report by considering four additional community dimensions sustenance, housing and sheltering, belonging and relationships, and education - with the objective of developing a richer and more complete understanding of the dependencies and interdependencies of community dimensions and services with the built environment. These four additional dimensions are discussed in Chapters 2 through 5, respectively. In Chapter 6, we summarize our main findings and recommend next steps. 


\section{Sustenance Dimension}

The goal of this chapter is to apply the framework proposed by Kwasinski et al. (2016) to the community sustenance dimension. The overarching question guiding Kwasinski et al. was:

How can communities of various sizes and resources objectively assess the extent to which proposed changes in the configuration or management of supporting infrastructure systems are expected to improve their short-term, medium-term, or long-term ability to provide health care services in the aftermath of a future routine, design-level or extreme event?

For our purpose, community is defined as a specific political unit, jurisdiction, or geographical space for which there is well-defined agency, government, or organizational influence over how a part of that location operates. In this chapter, we consider a community's ability to answer this question with respect to sustenance (i.e., food and water supply systems). Although the food supply system is clearly essential to the community sustenance dimension, the primary focus of our analysis in this study will be on the water system.

\section{a. Definition and Overview of the Community Sustenance Dimension}

The NIST Guide (NIST 2015) takes an approach towards prioritizing community resilience needs that is adapted from Maslow's hierarchy of needs (Maslow 1943). At a basic level, communities must take action to ensure the survival of their citizens. As stated in the NIST Guide, "survival includes necessary physical requirements, such as air, water, food, shelter, and clothing. If these needs are not met, the human body cannot sustain life." The community's ability to meet the food and water needs of its citizens is the community sustenance dimension.

Under normal circumstances, the sustenance dimension is frequently taken for granted, but during natural disasters or other extreme scenarios, the services required to support it can be severely disrupted. Nonetheless, the sustenance dimension can often be overlooked in key contingency planning activities. The impact of overlooking the sustenance dimension during planning can lead to diverse consequences, including runs on grocery stores, vandalism and theft after the initial impacts of a natural disaster have occurred, or public health impacts and morbidity or mortality if food and water supplies become contaminated or are not properly secured.

The community sustenance dimension relies upon several key community services. At a minimum, the sustenance dimension involves agriculture, food processing, water, wastewater, and public health services. These are supported and interlinked through the services provided by electric power systems, transportation systems, and the health care system. The management and coordination of the services required by the community sustenance dimension involve communications and information services, financial services, and government services. Figure 4 provides a simplified representation of the community sustenance dimension, focusing on the community systems and services required to ensure effective provision of water and how these are linked through supporting systems and services to the sustenance dimension. 


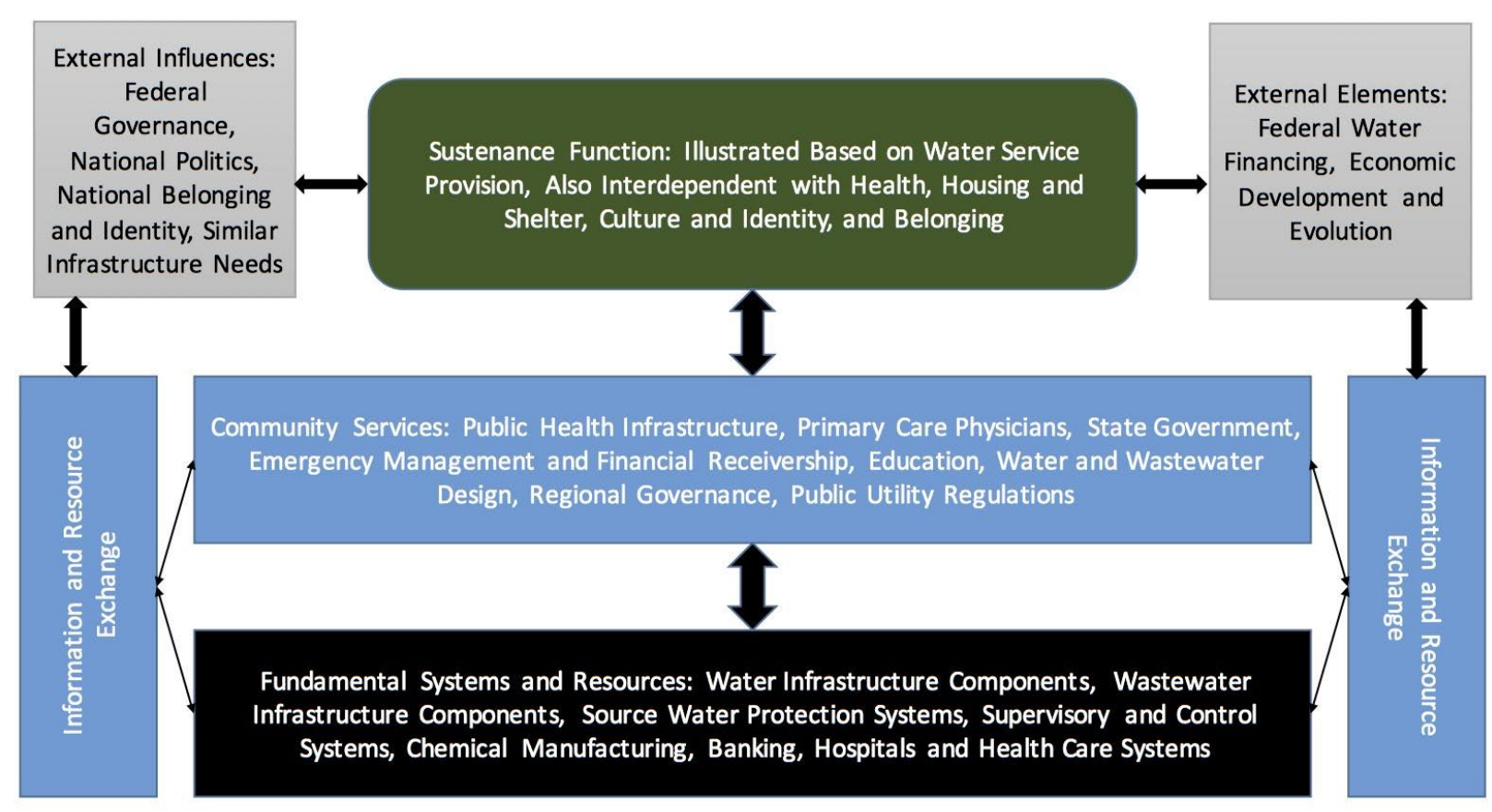

Figure 4. Simplified representation of the community sustenance dimension focusing on water service provision.

The temporal and spatial characteristics of the community sustenance dimension are diverse. While most citizens interact with the sustenance dimension primarily at a local level, the underlying elements of the sustenance systems are typically distributed over a large geographic area. For example, food security and supply involves the production of food commodities and livestock, manufacturing and processing of food products, and distribution of food to processing centers and food retailers.

For water systems, there are also challenges navigating the relationship between the local and the regional. For example, water resources are managed regionally, and during normal operations are distributed to citizens through water distribution systems involving: reservoirs, dams, transmission pipes and aqueducts, buried pipes, pumping stations, treatment facilities, and storage facilities. During emergency operations or emergency response, water resources may be sourced through the food supply chain in order to make bottled water available to citizens in the event that the water supply, treatment, or distribution systems are damaged or rendered inoperable. In this case, the suppliers of bottled water must be identified and coordinated in advance of the event to ensure supplies through the appropriate response window. This response is only suitable in the short-term, as water and wastewater facilities are critical to providing sanitation services necessary for shelter-in-place functionality.

\section{b. Description of the Infrastructure Systems Involved in the Community Sustenance Dimension}

The community sustenance dimension directly involves two infrastructure systems: food and water. The physical components of these two systems are briefly described below. 


\section{i. Community Food Supply Systems}

Community food supply systems are complex, networked systems involved in the delivery of food from raw production of commodities and other products through the distribution of food products to retail facilities and consumers (Flowers and Buckley 2011; Barron et al. 2010). At the regional or larger scale, the food supply system is primarily made up of the food supply chain and the transportation systems, electric power systems, fuel systems, and buildings providing the logistics involved in delivering food supplies to distributors. Food distribution involves critical facilities that may be interlinked with rail, port, air, and ground shipping terminals. Food is produced by farms, then sold to food manufacturers or delivered to processing facilities. These manufacturers and processors supply the demands of supermarket chains, wholesalers, or food distributors. At this point, the food supply chain shifts from a distributed set of producers to a de-centralized set of distributors. These distributors then deliver food to communities by transporting food to the terminals or retailers that interact directly with customers at the local level. There are multiple temporal and spatial scales involved in the food supply system. The components of the food supply system are almost wholly privately owned and may involve thousands of entities, thus making coordination of actions from a centralized perspective difficult.

For the purpose of natural disaster response, the food supply system principally involves the local food supply system, the U.S. Department of Agriculture (USDA) emergency supply system, and the Red Cross (Flowers and Buckley 2011). Local provision of food services involves local distributors and terminals during pre-event preparations, food retailers and specialty retailers, schools and other public facilities providing physical locations for emergency shelter and food distribution, and large food service providers coordinating with USDA and the Red Cross. The timeline of concern for emergency operations is on the order of days to weeks in immediate response due to food safety and preservation challenges. In natural disaster response, situational awareness must be constructed concerning the capabilities of these actors, and contingency plans must be coordinated with the private owners of the system as the capacity of each agent suggests.

\section{ii. Community Water Distribution Networks}

Community water systems during normal operations are networked systems of pipes, pumping facilities, treatment facilities, and communications networks involved in the treatment and distribution of drinking water. During emergency operations, these basic services may be degraded, and bottled water may be used in conjunction with a boil water advisory. Water is taken into the system through aquifer pumping stations, pumping stations at streams, river inlets, lakes or reservoirs, or through wholesale connections with other suppliers. This water is then distributed through the underground pipe network to end users. When these distribution facilities are not available, bottled water must be procured, and distributed to citizens. In some events, the water quality of the supplies in the distribution network cannot be fully guaranteed. In these events, a boil water advisory is administered in order to make the public aware of potential microbiological contamination or instability of the supplies.

\section{c. Notable Features of the Community Sustenance Dimension}

There are several key features of the sustenance dimension:

- The community sustenance dimension depends on decentralized networks of individual agents. Successful operation of sustenance systems requires person-to-person interactions and relationships. There may be thousands, or tens of thousands, of actors to coordinate. For example, there may be tens of food distribution facilities, hundreds to thousands of food retail 
facilities, thousands of restaurants, and hundreds of thousands to millions of citizens using these facilities. Water services are also largely decentralized on a regional basis, despite the large capital requirements involved in water infrastructure development and operation. While water services may be centralized for larger cities serving larger populations, rural or suburban populations may be served by smaller companies serving tens or hundreds of customers. This means that each metropolitan region may be served by hundreds of water service providers. Moreover, these systems may appear to be centralized during normal operations, but during emergency operations, there may be tens to hundreds of providers of bottled water and temporary sanitation services as the water provision sector turns to the food supply sector and other contractors to provide emergency response services. Moreover, maintenance and construction services for water supply are likely to be provided by large networks of private contractors and service providers. Because many of the required assets are privately owned and controlled, extensive coordination and planning are required for any of the event types under consideration. For example, during emergencies bottled water provision may depend on parts of the food distribution network.

- The community sustenance dimension is tightly coupled with the community health dimension. While the health dimension facilitates the provision of services to treat both chronic and acute health conditions, the health dimension requires access to high quality food and water supplies and wastewater conveyance during normal operations to ensure the health of the population. During emergencies, this tight coupling becomes more important. If sanitation is not carefully managed, disease may spread through the community post-disaster.

- The community sustenance dimension requires navigation of physical, cybernetic, and human interdependencies. Human interdependencies can be the result of management actions, regulatory actions, economic considerations, etc. These interdependencies are established based on services provided between human domains of the infrastructure and social systems that support community sustenance. The community sustenance dimension relies on successful coordination of management activities undertaken to operate the largely private food supply system. In emergency conditions, the community sustenance dimension may rely on similar coordination of private operators for bottled water supply.

- Many aspects of the community sustenance dimension are local in scope. However, escalating or cascading failures in more remote parts of the food supply chain or water resource system can impact the local delivery of food and water services. Moreover, emergency response may require activation of resource delivery from other geographic regions.

- The community sustenance dimension is highly regulated. Water and food supply systems are heavily regulated to ensure safety of and access to the services provided by these systems.

\section{d. Community Services, Systems and Resources Supporting the Sustenance Dimension}

Kwasinski et al. (2016) list a number of community services, systems, and resources involved in supporting community dimensions. These are defined as the building blocks of community functioning and can be thought of as the essential elements for the fulfillment of a community dimension. While any comprehensive assessment of the community sustenance dimension must include an assessment of food supply and security, the remainder of this discussion will primarily focus on the services, systems, and resources that support the water supply and its security. 


\section{i. Community Services Supporting the Community Sustenance Dimension}

To identify the community services interacting to support the water supply portion of the community sustenance dimension, we use the community service definitions listed in Kwasinski et al. (2016). In the list below, we include services that directly support the water supply aspect of the sustenance dimension:

- Water services provide water suitable for human consumption, fire suppression, irrigation, industrial processes, etc. Water supply services include collection, transmission, treatment, storage, and distribution. Some water systems are partially or fully dependent on wholesale producers to deliver water to their distribution networks. Water utility personnel may be critical participants in watershed protection activities that constitute the monitoring and management of the watershed serving as the community's water source.

- Communication services provide connectivity between a sender and receiver in order to allow information or a message to be exchanged. Water systems involve extensive distribution and collection networks that are controlled using industrial control systems. These systems depend on communication services. The business side of water systems also depends on the broadband Internet infrastructure in order to collect payments, obtain customer information, monitor demands, and engage customer relationships.

- Transportation services provide physical connectivity in order to deliver people and/or resources from one place to another. Water systems depend on transportation services for a wide variety of key resource inputs to their operations. Transportation services are critically important for shipping of chemicals used during treatment, monitoring and condition assessment by work crews, and repair, rehabilitation, or replacement of underground assets. The transportation system also enables the shipment of fuel for on-site backup power generation. Moreover, transportation systems also are co-located with water mains, facilitating access to critical system components for maintenance, rehabilitation, and replacement. For example, some water mains also rely on bridges for river crossing.

- Energy services provide electrical energy, natural gas, or liquid fuels to consumers. Electrical energy can be either locally produced or remotely generated. Water systems are critically dependent on electric power systems during normal and emergency operations. Electric power is required to operate pumping stations, tanks, filtration systems, chemical feeds, supervisory control and data acquisition systems, business and customer relations systems, etc.

- Sewage services provide the services needed to remove and treat wastewater. Wastewater treatment systems may serve as inputs into some water systems through groundwater recharge or reclamation services. Wastewater systems also provide services to water systems for normal operations by supplying their critical facilities with wastewater services.

- Governance provides rules and processes for the adjudication of public problems. These services also include collection and administration of public funds. Governance systems are critically important in determining the maintenance of water systems. Governance systems also determine, by way of laws and policies, the level of service that must be delivered by the water systems. The main performance drivers in the water industry are often provided by governance systems. 
- Commerce and exchange services provide mechanisms for buying, selling, or exchanging resources and services. These services include financial services that are provided to manage money and other fungible assets or assets that are part of individual or collective wealth, such as commodities and real estate. Examples of financial services include investing, lending and saving these assets. Insurance services are also considered part of the commerce and exchange services. Water system operators depend on financial services to support long-term investment in maintenance and capital improvements to distribution/collection systems and critical facilities. Financial services are often convolved with governance services to provide financing to water utilities.

- Policing provides a process for the enforcement of laws. Policing, especially after a natural disaster may be important for food supply security, as desperate citizens may attempt unauthorized access to food or water supply stocks of private businesses.

- Social services provide elder care, child services, housing subsidies, homeless shelters, etc. Social services are an important part of the distribution of food and water, as they may provide physical facilities for the distribution of food and water services.

- Religion provides services related to spirituality and self-discovery. These services can also be critical community organizers, connecting households and vulnerable populations to food, water, and shelter resources made available in extreme events. These services can also help fill the gaps in citizens' awareness of, or access to, important community services.

\section{ii. Community Systems and Resources Supporting the Community Sustenance Dimension}

To identify the community systems and resources required to support the community sustenance dimension, we use the definitions in the box beneath Figure 1 in Section 1.b. Recall that there may be multiple systems capable of providing similar levels of services (at least for some period of time). Thus, the distinction between services and systems becomes important so as not to limit the flexibility available to planners in determining appropriate response or recovery actions. While the responses available to food supply chain recovery may naturally involve this flexibility due to its decentralized and distributed nature, this way of thinking about the services provided by water systems is also important to the temporary delivery of services while conventional systems are being repaired.

In the list below, we highlight systems and resources that directly support the sustenance dimension:

- Water supply infrastructure collects and transmits water to treatment and distribution systems. Key components include:

- Reservoirs

- Dams and check dams

- Levees

- Inland waterways and locks

- Long-distance transmission pipelines, aqueducts, or conveyance systems

- Water treatment and distribution systems treat raw water and deliver it to consumers. Key components include: 
- Water treatment facilities

- Pipe networks

- Water pumping stations

- Water storage facilities (e.g., reservoirs, storage tanks, etc.)

- Commercial food distribution systems are critical in providing and/or supplementing emergency food and water supply. Examples include:

- Food distribution terminals (e.g., Hunts Point Terminal in New York)

- Commercial/private food distribution terminals (e.g., Safeway Distribution Centers)

- Commercial food wholesalers (e.g., Sam's Club, Costco, BJ's, etc.)

- Specialty food wholesalers (e.g., Restaurant Depot)

- USDA food distribution centers (e.g., USDA Kansas City Distribution Center)

- Buildings provide physical locations for distributing services and convening population groups. Buildings are required for treatment of drinking water and for distribution of water at emergency shelter locations. Examples include:

- Schools and recreation centers

- Shelters and homeless housing facilities

- Government buildings and facilities

- Sports, entertainment, and conference facilities

- Transportation systems are critical for delivering fuel and chemical inputs to water systems. Key components include:

- Roads, highways, and bridges

- Airports

- Railways and train stations

- Bus depots and fueling stations

- Commercial freight and shipping carriers (e.g., UPS, FedEx, USPS, etc.)

- Oil and gas are critical for backup power and maintenance fleet fuel. Key components include:

- Fuel refineries and distribution networks

- Natural gas pipelines and distribution terminals

- Oil and transportation fuel pipelines and distribution terminals

- Fueling stations and commercial re-fueling depots

- Information and communications systems are critical to obtaining situational awareness about distribution systems in normal and emergency operations. Examples include:

- Emergency networks

- Commercial wireless communications networks

- Commercial wireline and cable communications networks

- $\mathrm{AM} / \mathrm{FM} / \mathrm{XM} / \mathrm{HD}$ radio communications networks

- Cyber and cybernetic infrastructure components are critical to water supply industrial control systems. Key components include:

- Internet and supporting infrastructures 
- Control systems and SCADA (supervisory control and data acquisition) systems

- Situational intelligence systems

- Health care systems provide epidemiological surveillance and assist in determining appropriate maximum concentrations of contaminants or constituents in drinking water supplies. Examples include:

- Research facilities

- Hospitals and primary care facilities

- Testing facilities

- Religious and civic systems and facilities provide resources for connecting populations to sustenance services in the event of emergencies and provide advocacy and education services. Examples include:

- Churches, mosques, temples

- Non-governmental organizations

\section{e. What Should Be Measured to Characterize the Community Sustenance Dimension?}

There are several tools that have been distributed by the U.S. Environmental Protection Agency (EPA) and the American Water Works Association (AWWA) that should be consulted when assessing utility readiness and resilience (Edt 2014; Spence and Tuozzoli 2011; Long 2016; AWWA 2011; EPA 2011). Tools in widespread use include: the EPA Vulnerability Self-Assessment Tool (VSAT) (EPA 2015), the EPA Water Health and Economic Analysis Tool (WHEAT) (EPA 2016), the Utility Resilience Index (URI) (Morley 2012), and the Risk Analysis and Management for Critical Asset Protection (RAMCAP) J100-10 Standard (Long 2016).

For water utilities, the assessment of external dependencies and how they might influence the medium-term and long-term recovery of their system is generally perceived to have been a critical, yet historically undervalued task. While characterizing the immediate damage to their system and its short-term performance in the event of a disaster is important, there is some short-term flexibility in the water system response. On the other hand, the assessment of external dependencies reveals vulnerabilities in water system operations that cannot be ascertained when looking only at a utility's immediate system. Water systems operate at several time scales—minutes, hourly, daily, monthly, annually, and long-term—and they often have large storage capacity that provides slack time in the system in order to respond to events that may occur on the minutes to daily time scale. For example, the availability of substantial excess capacity in water distribution systems (due to fire-fighting requirements), and due to the ability to weather slight decreases in water quality (e.g., boil-water orders may be issued if disinfectant boosting is compromised) means that water systems may be tolerant of some disruptions in the infrastructure systems on which they depend.

Interviews with several intra-state Water Agency Response Network members in NY, CA, OR, and TX indicated that the value of resilience planning is in using the assessment process to identify the unique ways each system is interdependent with other community dimensions and services. These interdependencies may not be apparent at the sub-hourly to hourly operational timescales, but are critical when considering important hazards over the daily to long-term time scales. As a result, while some of the metrics recommended in the following tools are quantifiable, many are process-oriented and qualitative in nature. 


\section{i. EPA Vulnerability Self-Assessment Tool (VSAT)}

VSAT (EPA 2015) is designed to help utilities identify critical assets, threats, effective countermeasures, and costs in order to facilitate comprehensive vulnerability assessment. There are eight steps in VSAT: (1) baseline utility information assessment; (2) asset identification; (3) threat identification; (4) countermeasure evaluation; (5) improvement assessment; (6) cost evaluation; (7) risk evaluation; and (8) reporting. The first required inputs are basic asset lists and maps. Next, threat categories should be identified, including the threat categories listed below in Section 2.g. Next, countermeasures protecting against failures of critical assets are required. Example countermeasures include alternate power sources, onsite backup power generation, fencing and other physical barriers, guards, hardened doors, cybersecurity protection plans, redundant water sources, and emergency operating plans. Each asset should be assigned countermeasures that would mitigate against failures or disruptions of its functionality. Next, financial information is collected to estimate the cost effectiveness of potential countermeasures. Examples include average daily water service and rate per thousand gallons, value of statistical lives, and value of statistical injuries. Additional public health and economic costs may be collected. After this basic information has been collected, the utility may assess the service impact in terms of customers affected and length of service disruption.

\section{ii. EPA Water Health and Economic Analysis Tool (WHEAT)}

WHEAT (EPA 2016) is closely related to VSAT, and the two tools are meant to be used in combination. VSAT has a user-friendly capability to integrate results from WHEAT. The objective of WHEAT is to support the assessment of economic and health consequences of adverse events. The economic and public health results of the utility's WHEAT analysis can be used to populate VSAT. The steps of a WHEAT analysis are similar to VSAT. WHEAT's eight steps include: (1) system and scenario selection; (2) baseline inputs and asset condition assessment; (3) scenario inputs and service loss and response; (4) contamination event consequences; (5) public health consequences; (6) utility-level and regional economic consequences; (7) downstream impacts; and (8) summary reports. The major difference between WHEAT and VSAT is that WHEAT supports scenario-based assessment, enabling the utility to perform detailed analysis of scenarios of concern. These scenarios can then be used to populate VSAT for the threat-asset combinations indicated by each scenario.

\section{iii. AWWA RAMCAP J100-10}

The RAMCAP J100-10 Standard (Long 2016), provided by the American Water Works Association (AWWA) and the Association of Metropolitan Water Agencies, requires a ranking of critical assets for prioritization of resilience activities. The main steps that the RAMCAP standard requires are: (1) asset characterization; (2) threat characterization; (3) consequence analysis; (4) vulnerability analysis; (5) threat analysis; (6) risk/resilience analysis; and (7) risk/resilience management. While WHEAT and VSAT individually contain all of the requisite steps, a utility that desires compliance with RAMCAP should use WHEAT and VSAT in combination, as illustrated in Figure 5. 


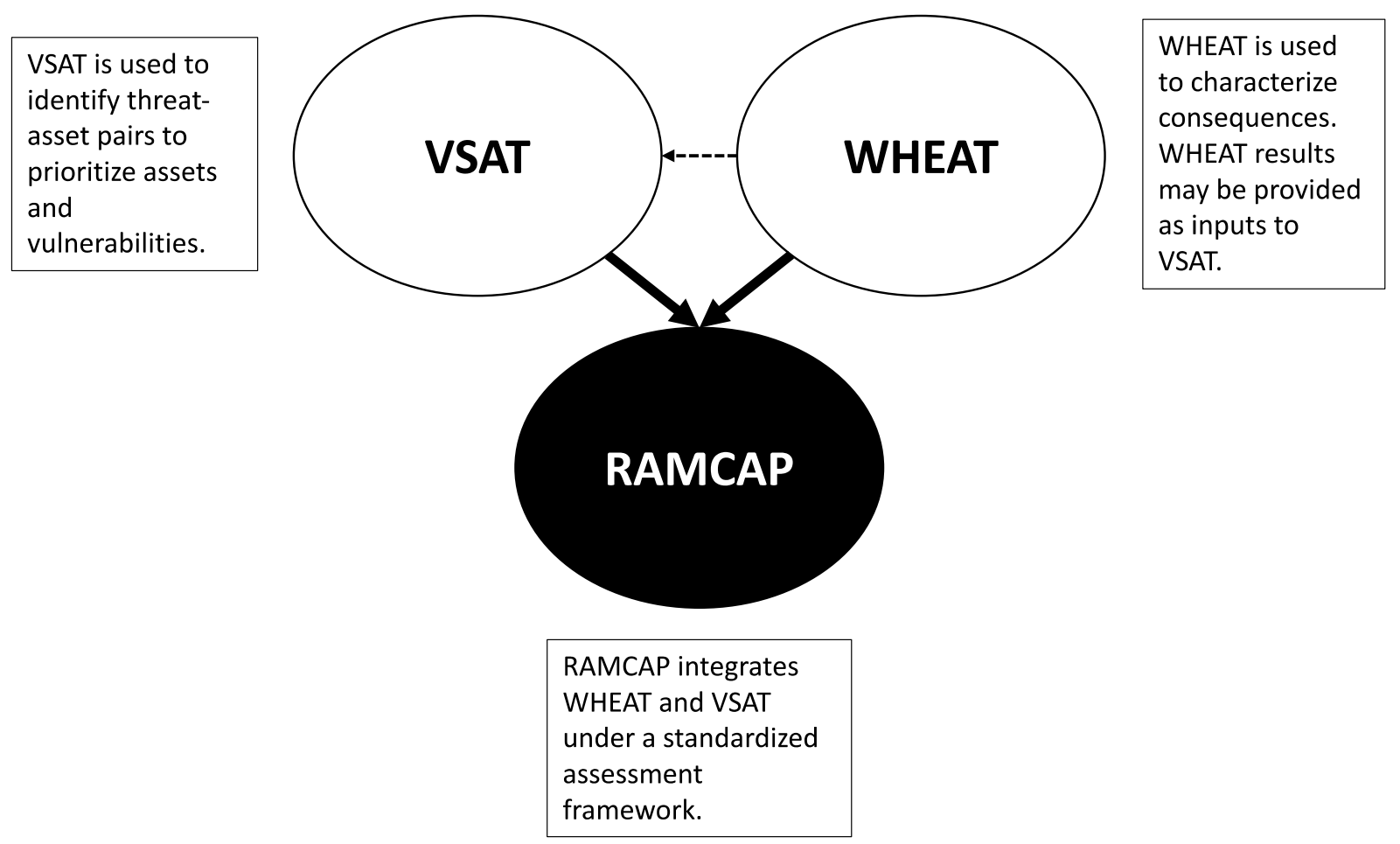

Figure 5. The EPA VSAT and WHEAT tools work together to support implementation of the RAMCAP J100-10 Standard.

\section{iv. Utility Resilience Index (URI)}

The URI (Morley 2011) involves the development of a methodology that concisely and simply communicates a utility's readiness and resilience to disruptions attributable to all-hazards. The URI has operational and financial resilience indicators. The URI methodology leverages readily available utility data and has been validated through the use of expert consultation. The URI operational indicators are: (1) emergency response plan readiness level; (2) national incident management system (NIMS) compliance; (3) mutual aid and assistance (e.g., interstate WARN agreement); (4) emergency power availability for critical operations; (5) ability to meet minimum daily demand; (6) lead time for critical parts and equipment repair (shorter is better); and (7) percentage of response-capable critical staff available for operations and maintenance with cross-trained staff backup. The URI financial indicators are: (1) business continuity planning exercised; (2) utility bond rating; (3) condition assessment coverage; (4) community unemployment (used as a proxy for utility financial stability); and (4) community median household income (another proxy for utility financial stability).

\section{v. Summary}

These tools suggest that water system resilience is dependent on utility management processes and practices more than metrics that can be collected to assess real-time performance. Based on a consideration of these tools and measurement systems, a resilience assessment of the water components of the sustenance dimension should include:

- Critical threat and hazard scenarios

- Utility data collection and management systems 
- Critical assets and their conditions

- Backup power availability and reliability

- Potential public health consequences

- Potential financial consequences

- Utility response readiness - repair and rehabilitation of critical facilities/components

- Utility response readiness - training and capabilities of personnel

- Utility response readiness - assessment of internal and external resources (e.g., Water Agency Response Network membership) for response

- Utility financial sustainability

- Water system impacts on other community systems and services

- Water system dependence on other community systems and services

\section{f. Other Efforts Relevant to the Community Sustenance Dimension}

The water services supporting the community sustenance dimension may be influenced or strengthened through awareness of other efforts. The U.S. EPA has made resilience a major thrust in its relationship with utilities, and has developed several planning tools that communities may find useful. Moreover, intra-state Water Agency Response Networks (WARNs) have proven important in responding to natural hazards. This has led the industry to begin thinking about how to establish inter-state emergency management relationships. Finally, water service provision can be greatly strengthened by considering ways in which Emergency Management Agencies (EMAs) can improve their partnerships with water utilities. Each of these efforts is described in more detail below:

- U.S. and State Environmental Protection Agencies. The U.S. EPA has coordinated efforts to aid water utilities in all-hazards resilience and contingency planning. One outcome of these efforts has been to assist water utilities in implementing the voluntary AWWA RAMCAP standard. The goal of the RAMCAP standard is to facilitate all-hazards preparations at water utilities. To aid utilities in becoming RAMCAP compliant, the EPA has promulgated the Vulnerability Self-Assessment Tool (EPA VSAT) and the Water and Health Assessment Tool (EPA WHEAT) discussed above in Section 2.e. While these tools are not resilience tools per se, they aid utilities in performing all-hazards self-assessments. These tools were extended by EPA efforts to assist utilities in emergency planning and incident preparedness. These resources include the "Community Based Water Resiliency Tool" (https://www.epa.gov/communitywaterresilience/community-based-water-resiliency-tool) and the report "Planning for an Emergency Water Supply" (EPA 2011). Moreover, the EPA has sought to engage water utilities with a variety of threat-specific planning tools, videos, and multi-media training resources for resilience planning. These include:

- Climate Ready Water Utilities (https://www.epa.gov/crwu - On the left hand side of the page there are links to six videos: https://www.epa.gov/crwu/risks-and-resilienceconsidering-integration-climate-readiness-financial-analyses-drinking;

- Drought Response and Recovery Guide - includes several case studies (https://www.epa.gov/waterutilityresponse/drought-response-and-recovery-waterutilities);

- Flood Resilience: A Basic Guide for Water and Wastewater Utilities - includes section on pilot (https://www.epa.gov/waterutilityresponse/flood-resilience-basic-guide-water-andwastewater-utilities); 
- Don't Get Soaked Video (https://www.youtube.com/watch?v=kPK9j2S5TwE);

- Water Utility All-Hazards Bootcamp Training - includes testimonials (https://www.epa.gov/waterresiliencetraining/waterwastewater-utility-all-hazardsbootcamp-training)

- Intrastate Water Agency Response Networks (WARN) (McLaughlin 2010; Morley 2006; Reeves 2013; Spence et al. 2011; Howe and Avery 2011). During the responses to the 1989 Loma Prieta Earthquake, the 1991 East Bay Hills firestorm, and the 1994 Northridge Earthquake, Northern California water and wastewater utilities began to realize that a statewide mutual aid response network would be advantageous for expedient recovery (Morley 2006). Utilities facing extraordinary pressures on their operational and recovery resources would need to have agreements with other utilities to mutually support one another by providing manpower and equipment for recovery. While some utilities had already established mutual aid agreements among smaller groups of utilities, coordination of emergency response could be difficult for large disasters due to the large number of existing agreements. California established a WARN that facilitated response through one statewide agreement in place of a diversity of agreements. During the early 2000's WARNs began to be adopted in many more states, with Hurricane Katrina as an impetus. Currently, interstate WARNS, called Emergency Management Action Compacts (EMACs), are the most pressing challenge facing WARN networks. For very large scale disasters such as a rupture of the Cascadia Subduction Zone, or a hurricane of the size of Hurricane Katrina, intra-state WARNs may not be effective due to the effects on the overwhelming majority of utilities in state. A seminal example of an interstate WARN activation is the Oregon deployment of resources to New Orleans through the WARN networks (Morley 2006; Scharfenaker 2006; Riordan and Moyer 2007). WARNs have been gaining increasing prominence in emergency response, operational resilience, and information sharing through the industry (Edt 2014, Morley 2006; Riordan and Moyer 2007; RMC Water and Environment 2006; Johannessen et al. 2014; Herrick et al. 2006; Morley 2010; Daniel and Morley 2011).

- U.S. Federal and State Emergency Management Agencies (EMAs). The relevant Emergency Management Agencies provide important coordinating activities in responding to events. However, utilities must be sure that their response planning includes providing emergency managers, firefighters, police, and other first responders' awareness of the nature of water and wastewater facilities and operations. In addition, one of the key outcomes of WARN organization across the states has been the awareness of the criticality of water and wastewater services to shelter-in-place functionality of buildings and homes. While bottled water or filtration systems may provide some limited recovery function for water systems, there are limited alternatives available for wastewater service at buildings and homes. Interaction between WARN and EMAs has led to a renewed awareness of the criticality of water and wastewater services for community recovery (Morley 2012).

\section{g. Threats and Hazards}

Following September 11, 2001, the water industry focused intently on assessing physical vulnerability to intentional terrorist attack. Academic research and practical guidance for securing water systems focused on network-theoretic and engineering studies investigating the potential impacts of intrusion events and other chemical contamination scenarios. However, it became apparent that natural hazards would be more 
of a threat than man-made hazards in the future (Morley 2013). The impacts of natural hazards would be more extensive and more severe. Moreover, preparations taken to mitigate impacts associated with physical vulnerabilities to man-made hazards did not always provide protection against natural disasters, while preparations to address natural disasters often were believed to increase the resilience of the system to all hazards, including terrorist attacks. As a result, the water industry began to focus on an all-hazards approach to vulnerability and security assessment. Hazards important in the water industry include:

- Tornadoes (EPA 2015a). Tornadoes can cause significant damage to water system infrastructure due to high winds, windborne debris, flash flooding and hail. Aboveground structures or equipment, such as the water storage tank in Figure 6, may be damaged during tornadoes. Ruptured service lines at customer locations and ruptured chemical storage tanks at treatment plants can cause disruptions to service. Loss of power can lead to challenges in service restoration.

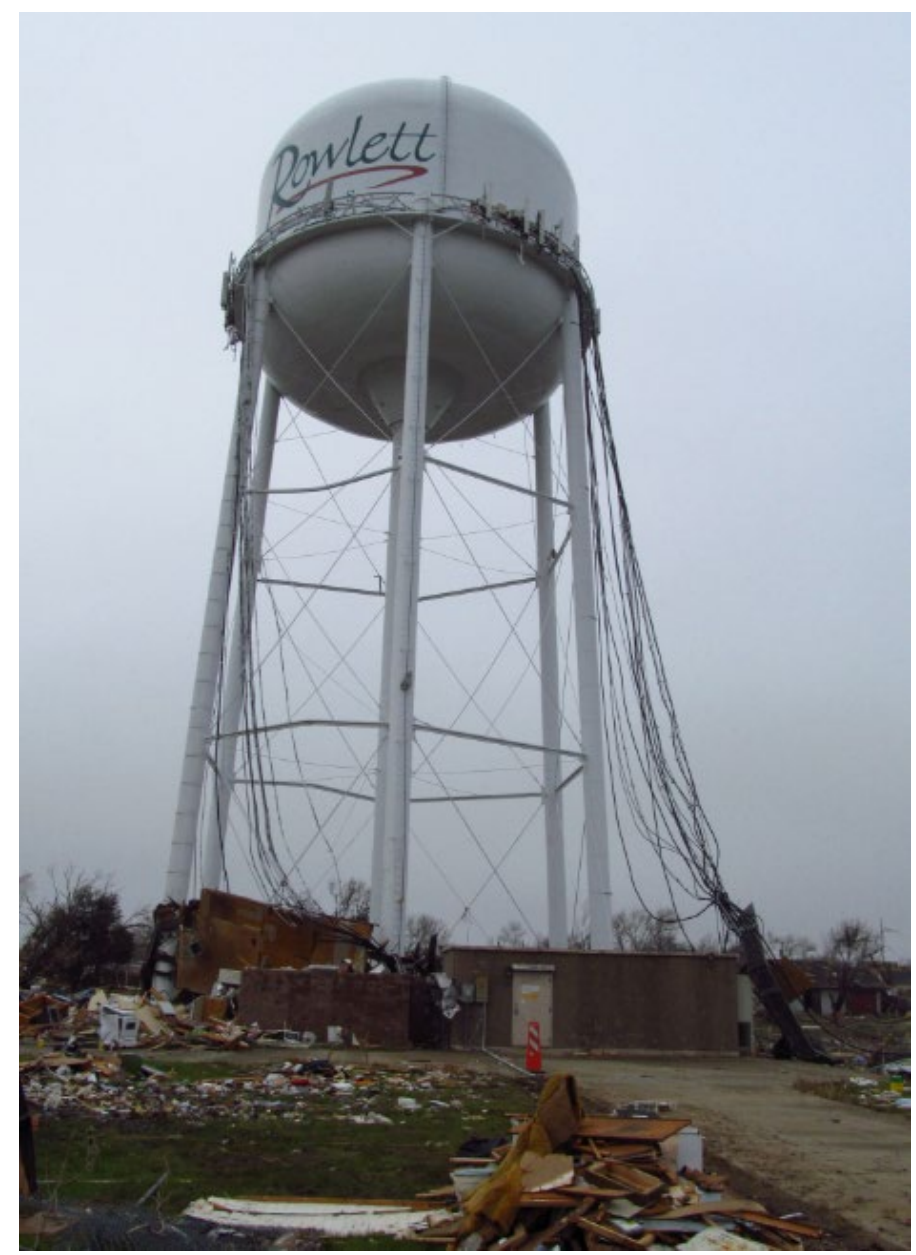

Figure 6. Water tank of the city of Rowlett, Texas, showing significant structural damage (note the bent horizontal braces) after being struck by a tornado in December 2015.

- Earthquakes (EPA 2015b). Earthquakes can cause damage to dams, buried water pipes, water tanks, wells, treatment facilities, and pumping stations. Moreover, earthquake impacts can be escalated due to the dependence of water infrastructure on transportation. Water infrastructure 
requires operational transport networks in order to receive shipments of fuel and chemicals, while also using these networks to perform inspection and repair activities.

- Floods (EPA 2015c). Floods cause a number of adverse impacts to water systems. These include potential pipe breaks, debris blockage at intakes, water quality changes to source waters, and escalating influences of impacts to transportation and power infrastructure. In addition, the risk of flooding may increase over time in low-lying areas where groundwater is used for irrigation. As the land subsides, levees may become less effective, requiring their elevation or reconstruction, or relocation of private assets.

- Hurricanes (EPA 2015d). Hurricanes can do great damage to water systems due to the combination of high winds, debris, flooding, and storm surge. Potential impacts of hurricanes on water systems include: pipe breaks, loss of power and communication infrastructure, and escalating failures due to dependence on transportation networks that may be obstructed by flooding.

- Sea-Level Rise (EPA 2015e). Sea-level rise can cause salt-water intrusion in both groundwater aquifers and surface water supplies. This scenario can be exacerbated when groundwater is over pumped for agricultural purposes, or if drought stresses fresh water resources that would otherwise recharge aquifers.

- Drought (EPA 2015f). Droughts are gradually developing and ending events that can lead to a number of regional impacts on water systems. Drought impacts can include flash flooding since dry surfaces may not readily absorb rain from high rainfall events, increased demands, increased treatment and pumping costs, changes in source water quality and potential regulatory compliance impacts, decreased capacity and stressed backup sources, potential power interruptions due to higher peak electricity demands typically associated with higher temperatures observed during droughts, potential electric power grid reliability impacts due to reduced water availability for power plant cooling and hydroelectric power generation, and possible declines in revenues due to conservation practices.

- Wildfire (EPA 2015g). Wildfires are not only significant events on their own, but may also be precursors to mudslides and flash flooding. Wildfires can cause second-order impacts to water systems after the event due to changes in source water quality due to nutrients and other contaminants, increased sediment and debris in runoff, and decreased water supply downstream due to changes in surface hydrology (e.g., increased evaporation due to loss of tree canopy and decreased snowpack).

- Extreme Cold and Winter Storms (EPA 2015h). Extreme cold can lead to a number of adverse impacts that include: pipe breaks due to freeze/thaw cycles, loss of power and communication lines due to ice storms, limited access due to ice/snow impacts on transportation systems, reduced workforce, salt and total dissolved solids' impacts on source water quality, potential flooding risk and intake or valve blockages due to ice jams and snowpack.

- Extreme Heat (EPA 2015i). Extreme heat incidents are the top weather-related killer in the United States, and can significantly influence water system workforces. Extreme heat events may also cause changes in source water quality attributable to algae blooms and other seasonal 
events. In addition, discharges and electric power generation facilities may also change source water quality. Moreover, extreme heat events increase power demands, potentially impacting electric power supply reliability.

- Tsunami (EPA 2015j). Tsunamis can cause widespread impacts due to the large geographic areas that can be affected by tsunami waves. Tsunamis can cause many of the same impacts as flooding, with the addition of saltwater intrusion into groundwater aquifers, direct damages to equipment due to inundation and debris, and possible backflows into treatment facilities.

- Volcanic Activity (EPA 2013). Volcanic eruptions can cause infrastructure damage due to lava flows, potential source water contamination by leachates, volcanic ash, and smog, damages to a wide variety of treatment equipment including vehicles, filters, tanks, and oxidation processes, and increased water demands for cleanup efforts.

\section{h. Impact of Routine Maintenance and Financial Operations on Community Function}

In water systems, the long-term view is often much more important than the short-term view when assessing the contribution of the system to community resilience. First, water utilities often have a considerable amount of storage in the system, and can operate at a slightly lower level of service in order to provide sufficient functionality for short term recovery (e.g., boil water orders can allow for water consumption during distribution system restoration activities). Because this system does not need to operate with a perfect match between supply and demand, there is usually residual "slack" within the system that can provide some inherent resilience to disruptive events. Second, many water systems face increasing financial pressures from aging assets at the same time as increasing awareness of non-regulatory performance objectives makes more stringent demands on operations. These non-regulatory performance objectives include asset replacement targets, net-zero energy goals, and chemical use reduction targets. Non-regulatory performance goals have grown in importance along with technological advances, and have become more prominent in public awareness even as it has become clear that underground and treatment plant assets require substantial capital investment. Underinvestment in plant and distribution system assets may leave plants more vulnerable to natural hazards, making achievement of community resilience with respect to water service more difficult. Moreover, underinvestment in water assets compromises the community's ability to achieve other dimensions, including health, belonging, and security/safety.

As an example, the 2014-2016 Flint, Michigan lead crisis has made national headlines because it has demonstrated the potentially catastrophic consequences of inadequate capital investment and maintenance in water systems (Edwards 2016). Ordinarily, sustenance infrastructure issues are not compelling, and they remain in the background of many citizen and stakeholder concerns because they typically fail gradually, over time. As a result, the investment needs and signs of deterioration attract attention most urgently in extreme cases, unless the prevailing culture of the surrounding community lends to a more proactive water management approach.

At the same time, the Flint lead crisis demonstrates the criticality of politics, governance, and management in sustenance functions such as water provision. Their role integrates each community dimension with all the others, while also linking the sustenance dimension to all the other services. For example, the degradation in service provision may, in fact, be directly contributing to the degradation of community health. Due to a series of management and communications decisions, community confidence in the integrity of the service is substantially degraded. There have been several points at which political or 
managerial decisions were taken which either directly led to an engineering failure or obfuscated the plain facts of the matter, leading to a failure of public trust.

Consequently, the Flint lead crisis is a useful case study for thinking about how to measure and assess the community sustenance dimension. First, this case demonstrates the criticality of the prior condition of the physical infrastructure systems on which the supporting infrastructure services depend, or through which they are delivered. Flint plainly indicates this because it is clear that the physical components of the water system were not properly maintained over the prior decades. This left the components in such a condition that the engineering and managerial decisions precipitated more severe engineering failures than might have otherwise occurred.

Second, the Flint case demonstrates the need to characterize the economic capacity of the community and its influence on community resilience. The Flint case demonstrates a challenge faced by a growing number of U.S. communities: declining population and escalating infrastructure costs. In other words, because water infrastructure is financed by rates paid by customers, the size of the customer base must be commensurate with the geographic scope of the infrastructure owned by the community. If the community has a much larger infrastructure geography than the rate-payer base can support, the infrastructure will decline because the rate-payers will become increasingly unable to afford the infrastructure investments required. Another economic capacity factor that may be discussed is the role of full-cost pricing in water infrastructure finance. Mehan and Kline (2012) discuss the fact that water rates in the United States are quite low, in part, due to the state and federal grants that had been made available during the construction of these systems. As a result, a "subsidy mentality" may have developed, leaving many systems underfinanced. Therefore, as state and federal grants decline in real terms, more economic stress may be placed on the community.

Third, the Flint case demonstrates the role of community organizing, that is, social capacity. On the one hand, diminished social capacity before the Flint water crisis made it difficult for Flint to avoid state receivership. On the other hand, Flint's social capacity during the water crisis coalesced in response to community needs. As it became clear that the state government was not able to respond to the citizens of Flint, local organizations mobilized in order to educate their citizens on potential water hazards, to coordinate surveillance and environmental monitoring projects with universities, environmental protection agencies, and key political stakeholders, and to ensure access to water service provision by way of pointof-use treatments or bottled water. Therefore, Flint's social capacity during the water crisis increased the likelihood that political resources would be diverted to the community as required in response to the crisis.

Finally, the Flint case study provides insights to the required capacity of other supporting services to provide some of the traditional resilience capacities in the event that the infrastructure service is disrupted. If we list the infrastructure resilience capacities as adaptability, speed of recovery, and absorptive capacity, the health care services, education, information and communications, and governance services are particularly critical in the speed of recovery and absorptive capacities. While these community services are not emphasized in the day to day delivery of the water service, their availability following an event is crucial to both assessing and restoring the sustenance dimension. 


\section{Housing and Sheltering Dimension}

The housing and sheltering (H\&S) dimension is defined both by the need for protection from the elements and by the emotional, economic, and legal attachments that it creates for individuals and families to a community. Examples of the emotional attachments associated with the H\&S dimension include the memories that people accumulate and the relationships they establish while living at a given place. Another example is the positive influence of stable housing on child development and adult mental health. Establishment of routines is a fundamental factor related to this emotional and psychological component of the H\&S dimension. These routines may relate to the basic H\&S function of protecting people from the elements, but they may also originate in emotional ties or in local legal or economic aspects. Economic and legal connotations of $\mathrm{H} \& S$ are also important components of the $H \& S$ dimension, influencing a community's formation and characteristics. Economic aspects of the H\&S dimension include taxation to support, for example, community governance or the community public education system. Economically, the H\&S dimension also has a strong relationship with job conditions within a community. For example, if people are able to remain in their established community after a disruptive event (even if in temporary facilities), community revenues from sales taxes or employment-related taxes may continue. From a legal perspective, H\&S strongly influences communities through civil representation, typically represented through elections. Legal influence is also observed through the judiciary process through jury participation.

\section{a. Housing and Sheltering Types}

The H\&S dimension is supported by a variety of building and shelter types. In the context of community resilience assessment, it is convenient to group H\&S types as follows:

1. Emergency shelter

2. Temporary shelter

3. Temporary housing

4. Short-term housing

5. Manufactured housing and recreational vehicles (RVs)

6. Circumstantial housing

7. Rental property housing

8. Permanent housing

9. Secondary housing

10. Seasonal housing

11. Other unclassified housing or shelter

As illustrated in Figure 7, the H\&S dimension depends upon a broad array of community services, systems, and resources. The H\&S dimension also interacts with the other community dimensions, and it can be strongly influenced by external factors, such as neighboring communities and the natural environment.

The eleven H\&S types listed above describe the facilities or systems used to deliver the corresponding H\&S services. It is important to clarify that for all other dimensions, buildings are resources that act as inputs to the systems that deliver services (Kwasinski et al. 2016). However, for the H\&S dimension, the buildings are the systems used to deliver the H\&S services. In the case of H\&S dimension, capital, building materials, and construction and maintenance personnel are examples of resources acting as inputs for the H\&S systems—i.e., the buildings - so their services can be provided. 


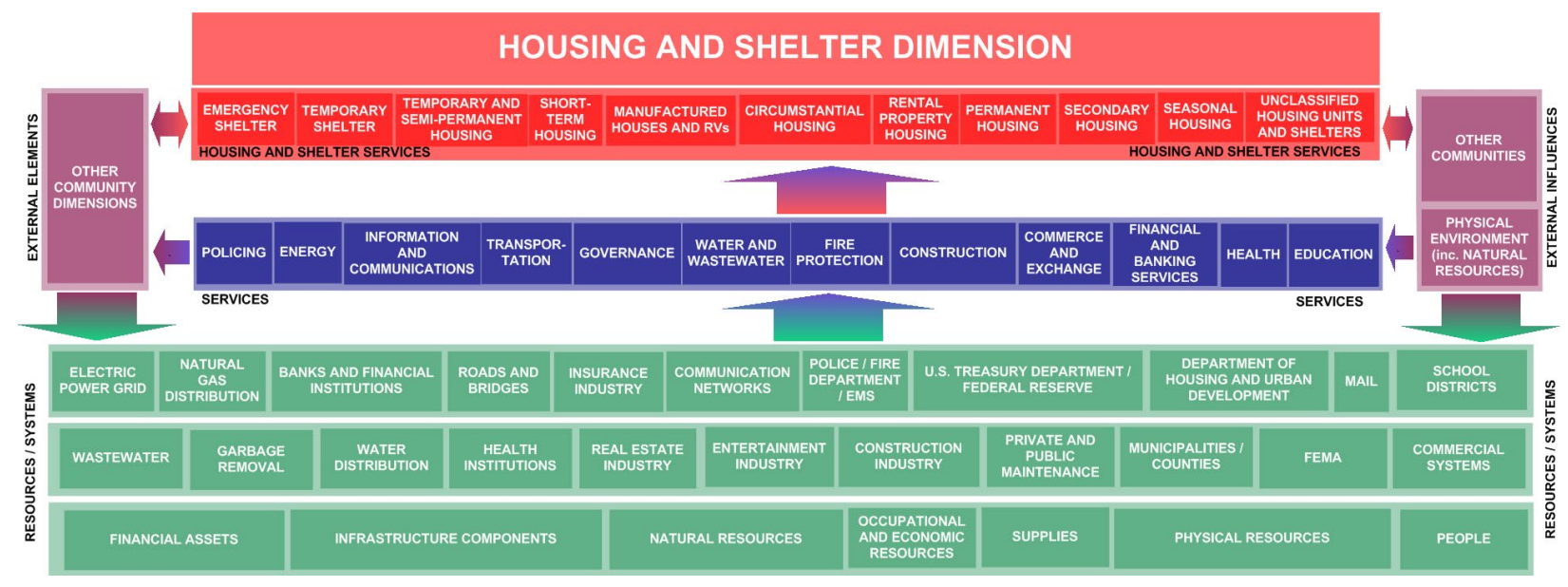

Figure 7. Structure of the Housing and Shelter dimension with its dependencies and necessary resources.

Although H\&S services are considered together as supporting the H\&S dimension, it is necessary to distinguish the use of housing and sheltering. A distinguishing factor between housing and sheltering is that the former involves establishing household routines and, thus, housing services involve long term (months or years) occupancy, whereas shelters are occupied on transitional basis until people can move into a housing unit (Quarantelli 1991). It is also important to note that long term occupancy of a housing unit does not imply continuous occupancy because seasonal housing, such as a summer home, still involves the establishment of household routines. For the same reason, occupancy of a housing unit does not require that the unit be at a fixed location. Some forms of housing, such as recreational vehicles or other easily relocatable housing units that allow occupants to move to different job locations throughout the year, involve living quarters where household routines are well established even though they may take place at different locations.

Within the context of community resilience, these H\&S services can also be distinguished in part based on a temporal scale that can be associated with the different recovery phases of a disaster (NIST 2015). Before a disaster strikes people will reside in the various types of housing units. During the disaster or immediately after it, people may be forced to move to an emergency shelter. This move to an emergency shelter is usually unplanned and spontaneous (Orrick 2015; Quarantelli 1982). Once the immediate aftermath of a disaster passes, people may relocate to temporary shelters where basic sustenance needs, such as food, drinking water, sleeping, and sanitary facilities are provided. Eventually, these people may move to temporary housing where household routines can be reestablished although at a non-preferred location or structure. Finally, it is expected that people will move again to other housing types to establish household routines but, this time, at a preferred housing unit.

Based on these preliminary clarifying concepts, it is possible to identify the following characteristics in the aforementioned eleven types of housing and sheltering types by expanding upon the work of Orrick (2015) and Quarantelli (1982):

1. Emergency shelters are facilities such as tents or other portable or rapidly assembled structures where disaster victims would seek short term refuge from the elements. 
2. Temporary shelters are places where people would transition after a disaster, either directly from their permanent housing or from an emergency shelter. Temporary shelters are often set up for a limited period in a permanent structure, such a community center, school, or religious facility. Living at a temporary shelter does not imply, yet, the establishment of household routines but, instead, the main purpose is to support the basic sustenance human needs, such as feeding, in a location with at least some sanitary facilities until people can move to locations where they can reestablish some routines.

3. Temporary housing units are buildings where people can reestablish a daily routine, but they are not intended to be permanent. An example would be the home of a friend or relative.

4. Short-term housing, such as a hotel or motel, is similar to rental property housing with the difference that stays are at most a few weeks. Still, despite the short duration of the stay, routines are established.

5. Manufactured housing units and recreational vehicles (including motorhomes and trailers) are living spaces that can be transported to different locations from time to time where household routines can be established. For the purposes of this report, manufactured housing and recreational vehicles are grouped together because they provide a similar type of H\&S service, regardless of any differences in size, the way they are transported from one location to another, or the standards that govern their construction. The U.S. Department of Housing and Urban Development (HUD) distinguishes these types of units primarily based on habitable space. Manufactured housing units are defined by HUD as "dwelling units of at least 320 square feet in size with a permanent chassis to assure the initial and continued transportability of the home” (CFR 2015). Recreational vehicles, on the other hand, are considered to be those that are: "built on a single chassis," have a habitable space of "400 square feet or less when measured at the largest horizontal projections," "self-propelled or permanently towable by a light duty truck," and "designed primarily not for use as a permanent dwelling but as temporary living quarters for recreational, camping, travel, or seasonal use” (HUD 2016). This last characteristic created issues with the established characterization of recreational vehicles and their exemption from HUD's Manufactured Home Construction and Safety Standards and its Procedural and Enforcement Regulations because it is possible to find recreational vehicles in use as long-term living quarters rather than temporary living quarters for recreational, camping, travel or seasonal use. In fact, residing in recreational vehicles is a relatively common practice after natural disasters. As a result, HUD proposed in 2016 to "revise the exemption for recreational vehicles that are not self-propelled from HUD's Manufactured Housing Procedural and Enforcement Regulations” (HUD 2016) so that recreational vehicles would have to comply with the same regulations applicable to manufactured houses. Examples of manufactured homes and recreational vehicles are shown in Figure 8. Household routines are established at each location. This type of housing includes living facilities used by people who need to move throughout the year to different locations, often due to job requirements, as with some farm and ranch workers. 


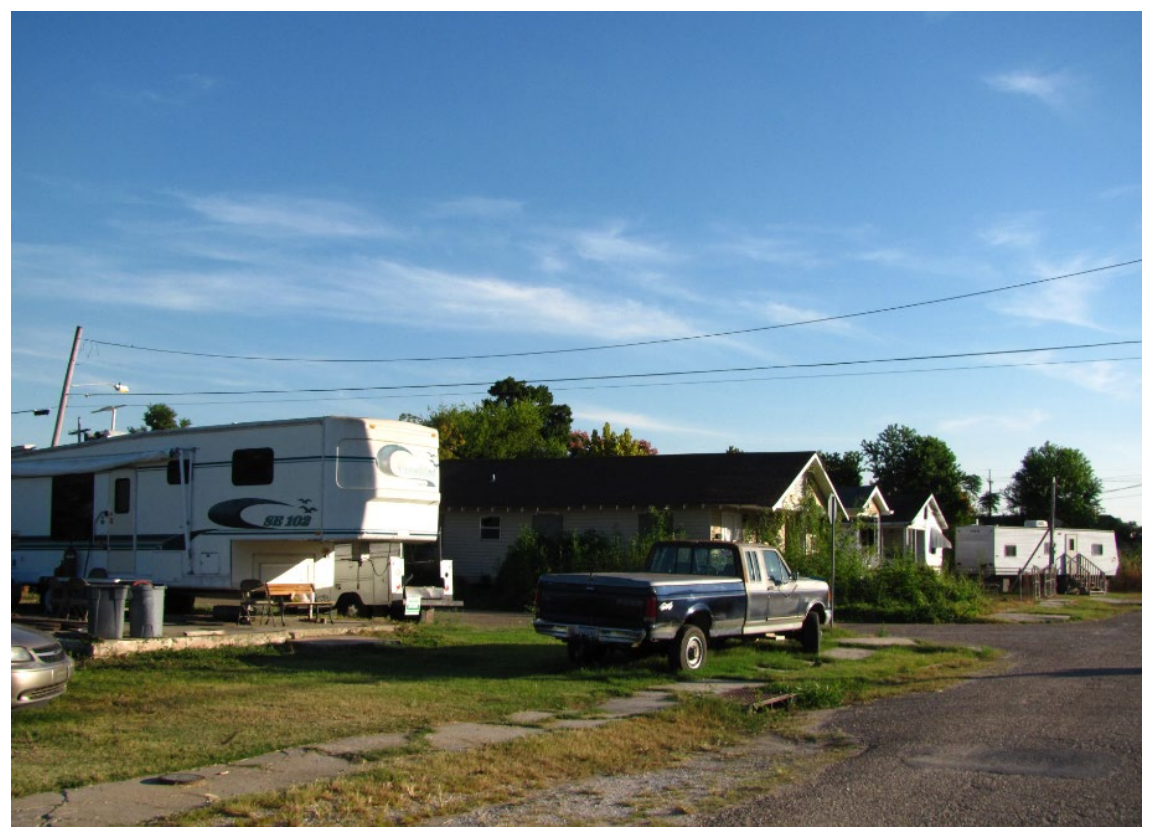

Figure 8. Examples of manufactured housing units (right) and recreational vehicles (left) used as semi-permanent housing in New Orleans, Louisiana in October 2010 (5 years after Katrina affected the area).

6. Circumstantial housing units are places where people reside based on individual particular life circumstances. In some cases, circumstantial housing can be associated with particular periods of people's lives, such as university dorms used by students during the time they are pursuing degrees in higher education. Another example is nursing homes. Correctional facilities can also be considered another example of circumstantial housing because these are the places where people are mandated to live when found guilty of a crime or other legal misconduct. Although these examples show that circumstantial housing includes radically different facilities than permanent or rental property housing and the life circumstances that that lead people to live in these locations are significantly different, they have in common that routines are established while living at these locations and that duration of stays may extend for several years.

7. Rental property housing is similar to permanent housing with the difference that residents do not own the property but, instead, pay a rent to reside in the property, often based on a lease agreement with a duration of several months to a year or more.

8. Permanent housing is represented by buildings at a permanent location where people establish their residence and where they stay most of the time. Residents have ownership of this property or they are under a financial contract, such as a mortgage, that would lead to full ownership of the property. Examples include single family homes, condominium units, and some apartment units.

9. Secondary housing units are buildings used by people as an alternative to their permanent housing where they live occasionally throughout the year but, still, household routines are established. Examples of secondary housing include cabins and cottages. 
10. Seasonal housing units are places used by people during a few months of a year but where household routines are established. Summer homes are a common example of seasonal housing. Another example of seasonal housing is the housing built and used by people who move to a given location in search of seasonal resources, as is the practice, for example, of some native Alaskans.

11. Other unclassified housing or shelter includes all housing units or shelters with characteristics that do not match any of the previous types. An example is temporary living spaces for the homeless population. Such shelters are distinguished from emergency or temporary shelters because they are used without the need for a disaster to occur.

Although the types of housing and sheltering units are characterized from an individual perspective, an important attribute to be discussed in more detail later in this chapter is that the H\&S dimension is formed by the aggregated physical, emotional and legal needs of humans for a place to support many of their activities and be protected from the elements. Hence, there are two sides to the H\&S dimension. On one side, communities are coalesced by the aggregation of many housing and sheltering units. On the other side, the housing and sheltering units act as anchors or attachments to the communities for the individuals or families living in them.

\section{b. Attributes of the Housing and Shelter Dimension and its Related Services and Systems}

Significant attributes of the community H\&S dimension and its related services and systems include the following:

- Sequential Patterns of Services. Typically, the use of H\&S services follows a sequential pattern through each person's life. For example, a person may live at their parent's house (permanent housing) until college when they move to a dorm (circumstantial housing). After four years they may move to a rental apartment (rental property housing) until buying a house (permanent housing) where they live until moving to a nursing home (circumstantial living) to live their final senior years. In reality, it is extremely unlikely that a person will live their entire life in just one type of housing, because even if this person always has permanent housing, trips may force him to occasionally use short-term housing services. A sequential pattern may also be observed during disruptive events when a person may move from permanent housing to an emergency shelter, then to a temporary shelter followed by a temporary housing unit before eventually returning to their original permanent housing unit.

- Diversity of Services. In this report, H\&S services are distinguished in part based on a varying span of time during which each service is typically used. Some H\&S services, such as shortterm housing, are used for a period of days or weeks, whereas others, such as permanent housing, are used for many months or years. An important distinction among H\&S services is the difference between housing and sheltering services. As explained above, housing services imply the establishment of routines whereas sheltering services do not imply having such routines.

- Widespread Use. A key attribute of the H\&S dimension is their almost universal continuous and prevalent use. However, even under normal circumstances, a small percentage of a community's population may be homeless, although many of these individuals may either 
create informal emergency shelters or utilize temporary sheltering services provided by relief organizations.

- Individual Relevance. From an individual perspective, H\&S is one of the main basic needs of humans as indicated by its placement alongside sustenance at the base of Maslow's hierarchy of needs.

- Social Relevance. The social relevance of housing and shelter is no less important than its individual relevance. As detailed in the next section, houses are the physical realization of an emotional, legal and economic attachment that people usually develop to their community. Additionally, housing represents a main benchmark of social status that influences human interactions within communities. Moreover, the H\&S dimension is a main source of revenue for communities through taxation. Housing and sheltering help shape a community culture and laws through rights and duties, such as voting and jury participation, that are based on people's permanent place of residence. Nevertheless, congressional districts and other jurisdictional boundaries applicable to legislative or judicial processes may not coincide with the community geographical boundaries. Such differences may lead to social stress and even conflicts within the community due to mismatches between communities' cultural and social identities and the legal connotations of living in that place.

- Existence of Quality as a Differentiating Factor. In most communities it is possible to establish different quality standards that differentiate houses or shelters of the same type. That is, houses and shelters of the same general type may show different characteristics. These different characteristics can be associated with different quality standards. For example, a new home built and inspected to modern building codes and standards may withstand storms better than a home built to less stringent standards. In this case, it is possible to define a quality of service (QoS) that is associated with how well individual houses or shelters protect from the elements. But it is also possible to observe that people have different perception of how well an H\&S service is provided or how much comfort a house or shelter provides. As a result, it is also possible to observe that there is a quality of experience (QoE) that is associated with how H\&S services are provided. While QoS could be defined in more objective ways, QoE tends to be more subjective, sometimes dependent on how people compare their own H\&S condition with respect to that of their community neighbors or with perceived standards of living in other communities.

- Varying Degrees of Dependence on Social and Physical Services. The degree of dependence of H\&S systems on social and physical services is inhomogeneous, varying widely with type and intensity of disasters. For example, natural gas and/or electric power is a critical need for houses during winter storms because people's health could be significantly affected in homes that reach freezing temperatures. However, people could still live relatively well for many days after a hurricane or earthquake in lightly damaged or undamaged homes that are experiencing electric power and/or natural gas outages. In general, houses and shelters seem to have weaker dependencies on most infrastructure or social services than other community dimensions. For example, with sufficient preparation people can still live in their homes for hours or even days without needing most infrastructure or social services as opposed to a hospital, for example, which cannot typically provide its services if it experiences issues with needed infrastructure or social services for similarly long periods of time. Degree of dependency is also influenced 
by individual needs. That is, some people may live in a home without hot water for many days whereas others may decide to move to a hotel or some other temporary housing location within a day or two of losing hot water. Technology development may affect degree of dependencies affecting housing and shelter. For example, increased reliance on internet connectivity at the residential level or increased use of electric vehicles may make homes dependent on electric power and communications with shorter time scales than what we have with current technologies.

- Realization of the H\&S Dimension. Since single isolated homes do not form a community, it is possible to say that the H\&S dimension is realized by the aggregated efforts of people building and buying dwellings within a given area. This form of aggregated development differs from infrastructure development in other community dimensions, such as health, which rely on separate infrastructure elements, such as a hospital. In the U.S., housing development is influenced by free market forces and, thus, tends to be driven by supply and demand dynamics. Moreover, even when development of an $\mathrm{H} \& \mathrm{~S}$ dimension requires an aggregation of individual efforts, from a legal perspective, these individual efforts are protected in various ways, including, for example, the due process and just compensation clauses of the Fifth Amendment to the U.S. Constitution.

- Relationship with Insurance and Banking Industries. Both of these industries have a significant influence on the H\&S dimension. Their effect is noticed not only during normal conditions, but also in case of disruptive events, for example, influencing recovery speed when repairing damage.

- Relationship with Other Communities. H\&S dimension of a given community influences other communities and is influenced by other communities both during disasters and in normal conditions. This influence can be exemplified by Hurricane Katrina when many families were evacuated from New Orleans to Houston (Patterson 2011; Turner 2015). In the short term, such displacement of people affected the H\&S dimension in Houston, including increased stress in some H\&S services, such as rental property housing and short term housing. In the long term, such migration also modified the cultural and social identities of both Houston and New Orleans (Patterson 2011; Turner 2015; Campbell 2014).

- Regulation. The H\&S dimension is heavily regulated. These regulations include building codes, permits, financing, etc. In general, changing existing regulations, such as building codes, and observing the implementation of these changes requires considerable time.

- Costs. Typically, high costs are associated with the use of services in the H\&S dimension. For most families, the cost of buying a home is the single largest investment made during their lives. The most significant cost is typically the acquisition cost of the dwelling itself, usually in the form of down payments and/or mortgage payments. However, other costs, such as property taxes, property insurance premiums, and maintenance costs, persist even after mortgages are paid off. These additional costs influence community resilience in direct or indirect ways. For example, in most communities property taxes are an important source of support for local school districts and community safety departments. Property taxes can also be used for local social programs or infrastructure maintenance and development programs that help to support or improve community resilience. Insurance costs have a particularly important 
influence on community resilience because recovery is accelerated when homeowners have their properties insured. Relatively high costs are also observed with rental properties. A majority of U.S. renters spend more than $30 \%$ of their current income on housing costs. ${ }^{1}$

\section{c. Meaning of Resilience for the H\&S Dimension and Services}

Resilience has been defined as "the ability to adapt to changing conditions and withstand and rapidly recover from disruption due to emergencies” (PPD-8 2011). Although buildings are required to deliver H\&S services, H\&S resilience should be interpreted within a broader view, in which protection from elements is only one component of what the H\&S dimension and services provide for a community. That is, resilience also needs to be understood within the context of the emotional, economic, and legal connotations that housing and sheltering have for people and, thus for a community. In particular, the physical, emotional, economic, and legal aspects of the H\&S dimension contribute both to creating a community and attaching people to the community. In case of a disaster, such attachments may survive even when a home (i.e., the physical infrastructure component of the H\&S dimension) does not survive. This surviving attachment may, in turn, act as an important motivation for recovery, thus, contributing to the intuitive notion of resilience of a community, which is in line to a broader view of the aforementioned definition from the PPD-8.

Another important aspect of resilience is the meaning of withstanding when applied to buildings and other physical structures supporting the H\&S dimension. Building codes have been developed prioritizing human survival over structure survivability. As a result, buildings designed to recent codes may survive an event and protect their occupants, yet they may be damaged to an extent that requires major repairs or even demolition. This issue raises a question within the H\&S dimension: what is a community? Is it a collection of buildings, a place, or the people who live there? In the NIST Guide (2015), a community is defined as:

... a place designated by geographical boundaries that functions under the jurisdiction of a governance structure, such as a town, city, or county. It is within these places that most people live, work, play, and build their futures. Each community has its own identity based on location, history, leadership, population, and available resources. Successful communities provide its members with the means to meet essential needs and to pursue their interests and aspirations.

Thus, within the context of the community H\&S dimension, resilience needs to be understood with a focus on the people living at a given place and not just in terms of building performance during a disaster. Hence, resilience is interpreted as the ability of the residents to prepare for and adapt to changing conditions and to withstand and recover rapidly from disruptions. Evidently, the performance of buildings where people live is an important component of how resilient a community is; however, resilience assessments focusing only on building performance may yield incomplete results if the emotional, economic, and legal connotations of the H\&S dimension are not also considered. These emotional connotations are related to community members' beliefs and values that form part of the local cultural identity. These beliefs and values affect resilience; sometimes improving it and sometimes worsening it. An example of this influence is the religious and self-reliant beliefs (both individually and as a community) that are part of the cultural

\footnotetext{
${ }^{1}$ U.S. Census 2013 American Housing Survey: https://factfinder.census.gov/faces/tableservices/jsf/pages/productview.xhtml?pid=AHS_2011_C10RO\&prodType=t $\underline{\text { able }}$
} 
heritage of many communities and that can be observed on display in damage assessments shortly after natural disasters, as exemplified in Figure 9 through Figure 11 from the aftermath of the tornado that affected Rowlett, Texas, in December, 2015.

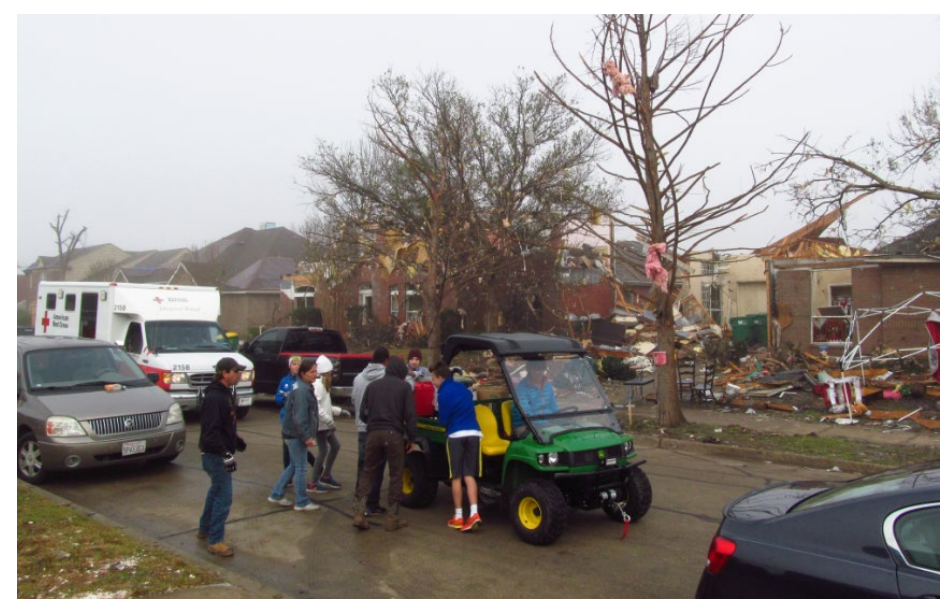

Figure 9. Example of a self-reliant culture in which community members provide food to neighbors affected by a tornado.

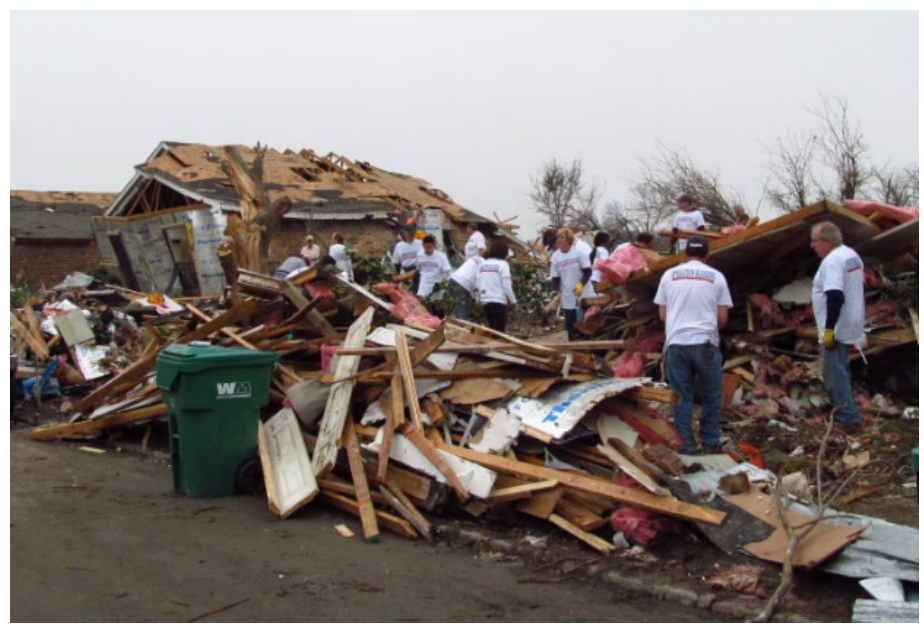

Figure 10. A group of volunteers from a religious congregation assisting in recovery efforts in the aftermath of the Rowlett tornado of December 2015. 

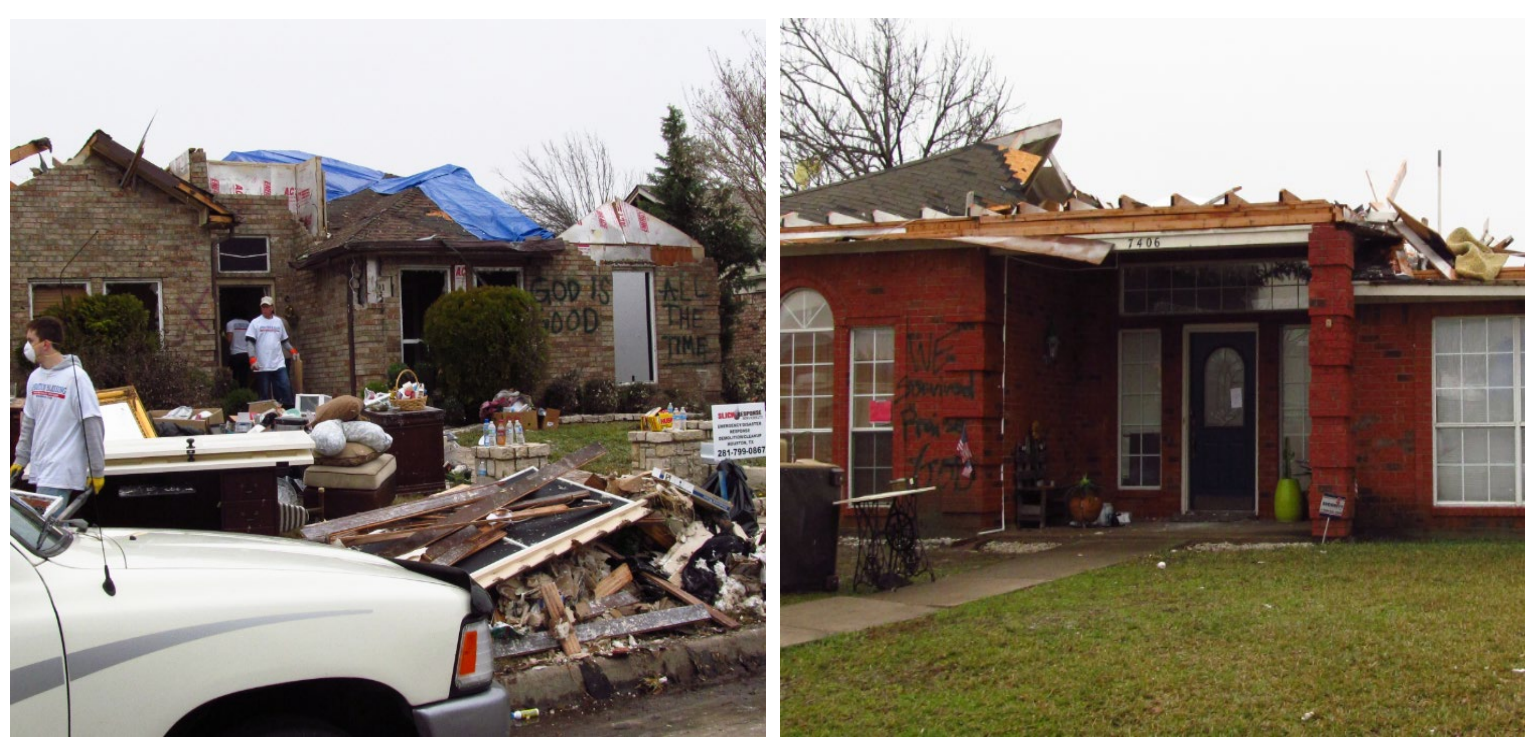

Figure 11. Religious messages painted on homes damaged by the Rowlett tornado of December 2015.

\section{d. Influence of Housing in Building Communities}

Housing is, arguably, the most basic dimension involved in building communities. In the United States communities are formed largely as a result of individuals following their own free will and shared interests to inhabit some location. As a result, communities are built from the bottom-up by initially forming a neighborhood, which, as it grows, is eventually connected to other nearby neighborhoods to form a larger community. The opposite approach is found in nations with state-directed economies. In these countries, communities could be formed by following a top-down approach in which a central government is the driving entity building communities. Since this government-driven approach to build communities is not commonly observed in the United States, it will not be further discussed here.

In the bottom-up approach to building communities, houses and other forms of housing units form the basic structure from which communities are created and developed. Still, the presence of housing units would not, by itself, create a community. Services, supporting infrastructures, and a proper social environment also need to exist in order to build a community. Once a neighborhood is built, a local associated community will likely be developed. As a result, it is possible to observe that within a city, there are neighborhoods or districts with characteristics different from those of other neighborhoods or districts within the same city limits. For example, in some cities it is possible to observe immigrant groups create differentiated neighborhoods within those cities. Still, local communities have common attributes with a broader community established at a city level by the combination of individual neighborhoods or districts. As a result, community resilience assessments need to recognize the existence of these local communities within the broader larger community. Such recognition includes identifying the potential different needs and motivations within each of the local communities and how these differences affect the broader community as a whole.

\section{e. Dependencies}

Housing and sheltering systems depend on a variety of community services. Key dependencies of the H\&S systems include: 
- Financial and Banking Services. The main financial and banking service needed by housing and sheltering systems is the provision of capital in order, initially, to develop an area with new buildings or to realize the acquisition of a property based on a mortgage or through cash exchanges. Later, provision of capital by financial and banking services is needed in order to keep buildings well maintained or to conduct repairs or improvements. In general, financial and banking services are provided by extensive systems that expand to the national level—e.g. Ginnie Mae, Fannie Mae and Freddie Mac — and are even linked to other countries through, for example, the federally issued securities and treasury bonds. Thus, housing and sheltering dependence on financial and banking services is an important external influence on a community's resilience.

- Energy. Energy services include electric power services and in many communities, natural gas and/or heating oil service. The degree of dependence on energy services may vary significantly within communities, with some people being more willing to wait longer than other people for service to be restored after an outage happens. The willingness to wait for energy services to be restored also depends on the type of event causing the outage. For example, people could wait for days for energy services to be restored after a hurricane when weather is warm (hurricanes only happen in warm weather conditions), whereas lack of energy services may become a life threatening situation after a winter storm when the weather is cold.

- Information and Communications. It is possible to identify various levels of dependencies of housing and sheltering systems with respect to information and communication services (ICS). These levels depend on the type of ICS needed. In some cases, such as calling 911 on a phone, ICS are needed in order to seek immediate help in case of an emergency. However, in other cases ICS services are needed for entertainment or social interaction purposes, such as when browsing the Internet to watch general videos or to access social media sites. Thus, as with energy services, the degree of dependence of housing and sheltering systems on ICS will vary depending on the circumstances.

- Transportation. Within the context of H\&S systems, transportation dependencies need to be interpreted as the need for open access to the buildings or structures where people live and the ability to travel from residences to places of employment and services (e.g. grocery stores). Such needs vary within most types of H\&S systems and among the various types of H\&S systems. For example, a well prepared family that is isolated when a disruptive event blocks access to their home could potentially wait for a few days for the access to be restored without much impact to their daily routines, as is typically the case during a winter storm. However, an elderly couple that lives in an isolated home may not be able to wait a few days for access to their home to be restored, even if they are equally well prepared. Moreover, the need for access may change if, for example, a medical emergency were to occur. Access needs also vary among types of H\&S systems. For example, an emergency shelter will not be able to provide its service if evacuees cannot reach it because of blocked roads. Adequate access is also important for $\mathrm{H} \& \mathrm{~S}$ systems in normal conditions when there is no disruptive event. In particular, adequate access influences both the development of new H\&S units and purchasing or renting decisions.

- Governance. Governance services have a critical influence on the ability of H\&S systems to provide their intended functions. Governance enables the existence of H\&S systems both by providing services, such as emergency shelters or public housing, and by creating and 
maintaining the legal environment that supports private H\&S systems protected through private property laws. The need for governance services by H\&S systems may be observed at a local level with ordinances, building codes and permits, and at the state or federal levels with regulatory actions and policies affecting financing or insurance markets. Taxation levels also influence H\&S systems and their ability to deliver their services. H\&S services are particularly dependent on governance services during disruptive events, for example, through economic aid for reconstruction provided within the legal framework of disaster declarations. An important effect of governance dependencies at a federal or state level is that they create a connection among communities within the corresponding administrative area.

- Water and Wastewater. Water and wastewater are one of the most critical services upon which H\&S systems depend. Without a local "buffer" for these services in their housing units in the form of locally stored water or a septic tank, respectively, people need to evacuate their housing units within a day after these services are lost. Thus, any demand to have these services restored rapidly would be indicative of a high degree of dependence of H\&S systems on water and wastewater services.

- Policing. This is a service upon which the H\&S dimension exhibits a high degree of dependence, as the acceptable waiting time for having this service restored when it has been interrupted is, in most situations, very short.

- Fire Protection and Emergency Medical Services (EMS). Like policing, fire protection and EMS are critical services for H\&S systems, as there is virtually no acceptable waiting time for these services to be restored if they have been interrupted.

- Construction. This service includes all the activities needed to construct, maintain, repair, and reconstruct H\&S units and, thus, also establishes a dependency relationship with H\&S systems.

- Commerce and Exchange. As discussed in the next paragraph, commerce and exchange services establish both direct and indirect dependencies with H\&S systems. Examples of commerce and exchange services upon which H\&S systems depend directly are real estate services (to buy, sell, lease or rent properties) and property-related insurance.

There are other services that are necessary for people to achieve their life goals and, thus, form a basic motivation for many of their established routines. Moreover, these other services influence how H\&S systems respond to disruptive events or how an H\&S area develops and thrives. These additional services are characterized by the fact that, in general, they are not provided at the H\&S units but, instead, they require people to travel to where those services are provided. Thus, it is possible to say that these are indirect dependencies because they are established mainly through the use of transportation services (although some of these services, such as virtual education programs, are established through ICS). Examples of services that establish an indirect dependency to H\&S systems include:

- Health. The availability and quality of health services can influence the demand for housing. On the other hand, the delivery of in-home health care services to those who require it depends on the availability of safe and affordable housing; therefore, the loss of housing may place increased demands on traditional health care facilities such as hospitals, nursing homes, and clinics. 
- Education. The availability and quality of education services is similar to the availability and quality of health services in how it can influence the demand for housing. However, as with health care, this influence may not apply equally to all population groups. For example, school district quality is not typically of relevance for elderly population. Another similarity with inhome health services is that ability to home school or pursue on-line education depends on the availability of safe and affordable housing.

- Commerce and Exchange. Examples of indirect commerce and exchange dependencies include the purchase of goods, food and services in relatively nearby shops. Employment availability within a community could also be considered an indirect dependence due to the strong influence this factor has on where many people decide to live.

System dependencies are established with respect to the services that the systems provide. The systems that produce these services require resources (Kwasinski et al. 2016). Examples of resources needed by H\&S systems include financing (e.g., capital), supplies (e.g., construction materials, tools, etc.) and human resources (e.g., contractors). These resources will also influence H\&S resilience because they are required inputs of the services needed by the H\&S systems.

\section{f. Direct and Indirect Effects of Hazards on Housing and Shelter}

Disruptive events can affect houses and shelters in a variety of ways, both directly and indirectly (Quarantelli 1991). Hazards affect H\&S directly when they produce some damage to dwellings. Hazards affect H\&S indirectly when there is no dwelling damage, but the ability of H\&S systems to deliver their intended service is limited because the services they need to operate are disrupted by the hazard. That is, dependencies make the H\&S dimension vulnerable to indirect impacts caused by a disruptive event. Such indirect impacts affect the ability of $H \& S$ systems to provide their services and, thus, they disrupt established household routines. Hence, indirect effects of hazards on H\&S are not limited to infrastructure lifelines. Disruptions to economic, social or legal services and conditions that support the H\&S dimension of a given community can also be considered indirect effects of a hazard on houses and shelters. For example, the financial crisis of 2008 can be considered one of such disruptive events causing indirect effects on the H\&S dimension of many communities, as foreclosures in some neighborhoods drove all nearby property values down causing new foreclosures and household displacements. Another example of indirect effects on H\&S is the aforementioned case of migration from New Orleans to Houston after Hurricane Katrina. In this case, Houston was not directly affected by Katrina so none of its dwellings were damaged, yet, in the long term, rental properties and short term housing services were under stress for the large number of people that moved from New Orleans to Houston. Moreover, in the long term, such relatively large migration affected the entire H\&S dimension in Houston.

Most evaluations of H\&S performance have focused on direct effects of disruptive events. However, this may overlook important aspects of how a given event may affect the community as a whole through the H\&S dimension because indirect effects are not considered. For example, consider the case of a winter storm that leaves a community isolated and with no electric power for several days. Such an event may not cause any damage to homes, yet households may lose considerable protection from the elements (i.e., extreme cold weather conditions) to the point where lives could be threatened. Careful preparation for such an event could include, for example, improving home insulation or storing wood in order to keep warm by making fires. This discussion also suggests that the ability of a home or shelter to provide its intended service may not be completely interrupted but may just be degraded. This notion of performance 
degradation suggests the need for a continuous metric or a multi-level scale for assessing resilience of the $\mathrm{H} \& \mathrm{~S}$ dimension and its services.

\section{g. Relationships between Housing and Sheltering and other Community Dimensions}

Housing and sheltering has a strong influence on other community dimensions. This influence is sometimes exerted through the basic H\&S function of protecting people from the environment but other times is exerted through the emotional, economic, or legal aspects of the H\&S dimension. In particular, some examples of how H\&S influence other community dimensions include:

- Sustenance. The H\&S dimension is important to human sustenance because dwellings not only protect people from the elements but also their food and drinking water from elements or pests. Modern sustenance chains count on refrigeration, which, in turn, requires working electric power. One of the most important routines applicable to daily lives in housing units is preparing and eating meals.

- Health. The H\&S dimension has a significant influence on the community health dimension (Kwasinski et al. 2016). This influence is observed, for example, through the lower risk of illness due to the presence of sewage systems in homes and the lower risk of injury or disease due to the protection that houses and shelters provide from the elements. Houses also contribute to long term mental health through the establishment of physical security and daily routines.

- Security and Safety. As Figure 12 exemplifies, houses and shelters play a critical role in maintaining security and safety. Such protection includes not only humans and their pets, but also their possessions. Photos and other media are particularly important possessions that are protected by houses and that relate to the emotional attachment that people develop with their families, friends, and community. Housing and shelter also influence community security and safety by financing public security services, such as police, through property taxes.

- Education and Personal Development. Housing and shelters contribute to education and personal development by providing a stable environment where learning and personal development can prosper. In particular, routines established in houses play an important role in children's learning processes. Additionally, in most communities property taxes are a main funding source supporting local educational activities. During emergencies, schools and other educational facilities may become emergency or temporary shelter facilities. Thus, educational infrastructure may temporarily become H\&S service providers. 


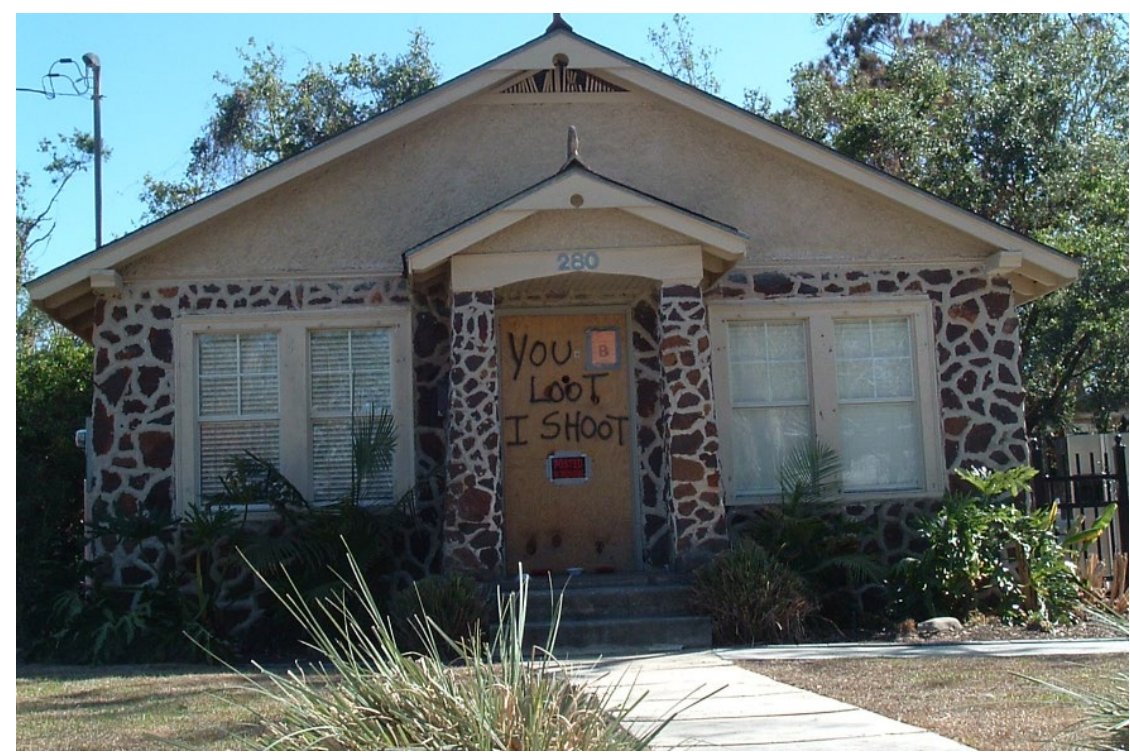

Figure 12. Security-related message painted on a home in the aftermath of Hurricane Katrina.

- Culture and Identity. Housing and shelters influence community culture and identity in several ways. From a physical perspective, architectural or housing styles contribute to the cultural identity of a community. In case of a significant disruptive event, the influence of H\&S on culture and identity may experience drastic changes, as exemplified by the Lower Ninth Ward of New Orleans (Figure 13) or Greensburg, Kansas, which were both rebuilt after a disruptive event-Hurricane Katrina in the former case and an EF-5 tornado in the latter case-with a focus on sustainability and the application of renewable sources of electric power. The aforementioned example of migration from New Orleans to Houston after Hurricane Katrina provides another example of how the H\&S dimension affects culture and identity.

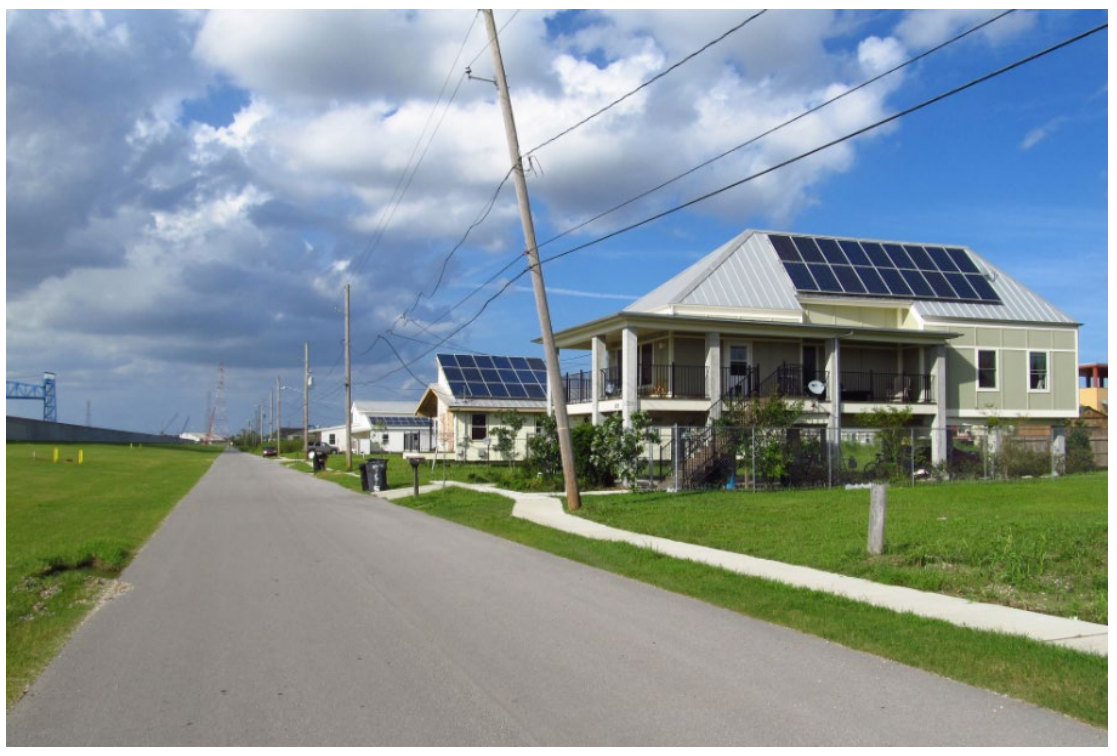

Figure 13. The Lower Ninth Ward in New Orleans in 2012. 
- Belonging and Relationships. Housing and shelters also influence the notion of belonging and the development of relationships. For example, children tend to play with their neighbors, thus establishing relationships among families within a neighborhood that contributes to create a sense of belonging to a group within the community. From a physical perspective, the location of a neighborhood also influences how people develop their sense of belonging and build relationships within the community.

\section{h. Resilience Assessment of the Housing and Shelter Dimension}

Traditionally, resilience assessments have focused on building performance (Comerio 2014; IOM 2015; Association of Bay Area Governments Resilience Program 2015). However, as previously explained, resilience for $\mathrm{H} \& \mathrm{~S}$ needs to be understood within a broader context with a focus on the people living in a given place. This focus applies both for baseline studies before a disruptive event happens and after an event happens. Within this context, resilience assessments could be considered at two levels: for the H\&S dimension as a whole or for each H\&S service. However, it is important to note that both in normal conditions and in case of disasters some H\&S services are generally utilized in a sequential pattern. For baseline assessments before a disruptive event happens, the sequence described in Section 3.b may be considered. However, after a disruptive event another sequence could be considered. During disruptive events, people may need to evacuate from their permanent housing to an emergency shelter, then move to a temporary shelter, followed by a temporary housing and eventually return to a permanent home. As a result, the community H\&S dimension needs to be assessed for each sequence of services rather than each individual service. That is, the assessment should look into whether such a sequence is interrupted or disrupted in some way.

The assessment should first define some baseline sequence of services so the assessment can evaluate whether the actually observed sequence follows the expected pattern. Defining such a baseline sequence could be done in various ways depending on the metrics used to evaluate resilience. One possible approach when characterizing sequences may include computing the average time that each household spends using a given H\&S service in the sequence and the percentage of households in a community that moves from a given service in the sequence to another service in the sequence. This latter evaluation may provide information about the percentage of households in a community that are forced to leave the expected sequence of H\&S services, which could suggest a disruption in the sequence and a potential reduction in $\mathrm{H} \& \mathrm{~S}$ resilience.

Because of the sequential pattern of H\&S services, a relatively poor performance in one H\&S service that is part of a sequence (e.g. too many permanent housing units destroyed during a disruptive event or an excessively long time in temporary shelters before being able to move back to permanent housing) may not necessarily imply poor resilience in the H\&S dimension. Such assessment of H\&S dimension resilience will depend on how it is measured. If it is measured by the number of households remaining in the community through the use of temporary shelters until permanent housing can be provided again, then the $\mathrm{H} \& \mathrm{~S}$ dimension may seem resilient. Instead, if resilience assessment is based on time it takes people to move back to their permanent houses, then the result may yield a relatively low resilience. Basing a resilience assessment on the sequence of H\&S services used addresses the issue of using H\&S services for different lengths of time. Moreover, it also addresses the fact that some H\&S services, such as the use of emergency shelters, are only used in case of a disruptive event.

The sequential utilization of H\&S services suggests a relationship with the recovery phases from a disruptive event and allows one to evaluate the four main attributes of resilience defined in PPD-21: 
withstanding capability, recovery speed, preparation ability and adaptation. For example, in the baseline sequence of services used in the case of a disruptive event-i.e., from permanent housing to emergency sheltering, to temporary sheltering, to temporary housing, and eventually back to permanent housing-it is possible to evaluate withstanding capability by measuring the percentage of households forced to leave their permanent housing arrangement. In this example, recovery speed could be evaluated by measuring how long it took for a given percentage of the households forced to leave their permanent housing facilities to return to the same or a new permanent housing facility within the same community. Alternatively, it could be possible to measure recovery speed by measuring the percentage of households returning to a permanent housing facility within the community after a given time since the disruptive event happened. Preparation and adaptation could be assessed by comparing similar metrics after similar disruptive events with and without preparation or by evaluating different sequences of H\&S services used during the recovery from the disruptive events.

One example of adaptation applied to the H\&S dimension can be observed in the Mississippi River Delta region. This area includes the towns of Yscloskey and Delacroix which were populated before Hurricane Katrina by communities of fishermen and oil industry workers who lived in homes often elevated on piles to prevent flooding during hurricanes. However, as Figure 14 exemplifies, this design was insufficient to withstand the effects of Hurricane Katrina, which destroyed most of the homes. After Hurricane Katrina, these communities were left outside of the area protected by the newly built levee system. Nevertheless, a substantial portion of the people living in these communities returned to these towns. However, instead of building homes similar to those they had before, they moved into recreational vehicles, such as the one in Figure 15 (left). The use of recreational vehicles provided these community inhabitants the ability to just drive away when their towns are threatened by another hurricane and temporarily park their recreational vehicles on the protected side of the levee gate until the hurricane passes and it is safe to move back to their original lot. This adaptation strategy is exemplified through the photo in Figure 16 taken a few days after Hurricane Isaac (2012) affected the same area.

A main challenge when assessing resilience of the H\&S dimension is to determine which factors or metrics need to be considered. Several aspects are important when determining which factors or metrics to use. One aspect is whether to use a quantitative or qualitative approach. In general, the former tends to be more advantageous as it provides an objective benchmark that can be used to compare different settings, communities or community sections. Another important aspect is the need to measure both the effects of dependencies and degree of dependence. One way of considering the effects of dependencies on resilience is by evaluating the local buffering needs for a given service (Kwasinski et al. 2016). The need for buffering could be interpreted within the H\&S dimension as an average time that the users of the service can wait for a service to be restored (Jiang and Schulzrinne 2000). One aspect that adds challenges when assessing resilience is that many metrics may depend on the type of disruptive event and its intensity. As a result, it may be difficult to find a way to relate resilience assessments performed for different disruptive events or intensities. Nevertheless, it can be expected that any resilience assessment, whether it is for the H\&S dimension, its individual services, or a specific sequence of services, needs to consider not only the main goal of protecting people from the elements, but also needs to consider the emotional, economic and legal connotations of housing and sheltering. 

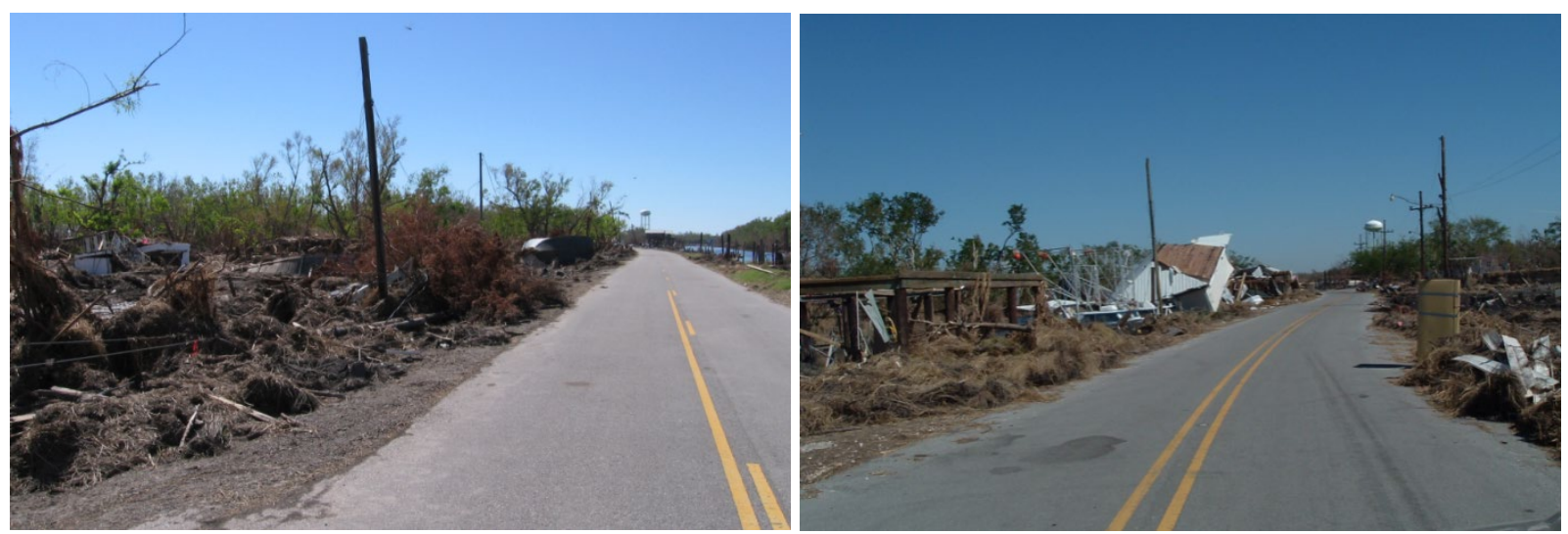

Figure 14. The town of Delacroix, LA, 6 weeks after Hurricane Katrina affected this area.
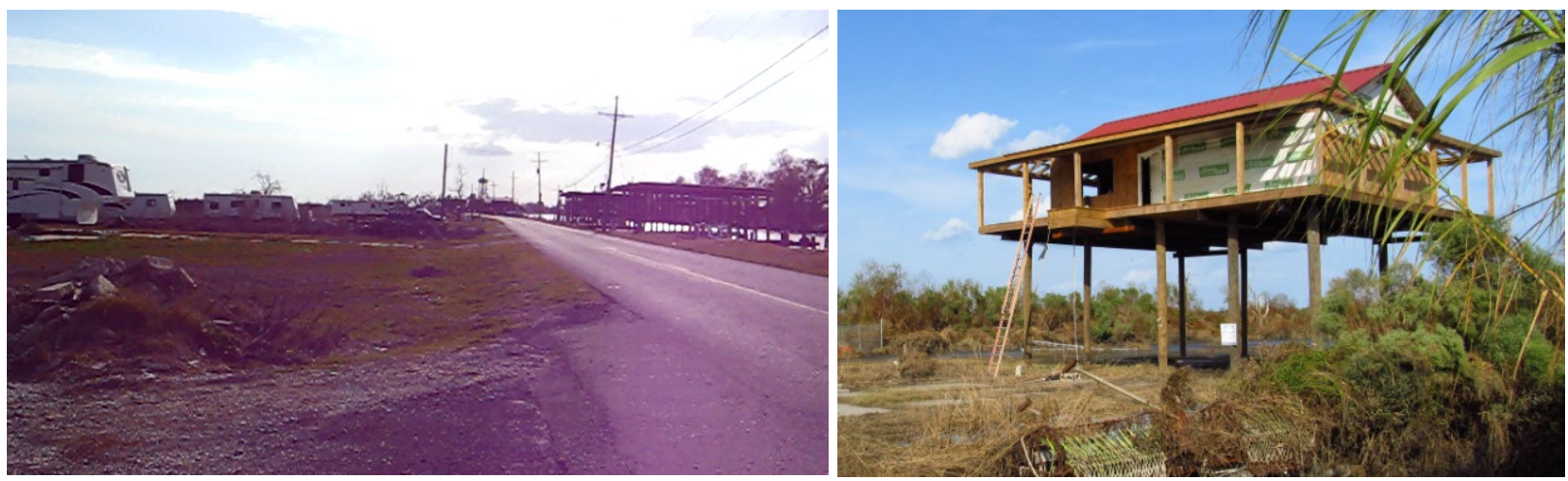

Figure 15 (Left) The same area of Delacroix depicted in Figure 14, showing recreational vehicles used to replace the permanent houses destroyed by Hurricane Katrina (photo taken in September 2008). (Right) The same area in Delacroix, LA, in 2012 showing a new home elevated on piles.

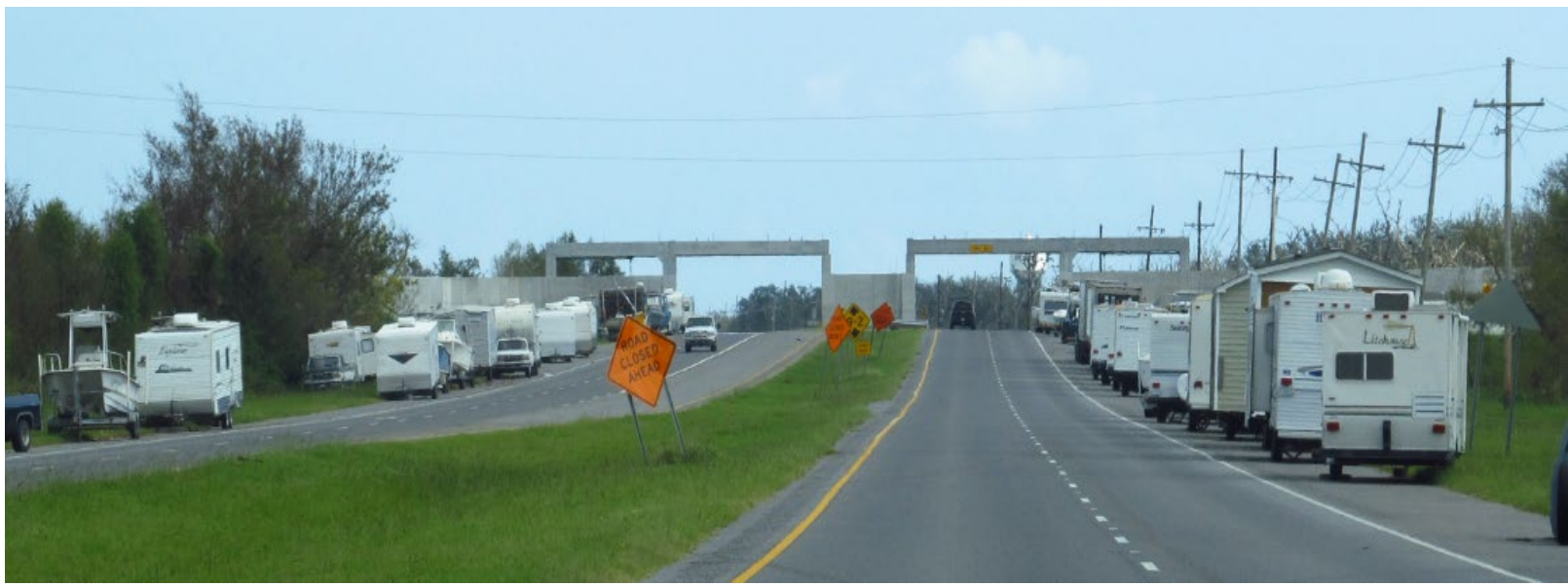

Figure 16. Recreational vehicles parked inside the gates of the levee protection system four days after Hurricane Isaac affected the Mississippi River delta area in 2012. 
Resilience of the H\&S dimension can be assessed directly or indirectly based on the effects that H\&S has on the community. Some of the direct metrics that can be used for assessing H\&S resilience have already been mentioned in this discussion. They include percentage of households that are permanently displaced out of the community after a disruptive event or some average period of time that households need to spend in temporary shelters compared to a total duration of the community's recovery from the disruptive event. However, resilience of the H\&S dimension can also be evaluated indirectly by measuring the effect of the $\mathrm{H} \& \mathrm{~S}$ dimension on the community. One potential way of performing such an assessment is to estimate real estate tax revenues under various scenarios. Tax revenues may include property taxes and/or sales taxes from business and industries, which may not only account for the indirect impact of the H\&S dimension on the community through its influence on overall economic activity but may also consider the possibility that people may remain in their communities in temporary living spaces after a disruptive event even when their dwellings may have been lost or property taxes may have been waived to assist in recovery efforts. Another potential approach is to calculate the economic activity associated with $\mathrm{H} \& \mathrm{~S}$ in terms of total dollars involved with H\&S transactions.

Ultimately, the decision of what approach or metric to use will depend on the ultimate objective of evaluating H\&S resilience. Notice that in all these potential metrics, the focus is on the people living in houses and shelters and not on the dwellings themselves. That is, a possible metric for H\&S services could be based on the number of housing units of a given type that have been damaged after a disruptive event and the time it takes to repair them. However, this may not be a good indication of community H\&S resilience because the fact that dwellings are in a habitable condition does not imply that those dwellings are indeed inhabited, as exemplified in Figure 17 after Hurricane Katrina. This distinction is in agreement with the interpretation of resilience for the H\&S dimension given above in Section 3.c: "resilience needs to be understood with a focus on the people living at a given place and not necessarily only as building performance during a disaster," and it acknowledges that a town of uninhabited houses in good structural condition is a ghost town rather than a community.

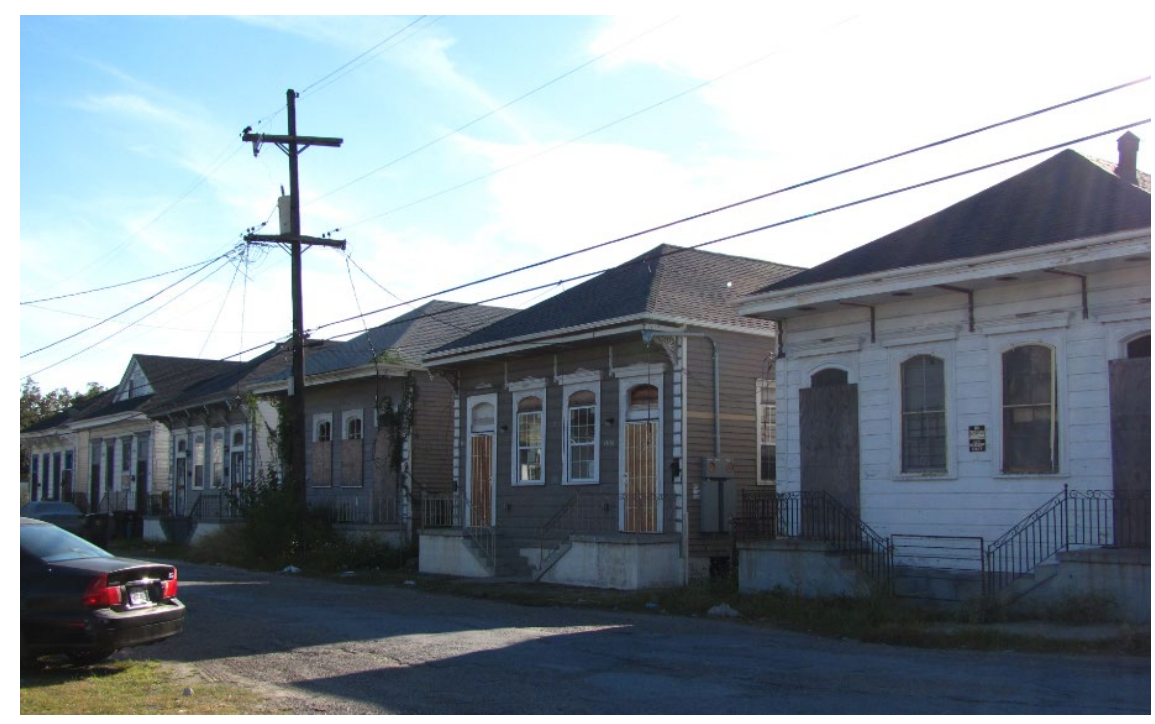

Figure 17. Abandoned habitable homes in New Orleans (October 2010).

As discussed in Section 3.b, it should be possible to define Quality of Service (QoS) and Quality of Experience (QoE) metrics for H\&S services. It can be expected that QoS metrics for a given H\&S service will likely be related to resilience metrics selected for that service. That is, it can be expected that a housing 
unit that protects its occupants better from the elements than another housing unit will also yield a higher resilience. Still, since H\&S services are typically utilized in a sequential pattern, a higher resilience associated with a given service with overall higher QoS levels may not necessarily yield higher community resilience for the H\&S dimension. The existence of QoS levels also indicates that resilience assessment may need to consider the fact that during disruptive events H\&S services may not fail completely or may not fail at all but, instead, they can experience some performance degradation or have their services temporarily interrupted (e.g., due to infrastructure dependencies such as lack of accessibility or lack of power, water, or wastewater services). Under these circumstances, while the buildings themselves may be robust, they may not be contributing to resilience, at least in the short term. Moreover, resilience assessments will need to take into account that the minimum acceptable QoS level for a dwelling is dependent upon the protection needs of its occupants. For example, consider a case of a heat wave affecting a community that experiences lack of electric power. In this case, a home with no working air conditioning may still provide sufficient protection from the elements for a couple in their 30s but may not provide sufficient protection from the elements for an elderly couple.

The notion of resilience depending on QoS levels needs to be distinguished from influence of QoE. While QoS is an objective attribute, QoE is subjective and dependent upon the occupants' perceptions. Still, QoE may influence resilience metrics. For example, people's varying tolerance to high temperatures may, in the heat wave example, cause some people to decide to move out from their permanent homes to short term housing (e.g., hotels) until power returns to their homes whereas others with higher tolerance to hot weather may decide to stay in their permanent homes. That is, different perceptions of how well H\&S services are delivered may affect household decisions on whether to stay or move out of their permanent housing arrangements and, thus, affect resilience assessments. 


\section{Belonging and Relationships Dimension}

This chapter discusses the relationship between the community dimension of belonging and relationships and community resilience. For some, this dimension may be more difficult to understand. Further, it may be hard to see something as personal as connections with other people as an asset that communities and governmental agencies should be concerned about or actively try to influence in some way. This chapter will clarify why it is not only possible, but critical, to recognize the role of social networks, relationships, and sense of belonging in the resilience of a community. Any effort that does not take into account these human dimensions will be less successful than expected.

While physical and material resources are critically important for any disaster response, as are the manmade infrastructure systems that deliver those resources, all of these are influenced by people and organizations who make choices that ultimately impact the community. Belonging and relationships are fundamental features that influence how those choices get made. Relationships are the lasting connections between people, organizations, or even communities that ease the flow of resources from and to the same. If we are to understand what makes places resilient to disaster, we must consider how people are connected to each other, the community, and even the buildings and landscape. This chapter is intended to provide a set of ideas and concepts that will help make sense of these elements and ultimately to measure them. Fundamentally, this chapter also operates from the assumption that we as communities choose to invest, or choose not to invest, in these elements, but often without explicit consideration of the benefits or consequences of doing so. Much of the creation of social organization roles, rules, procedures, precedents, and relationships is unplanned and purposive only in small ways. Its role as a form of social capital is mostly a by-product of decisions that were made for other reasons.

In order to measure belonging and relationship at the community level, it is important to recognize that communities do not "belong" or have "relationships" in the traditional way we discuss these ideas in common language. The notions are more often related to people or individuals within the communities, but with a benefit to the community as a whole. Even so, it is possible to identify a set of ideas that characterize and measure the connectivity of people and groups within a particular community. Further there are also concepts that allow us to capture the level of connectivity between the community and those outside it. This chapter will draw on social science and infrastructure research to help move towards the measurement of belonging and relationships at the community level as a measure of resilience.

\section{a. Relationships}

The idea of characterizing the level of relationship in a community is central to the concept of "social capital” (see Aldrich and Meyer 2014 for an excellent summary). As a result, related studies and findings can provide insight into how we can measure this community dimension. The general logic of these studies is that relationships are beneficial not only for the individuals who have them but also for the community more generally. While the exact mechanisms and the details of measurement are to some degree debated, there is clear evidence that strong relationships within a community matter for resilience. These relationships help communities achieve mutually beneficial goals (Baron, Field, and Schuller 2000); help facilitate shared values; facilitate information sharing; and serve as a conduit for providing social support. A recent National Research Council report (NRC 2011, p. 106) suggests that social capital is "the foundation for community adaptive capacity (see Norris et al., 2008)" and "the formation of effective and productive social networks constitutes a key element in [its] development.” 
These relationships are not all equal however. As a result, three types have been identified as described below.

\section{i. Bonding Relationships}

While it is fairly easy to recognize that most people associate with others and develop relationships, it is also easy to underestimate how important they are to our lives, our health, and in some instances even our survival as individuals and as communities. The first way of thinking about relationship in a community rests on the idea that when two people are friends or are related to each other the connection between them is a strong path for the exchange of information or resources. In other words, our intimate linkages to other people can manifest in disasters as feelings of connection and/or obligation to help. In short, when we are in need we can get real resources through our friends (Bordieu 1985). Measuring the strength of these most intimate relationships is called measuring "bonding social capital." The value of being connected to others should not come as a surprise given that research has long suggested that friends, family, and even acquaintances can be critical during disasters (Fischer 2008).

At the group level, these connections and the social expectations embedded in them matter because at the most basic level the more that people can rely on their connections to gain the resources they need, the less they will need to rely on response and recovery programs. Even so, it should be noted that there are limits to this concept.

\section{ii. Bridging Relationships}

The second way of thinking about and measuring relationships in a community is to consider how individuals or organizations can serve as bridges to diverse sets of skills and resources they may not have anticipated that they might need. As is often the case in disasters, flexibility and adaptation are critical determinants of success, and the ability to link together groups that have been loosely associated is a critical skill. This "bridging social capital" connects members of different groups or networks; facilitates crossing ethnic, racial, and religious groups within the community; and helps to bring together a more focused set of efforts, less laden with conflict. Mutual aid compacts and other less formal connections between communities or between levels of government are examples. Seasoned emergency managers have long known that relationships between communities and agencies are of critical importance for disaster operations. As a result, one of the major measures of relationships in a community is the measurement of interaction across formal and institutional levels in society.

\section{iii. $\quad$ Linking Relationships}

The third and final way of thinking about relationships in a community is to consider connections between less powerful/resourced groups and communities to stronger institutions and communities. In the U.S. context, the major expression of this form of capital is the connection between individuals, groups, or the community and the larger governmental units within which they are embedded, such as the county, state, and federal government. This can also express itself in terms of local businesses linking community units to broader sets of resources in their network. For example a local Home Depot can link the community to the resources of the corporate offices. The same kinds of relationships can occur in local non-profits, such as the Red Cross, as well. 


\section{b. Belonging}

The notion of belonging captures both tangible and intangible forces within a community that facilitate collective connections and actions. These are not specific connections between people, instead they are the context in which the community either facilitates or impedes collective actions. Resilience measurement needs to recognize and actively support activities designed to help bring people together.

\section{i. Cognitive}

In addition to the specific rules and structures that force people together, there is also a set of cognitive elements that can facilitate or impede a community's sense of belonging. Trust is a particularly important concept in emergency management, as people's decisions are often based on receiving information from a trustworthy source. Trust can also be tested when governments and agencies are perceived, or found, not to have performed according to plan or to community expectations. Sometimes this can be as simple as the notion of fellowship and goodwill (Hanifan 1916). Another expression of cognitive belonging is the degree to which helping or "standing together" at any unit of analysis is valued. It is important to understand the degree to which individuals and groups have an attitude of benevolence and loyalty within a larger group and are willing to act for the benefit of the larger community (Uphoff 2000).

\section{ii. Attachment to Place}

The second notion of belonging refers to the sense of emotional and/or economic connection between a person and the community setting. This connectivity is more than just a feeling. In order for communities to function well, those within them must feel a sense of commitment to that place and its vision. The importance of this sense of belonging has been well documented by researchers (Aldrich and Meyer 2014). Research also demonstrates that individuals benefit from a strong sense of belonging to a place, which inhibits their desire to relocate after a hazard event (Sanders et al. 2003; Groen and Polivka 2010; Cutter et al. 2014) and impacts a general willingness to invest time, effort, and resources towards building resilience or dealing with disasters. Attachment to place can be broken into three bodies of research: general attachment, identity, and dependence. General attachment typically refers to emotional connection to a place. Most literature recognizes sense of place as one of the most general constructs associated with attachment to place. It encompasses one's ability to organize self-referent cognitions, emotions, and behavioral commitments in relation to a certain place (Jorgensen and Stedman 2001). Identity refers to the degree a particular place serves as a critical element of who a person is. Dependence refers to the degree a person needs natural, social, or economic resources from a particular place in order to survive or thrive.

Taken together these ideas remind us that places are contexts within which interpersonal, community, and cultural relationships occur, and it is to those social relationships, not just to place qua place, to which people are attached (Low and Altman 1992). Attachment to place is measured across time. It is particularly interesting to look at this concept pre- and post-disaster. Successful recovery or lack of recovery in a community provides an interesting opportunity to see how attachment to place influences the process or is influenced by the process (Fried 1963). Research on the subject has shown that both the social dimension and the physical dimension are responsible for these feelings of attachment. It is important to respond to disasters in ways that foster just and sustainable outcomes that build resilience, respect human rights, and foster economic, social, and cultural well-being in reasonable timeframes and at reasonable costs (Howitt, Havnen, and Veland 2011). 


\section{c. Attributes of the Belonging and Relationships Dimension and its Related Services and Systems}

Unlike many of the other dimensions, belonging and relationships are far less tangible. Further, they are primarily social in nature, unlike buildings, pipes, and other forms of physical infrastructure, so it is considerably harder to capture and measure them. In addition, as ideas that represent and characterize relationships, it is important to note that, as with all relationships, they can change. Further, changes at the aggregate level may not always be evenly distributed across the area (Uphoff 2000, pp. 227-228).

As a result, unit of analysis is critically important. When we consider belonging and relationships, it is important to consider if we are aggregating individual patterns to a larger area or if we are looking at communities as individual units and considering the linkages between neighborhoods, towns, or states as separate units.

Another important fact to remember is that although connectivity can facilitate innovative responses with what is available, a lack of real resources can diminish the potential value of these linkages. In short, if there is nothing to exchange then the presence of connections alone is of less value. Different event scales may also impact value of different types of linkages.

Finally, while much of the literature around belonging and attachment suggests a strong positive effect it is also important to note the potential dual nature of attachment and connectivity. When taken to the extreme, these forces can become insular. Sometimes connections can lead to exclusion, the need to separate from other groups, and a general unwillingness to work beyond the group (Osborne and Beattie 2004).

\section{d. Dependencies on Services}

The dependencies of the relationship and belonging dimension on community services include the following:

- Housing. Homes often serve as an anchor for individual's lives and place them in specific neighborhood relationships. Housing is also an important determinant of belonging and attachment. For example master planned communities with housing focused on shared spaces and interaction can facilitate the growth of connectivity between individuals (Williams and Pocock 2010). Such housing arrangements encourage community and develop stronger relationships between people (Gwyther 2005; Perz et al. 2012).

- Financial and Banking Services. Access to banking services is important for the transfer of monetary resources, one of the major forms that assistance from friends and families take.

- Energy. Energy services include electric power services and in many communities, natural gas service. Particularly in the case of organizations and associations that serve as the center of social networks, energy is often used to facilitate activities.

- Information and Communications. Information and communication systems are a primary mode of exchange between people and as a result are important to facilitate relationships and the exchange of information through social networks. Although the infrastructure itself alone cannot create connectivity, the presence of internet service facilitates channels for local civic participation. The formation and active participation in local community electronic networks 
not only adds to but also amplifies civic participation and elevated sense of community attachment (Mesch and Talmud 2010).

- Transportation. The ability to move from place to place is important to facilitate relationships. One study of rural "regeneration" projects in the UK found that the level of community engagement in projects including the creation of riverside walks, restoration of historical landmarks, etc. was impacted by accessibility and transportation (Osborne and Beattie 2004). Others have made similar arguments. For example, Vickerman (1994) made the argument that transportation systems such as rail and road were critical for connecting communities and for the development of a sense of nationality in the EU. These systems also provide the ability to move materials and people to and from places where they might assist others.

- Governance. Governance services have a critical influence on relationships and belonging. A number of governmental programs and policies are intended to create frameworks or structures that facilitate the creation of relationships or ideas on how individuals and organizations should relate to each other. In many ways these are systems designed to facilitate specific forms of relationships. Over time these systems use sets of rules, policies, and procedures that form a social structural expectation for how relationships work. In particular, it is important to note the design of systems intended to facilitate: (1) decision-making, (2) resource mobilization, (3) communication and coordination, and (4) conflict resolution (Uphoff 2000). The form of these structures can, if well designed, facilitate people working together by lowering transaction costs, coordinating their efforts, creating expectations, making certain outcomes more probable, providing assurance about how others will act, and so on.

- Policing. As has been illustrated by recent events, the policing function and choices that are made in how that function is implemented can serve as a force that brings communities together or conversely pulls them apart.

- Health. Social connectivity is an important element of maintaining good mental health. It is a generally agreed upon notion that humans are social beings. The degree to which people are connected to each other helps to predict support services, access to recovery resources, and even the ability to find temporary or permanent housing. All of these forces are strongly associated with mental health outcomes.

- Education. Schooling is a major location for the creation of both relationships and a sense of belonging in communities. As an example, Williams and Pocock (2010) describe the importance of building design in facilitating connections between parents. They specifically describe pre-schools and waiting areas in schools, to form connections to others with similar interests.

- Commerce and Exchange. The economy is important for setting a resource base and is a root of relationships. It is also important for linking. Government and economic performance impact belonging and relationships by impacting social capital (Putnam 1993) and attachment to place (Cutter, Burton and Emrich 2010).

- Culture. Culture is very important to the belonging and relationships dimension, particularly in the case of belonging. Different cultures can have distinct views on who belongs and on how 
communal people should be. Cultural objects and practices also are a major determinant of where we belong and to whom we are connected. Culture provides a common reference base that people can use to relate to each other and build relationships based on affinity.

- Recreation. For teenagers, community recreational facilities can serve as meeting points to form connections and relationships. Young parents have also described the importance of recreational facilities, such as bike paths between homes and local playing fields, as places where they are often able to make connections with other young parents (Williams and Pocock 2010).

- Religion. Religion is often a very important institution for both interpreting the world and for connecting people in communities.

While it is common to consider belonging and relationships as purely social, it is important to recognize that planners, engineers, and architects have long considered the impact of design and space for facilitating connections between people. Some go so far as to say that all built environments are socio-technical systems or processes (Graham 2000) meaning that the built and the social are intimately connected. Those that write from this perspective note that infrastructure is a landscape for human interaction and/or a mediator of the relationship between people and the natural environment. In Graham's (2000) summary of Williams (1973), he suggests that "infrastructure networks, and the complex sociotechnical apparatus that surrounds them, are strongly involved in structuring and delineating the experiences of urban culture and what Raymond Williams termed the 'structures of feeling' of modern urban life” (p. 115). As such it should come as no surprise that research has shown that the form of these elements can impact the ability of people to form and maintain connections with each other.

Infrastructure systems themselves and the beneficial services that they provide can create inequity and/or work towards justice. As such, it is important to note that these systems can provide access to many resources, but can also be the root of political and social unrest that breaks communities apart due to real or perceived injustice. One only needs to look at the recent events in Flint, Michigan to see a poignant example of this playing out on the national stage.

\section{e. Measurement of Belonging and Relationships}

There are significant difficulties in measuring relationships and belonging systematically across the U.S., particularly for a comparative effort. Measuring belonging and relationships requires a great deal of interpretation and decision making, giving rise to a great deal of variability in how to specifically measure these concepts (Aldrich and Meyer 2014). This section begins to address these complexities.

\section{i. Unit of Analysis and Aggregation}

Before discussing specific measures, we return first to the issue of unit of analysis. What we mean by this is that there are many types of entities that can have relationships or belong somewhere. It is important to consider at what unit of analysis one is measuring these concepts. When thinking about disaster resilience in a community, these can be measured at the individual, group, organizational, or even governmental levels. The degree to which an analysis measures relationships within and between these different units of analysis will necessarily affect the perspective one sees. It is important to consider the issue of unit of analysis carefully before developing this type of analysis. 


\section{ii. Data Sources}

There are two general types of data available. First, there are related or proxy measures from existing data sets that may capture the essence of community belonging or relationships. Second, there are specific instruments that have been designed to capture these ideas more directly but have not been applied to the community of interest yet.

\section{Available Data}

One option for the measurement of belonging and relationships is to repurpose data from existing local and national sources. This is currently the most common approach. To do this, the major concepts discussed above are listed and extant measures are seen as proxies or as measures of the ideas. A partial listing of the national data sources that could be mined for related measures of these concepts would include:

- U.S. Census

- American Communities Survey

- General Social Survey

- National Health Interview Survey

While these options are appealing for a number of reasons, including comparability and the large scale nature of the efforts, it is important to note that using such data will require significant effort to identify the proper measures and/or proxies. In some instances, however, this may be the only data available to measure these elements.

\section{Available Instruments}

An alternative approach is to develop data collection tools that are specific to the jurisdiction in question. If a jurisdiction chooses to do so, it is recommended that they look to other efforts that have developed instruments and questions specific to this particular concern. Two notable examples of such efforts include:

- Social Capital Community Benchmark Survey². The Kennedy School of Government at Harvard University has assembled what is arguably the most developed set of measures of belonging and relationship. The instrument, developed by several research groups and deployed in a large collaborative effort, provides a long and short form instrument with measures of social capital. The instrument includes a wide range of measures of both belonging and attachment as described in the pages above. Among others, the instrument includes measures of connection to neighbors, volunteer behavior, trust, political participation, civic leadership, church membership, organizational memberships, ability to help the community, and informal social relationships.

- UK Office for National Statistics Measuring Social Capital (Siegler 2014). Based on the Organization for Economic Cooperation and Development, the UK has developed an approach to measuring relationships and belonging. Their approach includes measures of personal relationships (relationships), social network support (relationships), civic engagement (belonging), and trust/cooperative norms (belonging). Within this instrument a number of

\footnotetext{
${ }^{2}$ https://www.hks.harvard.edu/programs/saguaro/measurement/sk-2006-community-benchmark-survey
} 
important measures are included. The details of these measures are included in the discussion of specific measures below.

As was the case for available data, there are many more than two instruments available. If a jurisdiction were to want to further develop such measures, they should engage in a systematic review of instruments in order to identify which measures exist and which are most appropriate for their context.

\section{iii. Types of Measures}

Given the somewhat abstract nature of belonging and relationships, this section provides an overview of the types of measures that have been commonly used in past efforts.

\section{Relationships}

Measures of relationships include:

- Social Networks: patterns of connection to other people such as friends, spouse, neighbors, etc.

- Civic Participation: volunteering, membership in associations, membership in churches, nonprofit participation, attendance at community meetings

- Social Support: people to discuss problems with, perception of having someone to rely on, perception of quality of relationships

\section{Belonging}

Measures of belonging include:

- Community: conflict resolution system, inclusive and exclusive rules, celebration of community successes

- Cognitive/Affect: belief in rules of the community, perceptions of conflict, trust in local government, trust in policies, trust in groups, feeling of safety

- Volunteer Behavior: help at school, volunteer in an organization

- Political Participation: voting, attending community meetings, interest in politics

- Behavioral Manifestations: leave doors unlocked

- Attachment to Place: as discussed above, belonging can be measured as attachment to place, a measure of the "affective bond or link between people and specific places" (Hidalgo \& Hernandez 2001).

- Physical attachment encompasses things that are physically keeping you in the place such as your material possessions or people, like a house, family, etc. (Ainsworth \& Bell, 1969).

- Emotional attachment involves the investment you have in the place and the strong feelings you have about it (Fried 1963).

- Community attachment embodies the sense of community that you feel. You can be connected to the people, the businesses, the local government, and the physical environment in which you live (Hidalgo and Hernandez 2001). One set of measures includes length of residence (Kasarda and Janowitz 1974) under the assumption that this is crucial in development of social bonds that create attachment and that over time a population that is large will grow to assimilate with each other.

- Place identity is the way you might self-identify in relation to the place (Jorgensen and Stedman 2001). A common example is when someone suggests they are a "city girl" or 
"city guy.” Other people similarly link who they are with specific cities or communities. This identity can be linked to the physical space and location or, in the place that you can identify yourself with, a specific group within or near the place.

- Place dependence concerns how well a setting serves goal attainment given an existing range of alternatives (Jorgensen and Stedman 2001). It can also describe the individual's perception of being strongly attached to the place (Stokols and Shumaker 1981).

\section{f. Belonging and Relationship Community Program Examples}

It is important to note that government is not powerless to influence the community belonging and relationships. There are a number of possible interventions (Aldrich and Meyer 2014). Even so, like resilience, these elements are not something that can be imposed on a community or built overnight. Funders of these activities, on which disaster resilience work can be founded, need to take a longer-term view on the measurement of these dimensions. According to the National Academies (2012) report, social capital and therefore community resilience could be enhanced via:

- Dense community social networks that build communication and social interactions in a community or among people and organizations that have a common interest.

- Widespread voluntary organizations that afford community members opportunities for participation and collaboration.

- Development of community members' skills in negotiation, compromise, and leadership as a result of participation in voluntary organizations and social networks; widespread access to and use of social media.

- Development of a network of private and public partnerships in the community.

The development of social capital, in turn, fosters higher social trust in the community, an important resource for effective risk management and decision making. 
This Page Intentionally Left Blank 


\section{Education and Personal Development Dimension}

In this chapter, we consider the relationship between the community dimension of education and personal development and community resilience. Formal education can be divided into a sequence of stages from nursery school and kindergarten, to elementary, middle and high school, and lastly vocational schools, colleges, and graduate schools. Also included in this community dimension are: adult education, special education, and informal education or personal development, which are defined in Section 10.4.5 of the NIST Guide (NIST 2015) as follows:

Adult education ranges from basic literacy to personal fulfillment (e.g., culinary or language classes) to attainment of an advanced degree (Peterson 2015). Special education provides "specifically-designed instruction to meet the unique needs of a child (or adult) with a disability" (U.S. Department of Education 2004). Finally, informal education can include any other means of knowledge, skills, or value transfer, including visiting museums, reading books, attending book clubs, or participating in recreational classes or demonstrations.

There is little disagreement on the significance of education as an important community dimension. After a disaster, children may be displaced and the displacement from their usual, familiar neighborhood surroundings can potentially cause psychological distress and affect their academic performance. The trauma caused by a disaster can also potentially have long-term effects on children into their adult lives. Equally important, following a disaster, if schools cannot reopen or alternative education arrangements cannot be made for a prolonged period, families with children will leave the area, possibly followed by the exodus of businesses. Loss of population and businesses will significantly affect a community's capability to rebound after a disaster. Equally important, for many communities in the country, schools (in particular from pre-K to grade 12) have long acted as community hubs, which are not only open to students during class times but are also open to all community members during non-class times (Cohen and Shuchter, 2013).

Despite these potentially significant impacts on our children and our communities, how schools can reorganize themselves following a disruptive event for the purpose of delivering education and personal development is not well studied. Additionally, even though many studies recognize the important roles that schools can play in post-disaster response and recovery effort, there is also little research to understand how schools can optimize their roles within the context of communities that are supported by a complex web of interdependent physical infrastructure and social systems. Consequently communities have few resources and tools to address the pertinent issues. This chapter will focus on the education component of the education and personal development dimension, in particular K-12 education, as it is provided by many communities throughout the nation. The first goal of this chapter is to provide a preliminary but comprehensive discussion on the various issues that need to be considered when it comes to a resilience discussion about education. More importantly, we hope to provide some directions on the assessment that communities may be able to follow to improve their resilience for this particularly important community dimension. This constitutes our second goal.

\section{a. The Education System in the United States}

The education system in the United States is highly decentralized, meaning that individual states have broad control of the curriculum, standards and requirements that students must meet, and are also responsible for funding the school systems. Public schools are mostly funded by property taxes and thus, the quality of the public schools may vary significantly depending on where they are located. In most states, there are school 
districts, managed by school boards. However, the size of the school districts and their geographic and administrative relations to their corresponding cities and counties can vary substantially. Some school districts can be small, covering a small town, while others can be enormous covering a large city or even several cities and counties (regional school districts). In some states, school districts are operated by county or city governments, and they often share the same geographic boundaries. In other states, there are independent school districts with their own boundaries that can extend across multiple jurisdictions. The relations of the school districts to relevant city and county governments become an important issue in the resilience planning and implementation as the independent school districts may have broader concerns than the local government.

In general, the education system in the U.S. comprises early childhood education, elementary and secondary education, vocational and technical education, postsecondary education and adult and continuing education (U.S. Department of Education 2005).

- Early Childhood Education. Early childhood education includes nursery, preschool, daycare centers, prekindergarten and kindergarten. There is also a federal Head Start program that funds child development programs for low-income families.

- Elementary and Secondary Education. Elementary and secondary education totals 12 academic years or grades. Since the education system in the U.S. is highly decentralized-meaning that states have the primary responsibility in creating and administering schools, the number of years and how the students spend time in their schools varies by states. With some exceptions, such as homeschooling, all states mandate students to attend elementary and secondary schools, but the ages of compulsory attendance vary by state. Individual states set broad curriculum guidelines for the knowledge and skills that the students should obtain. Within a state, the school districts are often responsible for selecting actual textbooks, adhering to the broad guidelines. In some states (e.g., Texas), the state government selects and purchases textbooks for the public schools.

Nearly all states set academic standards that describe what the students shall know and be able to do. There are also achievement or performance standards that describe what level of performance is considered basic, proficient and advanced. Most or all states also administer achievement tests on a regular basis to assess student performance at various grade levels. The 2001 federal "No Child Left Behind" act requires states to test all students in reading and mathematics in grades 3-8 and at least once in high school. These results are tied to the funding states receive for educational improvement.

There are a variety of schools for parents to choose for their children, including public schools, private schools, special education, and talented and gifted programs. Within public schools, there are also various options, for example; magnet schools, charter schools, virtual schools, dual enrollment programs, etc.

- Vocational and Technical Education. Vocational and technical schools have traditionally prepared students for entry-level jobs that do not require an undergraduate degree. This traditional, relatively narrow focus has evolved over time though, and today the curriculum at those schools is broader, including developing students' academic skills. Many public, private and charter schools offer vocational educational programs jointly supervised by teachers and employers. At the postsecondary and adult education levels, most schools offer such programs. 
- Postsecondary Education. Postsecondary education includes programs for bachelors', masters', doctoral, and postdoctoral training. There are about 9,000 postsecondary institutions in the U.S., including over 4,000 degree-granting institutions, such as colleges, universities and community colleges, and over 5,000 non-degree-granting institutions that provide specific vocational, technical and career training.

- Adult and Continuing Education. Adult education is provided to meet the needs of mature adults who have education, family, work and life experience but desire additional education for personal or work-related reasons. Continuing professional education is usually for specific categories of adults who are already licensed in certain fields but need refresher courses to update or maintain their licenses.

\section{b. State of our Knowledge}

Within the education and personal development dimension, we are first interested in understanding the impact of disasters on students' academic performance and psychological health. Additionally, we also want to document the existing research on the roles of schools in community response and recovery effort. Though not directly related to the education and personal development dimension, it is an important notion that schools can play a significant role in improving community resilience.

On Academic Performance. Disasters, whether natural, manmade, or pandemic, can have a range of impacts, academically and psychologically, on students (especially those under 18 years of age), their parents and teachers. Surprisingly, studies on the impact on students' academic performance are much fewer than those on psychological and emotional health of the students, their parents, teachers and staff. The conclusion from this limited number of studies is that the impact on academic performance appears to be mixed, or at least a lasting negative impact is not universally found in the existing literature. These studies have mostly examined scores from standardized tests and have employed different methodologies, including regression models (e.g., Holmes 2002) and statistical tests by comparing between pre- and postscores or between exposed and non-exposed students (e.g., Smilde-van den Doel, Smit, and Wolleswinkelvan den Bosch 2006). A study in North Carolina examined the impact of four extreme weather events (Hurricane Floyd of 1999-2000, snowstorm of 1999-2000, Hurricane Bonnie of 1997-1998 and Hurricane Fran of 1996-1997) on both school-level performance and student-level performance (Holmes 2002). For the former, the metric used was the percentage of students who met the academic standard implemented by the state (level III proficiency); for the latter, the metric used was students' end of grade test scores on math and reading. The results at the two levels appear to be consistent with each other and in sum, there are four main findings: (1) negligible effects were found on school-level performance and the only small effect was found for Hurricane Floyd, which was only significant at the $10 \%$ level; (2) the amount of federal funding allocated to disaster relief had no impact; (3) if there were any impacts, the extreme weather events impacted schools of lower performance more than those of higher performance; and (4) the number of lost days was not found to have an impact. Based on the results, the authors suggest household-level factors, not accounted for in the study, are likely playing a more important role than the weather effects. A study in the Netherlands after a fireworks disaster in 2000 found that children exposed to the disaster actually performed as well as or in some cases better than non-exposed students (Smilde-van den Doel, Smit, and Wolleswinkel-van den Bosch 2006).

Several studies have been conducted to examine how school children in New Orleans fared after Hurricane Katrina, to a large extent motivated by the fact that prior to Katrina, the school districts in New Orleans performed next to the bottom in the state (Eisele-Dyrli 2013). In conjunction with the reconstruction and 
relocation of schools, substantial changes were implemented in the funding and administration of the New Orleans school system (Saltman 2007). Overall, academic performance improved after Katrina, including an increase from 28\% in 2008 to 59\% in 2013 on the percentage of students who scored at or above grade level on the Louisiana Educational Assessment Program (LEAP) standardized test (Eisele-Dyrli 2013). Though representing an impressive improvement of 31 percentage points, it is still below the 2013 state average of 69\% (Eisele-Dyrli 2013). The new school district (Recovery School District, or RSD) ranked "57th out of 70 Louisiana districts in student achievement, up from 65th out of 66 in 2002" (Eisele-Dyrli 2013). Since more than a quarter of the students did not re-enroll in New Orleans public schools after Katrina and these students are most at risk for poor academic performance (Pane et al. 2008), the true percentage increase may be smaller than stated.

A comprehensive study by the Rand Corporation examined emotional, behavioral and academic performance of students displaced after Katrina (Pane et al. 2008). Over 196,000 students changed schools after Katrina and many were out of school for over a month. Four groups of students were examined, including those who were out of their original schools temporarily and returned to the same schools without enrolling in other schools (Group A), those who returned to their original schools after enrolling briefly in other schools (Group B), those who did not return to their original schools during the 2005-2006 school year (Group C), and those who did not enroll in any Louisiana public schools for the remainder of the school year (Group D). The study examined the effect of Katrina on both student-level and school-level performance. A series of multi-level models were used to identify the effect of Katrina, while controlling for prior year performance, race/ethnicity, and gender effects. When student-level performance is examined, the higher-level school- and district-level effects are controlled. Overall the models show that displaced students tended to score worse than other students and the effect tends to be larger at lower grade levels. In this case, the effect was particularly large for Group $C$ students who did not return to their original schools for the remainder of the school year. In addition, the study found that the school performance is a factor, i.e., relocating to a higher-performing school mitigates the negative effect of displacement. School conditions and policies as reported by the school principals are, however, not related to students' achievement. The analyses, as the authors cautioned, did not include those students who did not reenroll in any of the Louisiana public schools and this constitutes more than a quarter of displaced students; these are the students who tend to be at most risk.

On Psychological Health. On the other hand, the many studies on psychological and emotional health of students and their teachers reported a negative impact from the disaster. The symptoms reported are many including, for example, fear, grief, anxiety, anger, guilt (for failing to help others), eating and sleeping disorders, depression etc. These various symptoms may be categorized as Post-Traumatic Stress Disorder (PTSD). In a phone survey conducted five days after the September $11^{\text {th }}$ attack, parents were asked to rate their children's emotional reactions. $47 \%$ of the parents reported the presence of anxiety symptoms (Schuster et al 2001). These psychological and emotional impacts can be long-lasting. A study conducted 26 months after Hurricane Andrew found that $70 \%$ of the children from the primary impact zone still suffered from serious PTSD symptoms (Shaw, Applegate and Schorr 1996). In addition to the students, the teachers have also reported PTSD symptoms such as eating and sleeping disorders and stress (McKen 2001).

On the Role of Schools. The role of schools in community recovery and rebuilding effort is undisputable. Many studies show that aside from providing education to students, in a post-disaster context, schools can play a number of important roles to the community, including providing material goods (Loebach and Stewart 2015), social support (Joshi and Aoki 2014; Loebach and Stewart 2015), sheltering, maintaining 
ties with outside groups that provide critical resources (Loebach and Stewart 2015), and acting as an information dissemination center and a psychological clinic (Herrman 2012).

\section{c. Dependencies on Other Services}

It is unambiguous that the education and personal development dimension of a community depends on the services delivered by a number of critical infrastructure systems. Below we discuss several key dependencies (also see Figure 20 in Section 5.d).

- Buildings. Traditional schools have a clear dependency on the availability of structurally sound facilities in which classes can be held safely and effectively. It is worthy to note that evaluations of the various facilities are functionally related: in other words, a facility not suitable for one function (e.g., housing due to lack of water) may be perfectly suitable for another function (e.g., temporary gathering place or neighborhood distribution center).

- Transportation. Most education and personal development is still delivered face-to-face, which requires a working transportation system that connects schools to the rest of the community. Students, teachers, and staff need to be able to access schools from where they are located; and other service providers (e.g., utilities, food, and other supplies) also need to access schools from time to time. Given that schools involve about $20 \%$ of population, it is most natural that schools (at least in urbanized areas) are located in transportation-rich areas where multiple modes of transportation are offered.

- Power and Gas Services. It is also obvious that normal operation of schools (at least in the U.S.) requires electric power for lighting and equipment. Depending on the specific area of interest, either power or gas services (or even other sources of energy) may be needed to provide heating in the winter and cooling in the summer. How schools depend on such services may vary substantially by community. As an example, the implications of the dependencies in a centralized utility system are very different from those in a decentralized or distributed system. Utility services in most of the U.S. are delivered through centralized systems where services are produced in bulk and delivery is coordinated by a central agent (e.g., a municipal or regional electricity service provider). Reliance on a centralized system creates a high degree of dependency. If properly designed and maintained, distributed systems (e.g., microgrids) can be more resilient because they lessen or even eliminate the degree of dependency on centralized providers.

- Water and Wastewater. Like power or gas services, clean water and wastewater services are required for normal functioning of schools. Most schools will rely on municipal or regional providers for water and wastewater services, creating a high degree of dependency.

- Information and Communications. Today, information and communication services (e.g., connection to the internet at high speeds, wireless coverage) have become a norm, like other utility services such as power and water and wastewater.

- Banking and Financial Services. Schools rely on available banking and financial services for their normal operation needs, including billing, grants and contracts processing and payroll needs. 
- Health Services. Many schools have their own health clinics on site, addressing a range of routine and minor health issues; however, they rely on larger health services available in the community for dealing with more severe health issues.

- Policing. Similar to health services, many schools have their own guards for safety considerations. They are in place to handle minor safety infractions. They must rely on formal and larger police forces in the community for more severe matters.

\section{d. The Education and Personal Development System}

\section{i. System Overview}

The education and personal development system can be modeled as a system of systems (SOS), where each system comprises nodes and links and the systems themselves are interrelated with dependent or interdependent links.

The primary system comprises the various schools (e.g., K-12 schools and in some cases universities) and other facilities used for education and personal development purposes. Connections between the components represent relationships: for example, a community college may have some formal programs set up to allow high school graduates who meet a set of requirements be admitted to the college directly. The relationships may also be informal between staff and officials, and between components (entities). Some components may be physically located in a community, in which case service may be provided through face-to-face contact (via the transportation system); other components may not be physically located in a community, in which case service is provided through the internet (via the communications system). Both cases are shown in Figure 18.

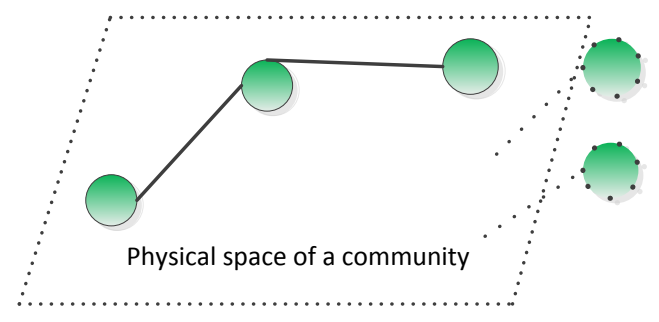

Figure 18. Simplified primary system for education and personal development (comprises components physically within the community and those providing service to the community via virtual links).

Supporting the primary system is a set of systems providing services for infrastructure resource support (e.g., transportation, electricity, water, and communications) and government and social support (e.g., funding from governments and family support). Not only are these support systems linked with the primary system on education and personal development, but they are also connected with each other (e.g., electricity is needed to power traffic signals at intersections in the transportation system). A simplified example is shown in Figure 19. 


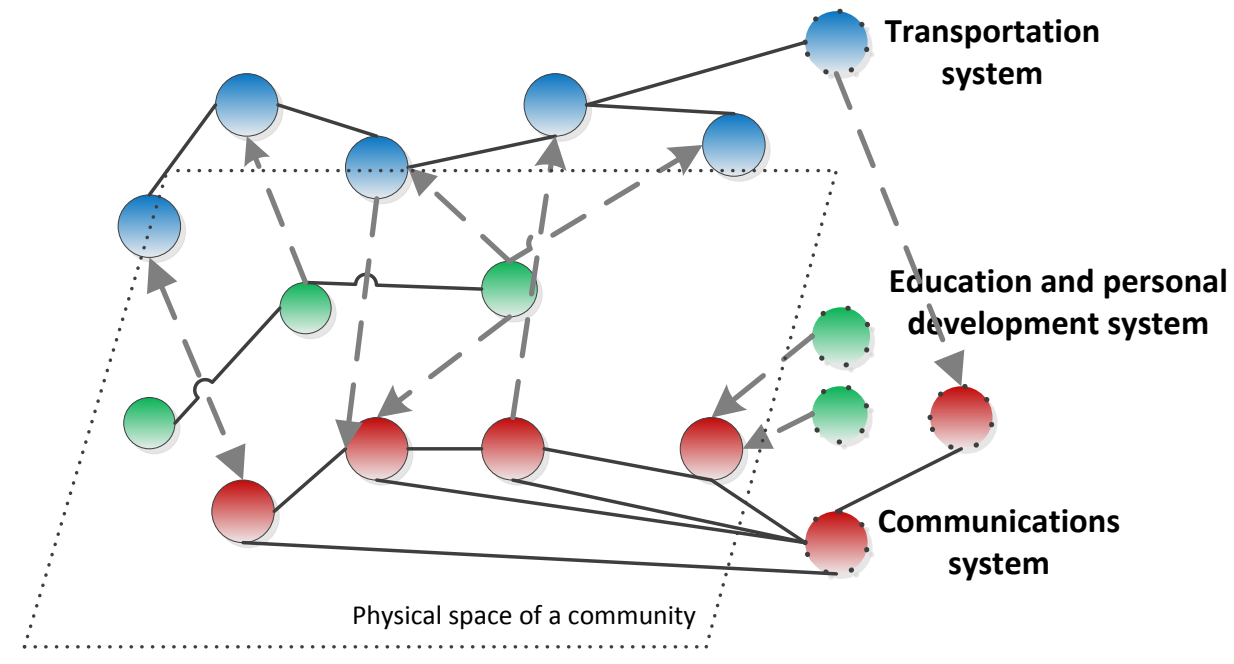

Figure 19. Simplified system of three systems for education and personal development.

Figure 20 provides a more comprehensive illustration of the various systems and resources that may be needed to support education and personal development. In identifying the system of interest, one must also consider dependencies and interdependencies between systems and the resources available to the systems. Clearly, the operation of the primary system (e.g., schools) depends on services provided by many supporting systems (e.g., providing electricity, access, and water), and the various supporting systems are dependent upon each other's services. The degree of dependency can vary depending on how the school system and its support systems are configured. In a typical centralized system where services such as electricity, water and solid and liquid waste processing, and transportation are provided through centralized facilities at a city or regional level, continued operation of educational facilities depends on the normal operation of all these physical systems including power, water, waste, telecommunications, and transportation. At the city or regional level, these support systems are interdependent with each other. In other words, the operation of schools and educational facilities at the community level depends on the operation of the interdependent resources at the city or regional level. In a more distributed system, the interdependencies may happen at the local (community level), if, for example, power is supplied by a combination of solar panels and battery storage and water is supplied by a local well. In terms of order, they can be direct, second order, or higher order, depending on the channels through which a failure in one system causes failures in other infrastructure systems (Rinaldi et al. 2004; Chang et al. 2005).

Some dependencies can be circumvented by substituting services from another system. Systems that have strong substitution potentials may need to be included together. As an example, physical travel to schools (provided via the transportation system) may be potentially replaced by virtual access (provided via the communications network). In some cases, a qualitative assessment of dependencies and interdependencies may be sufficient and may be achieved by assembling experts from different system operators. One example is the San Francisco lifelines study (Lifelines Council 2014) where different infrastructure operators were gathered to assess the impacts of an earthquake of magnitude 7.8 (a repeat of the 1906 earthquake) on the Peninsula Segment of the San Andreas Fault. 


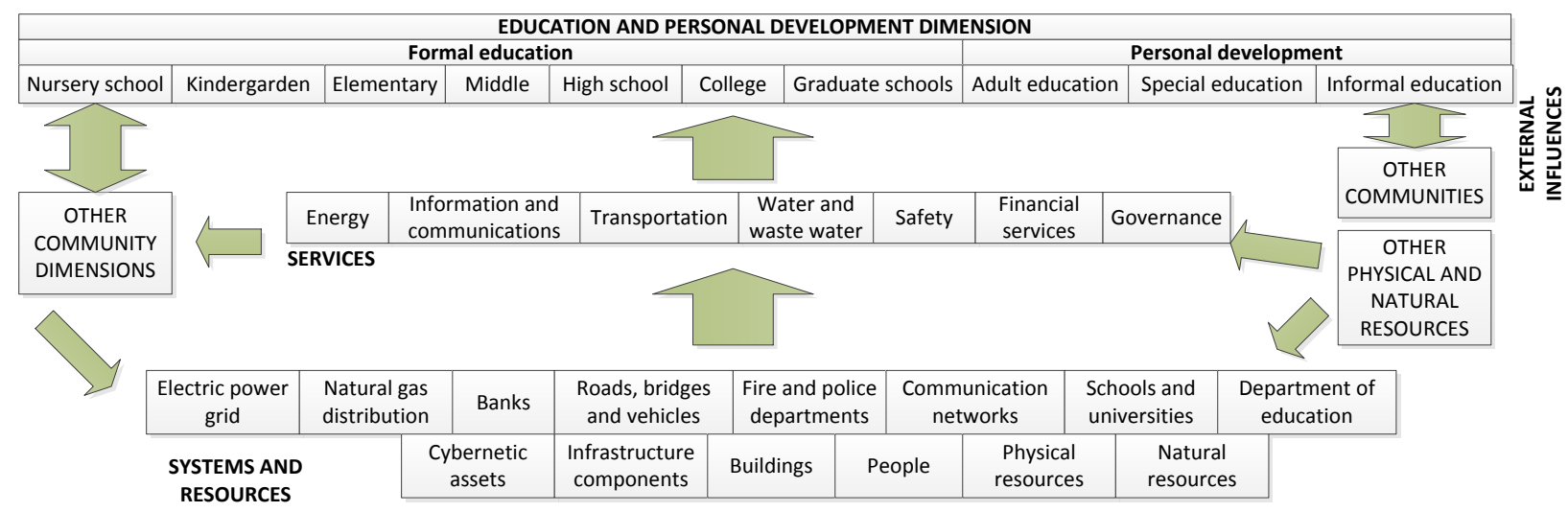

Figure 20. Education and personal development dimension with supporting services, systems and resources.

\section{ii. $\quad$ Services Provided and Desired Attributes}

Different facilities within the primary system of education and personal development perform different services. Common to all of them is that all have the mission of promoting student achievement and enriching personal experiences. Formal education facilities (e.g., K-12 schools and colleges) also have the mission of preparing students for global competitiveness. A well-functioning education and personal development system should have the following attributes:

- Comprehensiveness. A comprehensive range of formal and informal education and personal development services are available, appropriate to the needs of the target population in the community. Comprehensiveness refers to both the variety and the depth of the services that are available.

- Accessibility. There are multiple ways to access the services provided with no undue barriers of cost, language, culture, or geography. Services may be accessed from multiple points (spatially), including not only facilities that directly provide education and personal development services but also other private and public spaces such as home, workplace, and public spaces (e.g., indoor spaces such as libraries and outdoor spaces such as parks), and at different times of a day. Continuous accessibility in space and time may be viewed as the highest accessibility possible, but it may not be necessary for most communities.

- Quality. Services provided are of high quality, meeting the needs (both long- and short-term) of the target population.

- Coordination. Service providers (whether within or outside the community) are actively coordinated among themselves and with other related entities (e.g., transportation agencies, electricity companies, families and government agencies), not only meeting the needs of the target population but also facilitating resource sharing.

- Accountability and Efficiency. The provision of the services is well managed to meet the needs of the target population while incurring minimum resources. It is important to recognize that the expectations of the education providers at the school and district level may not be same as 
those of the target population. Thus, it is important that any differences that may exist be discussed and resolved.

\section{e. Resilience Assessment}

In this section, we discuss the key steps and activities involved in planning for community resilience for the education and personal development dimension. While the text frequently refers back to this particular dimension, it is believed that the key steps and main activities recommended here are broadly applicable to other dimensions that are important for a vital and resilient community. The discussion here is consistent with the six-step planning process outlined in the NIST Guide (2015). Within this context, we advocate a holistic approach that involves families and businesses throughout the process, recognizes the importance of community assets, and identifies effective strategies that involve not only physical infrastructures but also social ones. In addition, while recognizing it is important to define community goals (and system metrics), it is equally important to understand how the system may respond at a time of disaster and how system responses may be related to those goals and metrics.

\section{i. $\quad$ System Description}

An initial task for a community to engage in is to describe the system of interest. The first consideration is the components in the primary system. These could include, for example: school buildings, teachers, students, parent and guardians, administrators, and support staff. If a community is also interested in assessing the role of schools in community recovery effort, non-school-related families may also be included. The second consideration relates to whether and how much of the supporting systems can be included in the system of systems model. Shall the transportation system be included? Shall the electricity system be included? Which other utility service providers shall be included? Shall day-care service providers be included? Many teachers and administrators with young children will not be able to return to work if day-care is not available. While the inclusion of more support systems makes the system of systems model more complete and comprehensive, it may also unnecessarily complicate the model. The NIST Guide (2015) recommends using one level of dependency in identifying the system of interest, as including multiple levels of dependency may become intractable. In addition, a number of other factors may also matter; for example, the types of hazards a community is most likely exposed to, their intensity levels and the affected areas, and how the disaster may propagate through various support systems.

\section{ii. $\quad$ Defining States}

After the system of interest is defined, at least two critical states of the systems need to be defined. The first critical state is the state of total collapse. For education and personal development, this state may be defined in one or more of the following ways:

- $\quad$ More than X\% of the schools are closed;

- More than Y\% of the students can no longer receive education;

- The number of days for school closing exceeds Z days;

- More than W\% of the parents have lost confidence in schools.

The second critical state is the state of full recovery. This state may be defined by one or more of the following:

- More than R\% of the schools are back in operation;

- More than S\% of the students have returned to schools; 
- More than T\% of the parents have a higher than U threshold level of confidence in schools.

Between the state of total collapse and the state of full recovery, there may be some intermediate states. A pre-disaster state is a state that existing studies often base their resilience studies upon. Capturing the predisaster state as the baseline is important, though two questions need to be asked: (1) is the pre-disaster state at the desired level? and (2) is returning to the pre-disaster level considered as resilient? Different communities may have different answers to these questions.

Another state that needs to be identified is the minimum operating state, i.e., at what level, the system is considered operating at the minimum level, which may be defined as serving the most essential functions of the system. This minimum operating state corresponds to the $30 \%$ functional level in the NIST Guide (2015).

\section{iii. Hazard Assessment and System Responses}

Given a hazard, its intensity and the possible affected areas, it is important to understand: (1) the scope of the initial and the subsequent cascading damages inflicted on the system; (2) how the system of interest may move from one state to another; and (3) what recovery strategies may be employed to recover or maintain the system. Different approaches may be employed to assess the scope of the damages, from qualitative to quantitative and from simple to sophisticated. In such an assessment, the following questions are answered (given a hazard scenario):

- Extent of initial and subsequent damages:

- What are the initial damages that are likely to occur?

- Where do these initial damages likely occur (in what systems and on what components)?

- What is the likely extent of the damages in different systems?

- What are the cascading failures that are likely to occur? In what system and on what components?

In the immediate aftermath of a disaster, the existing literature provides some clues on what obstacles schools often experience. They include, in particular, transportation issues (Kim 2008), building damages (Serrant 2013), teaching at alternative locations (Hintz 2013), lack of school and emergency supplies (Kano and Bourque 2007; Sturgill 2008), experiencing psychological distress for both staff and students (Sturgill 2008), and training and inter-agency coordination (Kano and Bourque 2007). Existing tools such as HAZUS (https://www.fema.gov/hazus) can be used to identify the initial damage and some of the subsequent damage inflicted on various facilities in a community.

- System Responses:

- Under what conditions does the system transition from normal operations to collapse and then to recovery and back to normal or near-normal states? Returning directly to a normal education function may not be the first priority during the first few days after a severe disruption. The short-term function of a school building may, for example, be to serve as an emergency shelter. 
- How may the demand and needs in the community change? In the context of education and personal development, these may refer to students' and their parents' demands after a disaster, which may be significantly different from the pre-disaster case.

- How long do the changes on the system take and where they might be?

- Can the system-level responses be related to metrics that have been selected for use by a community?

- Response and Recovery Strategies:

- What are the possible response and recovery strategies that will bring the system back to operation? A broad set of strategies should be considered. For example, if the transportation access to schools is disrupted, face-to-face delivery of education may be substituted with the use of communications services while the roads are being repaired. Or grass-roots efforts may be encouraged so that neighbors of certain skills can be temporary teachers in the short term, in which case, consideration of parents and households in the community may be needed in defining the system of interest.

- What are the resources required to execute these strategies? Or how shall these strategies be implemented?

\section{iv. A Holistic Resilience Planning Process}

Answering the above questions and truly developing a community resilience plan that will work in a realworld disaster scenario requires a holistic planning process. At a minimum, this means:

- Families and businesses comprise the most important fabric of a community and thus need to be included in the process;

- While it is important to map out vulnerabilities that exist, it is equally (if not more) important to identify community assets, which go beyond the physical assets;

- Planning for response and recovery efforts should be broad and innovative, utilizing the resources that communities have and leveraging the interdependencies between the systems. As an example, vehicles that are originally designed for transportation purposes can also be used for facilitating communication services, not only strengthening the interdependencies between two systems but also facilitating recovery effort, following a disaster.

The NIST Guide (2015) identifies a 6-step process to planning for community resilience. These steps are consistent with what has been discussed in this chapter for the educational and personal development dimension. In Table 1 below, we list these 6 steps and provide annotations that are specific to this particular dimension. 
Table 1. The Six-Step Process for Community Resilience Planning for Education and Personal Development

\begin{tabular}{|c|c|c|}
\hline Steps & NIST Guide (NIST 2015b) & Annotations for Education and Personal Development \\
\hline Step 1 & Form a collaborative planning team & $\begin{array}{l}\text { It is important to include families/households and } \\
\text { businesses in the community. This should be not simply a } \\
\text { few residents and businesses in the community. Instead, } \\
\text { families and businesses should be involved from various } \\
\text { neighborhoods in a community. It is possible that one or } \\
\text { two pilot neighborhoods be selected first to implement } \\
\text { this strategy. }\end{array}$ \\
\hline Step 2 & $\begin{array}{l}\text { Understand the situation: } \\
\text { - social dimension } \\
\text { - built environment } \\
\text { - link social functions \& built } \\
\text { environment }\end{array}$ & $\begin{array}{l}\text { This step is consistent with identifying the system of } \\
\text { interest in the community. }\end{array}$ \\
\hline Step 3 & Determine goals and objectives & $\begin{array}{l}\text { This step is consistent with identifying the critical and } \\
\text { intermediate states of the system of interest. }\end{array}$ \\
\hline Step 4 & Plan development & $\begin{array}{l}\text { In addition to identifying gaps, it is equally important to } \\
\text { identify community assets, which include not only } \\
\text { physical resources, but also human and social resources. }\end{array}$ \\
\hline Step 5 & Plan preparation, review and approval & $\begin{array}{l}\text { Allow room to deviate from plans and create } \\
\text { opportunities for improvisations. }\end{array}$ \\
\hline Step 6 & Plan implementation and maintenance & $\begin{array}{l}\text { As plan indicates: execute, evaluate, update and modify } \\
\text { as needed. }\end{array}$ \\
\hline
\end{tabular}

\section{f. Discussion}

In the aftermath of a disaster, the ability of elementary and secondary schools to return to their normal functions is very important because of the important role they play in children's lives. In addition, schools have important functions throughout, from disaster preparedness, to response and recovery (Mutch 2014). As sites serving the education and personal development dimension in community resilience, schools are an integral part of the disaster planning and preparedness process. During the response stage, schools can serve as relief centers and community response and communication hubs, and during the recovery stage, schools are important hubs for pastoral care, community re-bonding, and students and families in the community (Mutch 2014).

Since most of the existing literature on this subject relates to K-12 students, the review provided here concentrates on the K-12 schools. However, it is important to remember that the education and personal development dimension (as discussed in Section 5.a) generally encompasses facilities and services much broader than just those offered by K-12 schools. For example, they include vocational and technical education facilities where training to acquire certain skills is provided, community colleges and universities, and continuing education facilities where people enrich themselves for personal development. Likewise, these facilities can also serve important functions during preparedness, response and recovery stages to enhance community resilience. 


\section{Conclusions and Recommendations}

The Community Resilience Assessment Methodology (CRAM) framework presented by Kwasinski et al. (2016), and summarized in Section 1.b of this report, was developed with a broad range of community dimensions and services in mind. The CRAM framework explicitly considers the integration of social systems and infrastructure systems, while differentiating these systems from the services that they provide. The framework further identifies several classes of resources (or capitals) that are used by the systems to produce the services that are needed to support the community dimensions. Kwasinski et al. (2016) tested the framework by applying it to the community health dimension.

Four additional community dimensions are considered in this report: sustenance, housing and shelter, belonging and relationships, and education and personal development. Our key findings and recommendations are summarized below.

\section{a. Sustenance Dimension}

The community sustenance dimension is highly decentralized, tightly coupled with the community health, and highly regulated. To assess the water supply component of the sustenance dimension, communities and their utility operators should assess data collection and management systems, asset conditions, backup power availability and reliability, potential health consequences, potential financial consequences, response readiness, and dependencies. Water systems differ from other community systems in the availability of substantial excess capacity in water distribution systems for fire-fighting and the ability to weather slight decreases in water quality through boil water orders. Within the specific aspect of drinking water supply, there are several existing process-focused tools that should be consulted when assessing utility readiness and resilience, including: VSAT, WHEAT, URI, and RAMCAP J100-10.

Over the past decade, the water industry has moved towards an all-hazards approach to vulnerability and security assessment. However, many water systems face increasing financial pressures from aging assets, even as more stringent demands are made on their operations. Underinvestment in plant and distribution system assets may leave plants more vulnerable to natural hazards, making achievement of community resilience with respect to water service more difficult. Moreover, underinvestment in water assets compromises the community's ability to achieve other dimensions, including health, belonging, and security/safety.

The Flint, Michigan lead crisis is a useful case study for thinking about how to measure and assess the community sustenance dimension. It demonstrates the criticality of the prior condition of the physical infrastructure systems, the challenges posed by declining population and escalating infrastructure costs, and the role of community organizing. The Flint case study also demonstrates the importance of health care services, education, information and communications, and governance services in restoring the sustenance function after it has been disrupted.

\section{b. Housing and Sheltering Dimension}

The housing and sheltering $(\mathrm{H} \& \mathrm{~S})$ dimension is much broader than just a need for protection from the elements; it must also consider the emotional, legal, and financial implications of housing and shelters. Several types H\&S systems have been identified and defined, including: emergency shelter, temporary shelter, temporary housing, short-term housing, manufactured housing and recreational vehicles (including 
camping trailers), circumstantial housing, rental property housing, permanent housing, secondary housing, seasonal housing, and other unclassified types of housing units and shelters.

Within the context of community resilience, H\&S services can be distinguished, in part, based on the recovery phases that create an $\mathrm{H} \& S$ service utilization sequence. Before a disaster strikes people will reside in the various types of housing units. During the disaster or immediately after it, people may be forced to accept emergency shelter before finding temporary shelter where basic sustenance needs can be provided. Eventually, these people may move to temporary housing, where household routines can be reestablished, before moving on to a permanent housing unit.

Attributes of the community $\mathrm{H} \& \mathrm{~S}$ dimension and its related services and systems include: a sequential pattern of services; a diversity of services; continuous use; emotional, legal and economic attachments; a somewhat weaker dependency on most infrastructure or social services compared to other community dimensions; the strong influence of free market forces (i.e., supply and demand); the existence of quality as a differentiating factor; and the importance of safety, employment opportunities, educational opportunities, and transportation availability as key drivers of affordability and availability.

A resilience assessment of the community H\&S dimension could include modeling the average time that each household spends using a given $H \& S$ service or the percentage of households in a community that has been able to move from one type of service to the next type of service in a sequence (e.g., temporary to short-term). If resilience assessment is based on time it takes people to move back to their original permanent houses, then the result may yield a relatively low resilience. However, poor performance in one H\&S service need not necessarily imply poor overall resilience, if the community is able to plan for and adapt to an alternate $\mathrm{H} \& \mathrm{~S}$ recovery sequence.

Challenges in assessing resilience of the H\&S dimension include determining which factors or metrics need to be considered, whether to use a quantitative or qualitative approach, and how to measure the effects of dependencies and degree of dependence. The metrics selected must reflect the primary objective of protecting people from the elements, but they should also reflect the emotional, economic and legal aspects of housing and sheltering. One approach to assessing resilience is to consider quality of service (QoS) metrics that are associated with how well individual houses or shelters protect occupants from the elements. The existence of QoS levels also indicates that resilience assessment may need to consider the fact that during disruptive events H\&S services may not fail completely or may not fail at all; instead, they may experience some performance degradation or have their services temporarily interrupted. Resilience of the H\&S dimension can also be evaluated indirectly (e.g., through real estate tax revenues or H\&S transactions). With either direct or indirect measures, the focus should be on the people living in the homes and shelters rather than the dwellings themselves. As a result, QoS-based metrics may be influenced by quality of experience (QoE) evaluations and how these evaluations relate to the needs of various groups within the community or the community as a whole.

\section{c. Belonging and Relationships Dimension}

Recognizing the role of social networks, relationships, and sense of belonging is a critical aspect in assessing the resilience of a community. Any community resilience planning effort that does not take into account these human dimensions will be less successful than expected.

Relationships are the lasting connections between people, organizations, or even communities that ease the flow of resources from and to the same. The idea of characterizing the level of relationship in a community 
is central to the concept of social capital. Three types of relationships have been identified in the literature: bonding, bridging, and linking. The sense of belonging within a community depends on cognitive elements and attachment to place. Cognitive elements, such as trust, can facilitate or impede a community's sense of belonging. Attachment to place can inhibit an individual's desire to relocate after a hazard event or impact the general willingness of community members to invest time, effort, and resources towards building resilience or dealing with disasters.

There are significant challenges to measuring relationships and belonging systematically across the U.S., particularly for a comparative effort. These complexities include the unit of analysis and aggregation (i.e., individual, group, organizational, or even governmental levels), data sources (i.e., nationally available measures that serve as proxies for relationships and belonging vs. specific instruments that have been designed to capture these ideas but not applied nationally), and the types of measures. Several specific types of measure for relationship and belonging are recommended in Section 4.e.iii.

Government can influence the degree of community belonging and relationships. Community resilience can be enhanced via development of dense social networks, widespread participation in voluntary organizations, and development of public and private partnerships. The development of social capital, in turn, fosters higher social trust in the community, an important resource for effective risk management and decision making.

\section{d. Education and Personal Development Dimension}

The formal education system in the United States is highly decentralized. The size of the school districts and their geographic and administrative relations to their corresponding cities and counties can vary substantially. The relations of school districts to relevant city and county governments can become an important issue in resilience planning and implementation, especially in the case of independent school districts.

A resilience assessment of the education and personal development dimension should focus on understanding the resilience process, in addition to resilience metrics. We advocate a holistic approach that involves families and businesses throughout the process, recognizes the importance of community assets, and identifies effective strategies that involve not only physical infrastructures but also social ones. It is important to understand how the system may respond at a time of disaster and how system responses are related to the community's resilience goals and metrics.

To assess the resilience of the community education and personal development dimension, one must first describe the components of the educational system and to decide which supporting physical and social systems to include in the assessment (e.g., transportation, electric power, government, employees, students, and families). While the inclusion of more support systems makes the system of interest more complete and comprehensive, it may also unnecessarily complicate the system. Additional factors to consider include the types of hazards to which the community is exposed, their intensity levels and affected areas, and understanding how the disaster may propagate through various support systems.

Given a hazard, its intensity and the possible affected areas, it is important to assess the range of likely damage, the subsequent cascading damages that may result from system dependencies, how the system of interest may move from one state to another, and what strategies may be employed to recover or maintain the system. Different approaches may be employed to assess the scope of the damages, from quantitative to qualitative and from simple to sophisticated. 
Schools are an integral part of the disaster planning and preparedness process. During the response stage, schools can serve as relief centers and community response and communication hubs, and during the recovery stage, schools are important hubs for pastoral care, community re-bonding, and students and families in the community. Of course, the education and personal development dimension encompasses facilities and services much broader than just those offered by traditional K-12 schools. It also includes vocational and technical education facilities where training to acquire certain skills is provided, community colleges and universities, and continuing education facilities where people enrich themselves for personal development. These facilities can also serve important roles in enhancing community resilience.

\section{e. Summary}

Resilience must be evaluated not just in terms of the physical components of the built environment, but also in terms of community services and dimensions that they provide and support. The CRAM framework provides a construct for assessing community resilience at a richer level than the three D's: deaths, dollars, and downtime (i.e., safety, repair cost, and time to regain function). When evaluating resilience, a significant focus should be placed on people and how they perceive a given disaster will affect them. That is, a resilience assessment should also include metrics that evaluate peoples' responses by, for example, measuring percentage of the population that remains in a community after a disaster strikes instead of merely counting number of damaged and destroyed dwellings, or by evaluating students' cognitive and emotional progress after a disaster instead of counting number of damaged educational facilities.

Having now considered four additional community dimensions (sustenance, housing and shelter, belonging and relationships, and education and personal development), we have not identified any needs for alterations to the conceptual framework. Further, we find that the challenges and conclusions presented by Kwasinski et al. (2016), and summarized in Sections 1.c and 1.d of this report, are also applicable to the four new community dimensions considered in this report.

\section{f. Next Steps}

The next steps should focus on being able to translate the broad assessments presented in this report into a practical step-by-step procedure or flowchart that can be used by community planners and decision makers to guide them through their own assessment process and help them make decisions that will improve the resilience of their own community. The challenge is to develop cost-effective strategies that are equitable for all members of the community.

A set of pilot community resilience assessments should be conducted and documented for a broad range of real-world case studies. A key focus of the pilot studies should be the selection of metrics or indicators that are appropriate to the pilot communities and the development and evaluation of methods for displaying multiple disparate measures or meaningfully aggregating them into an overall score.

The next step is to build upon the conceptual framework and the practical lessons learned from the pilot communities by developing a flexible tool for making risk-informed investment decisions. The inputs to this decision support tool or process will be an assessment of the current resilience of the community and a set of resilience goals for one or more community dimensions. The output of the process should be a prioritized set of investments needed to improve community resilience.

More analysis is needed in order to understand how to connect resilience metrics and goals (taking into consideration the focus on people) with investments made towards improving specific systems (both 
physical infrastructure and social systems). This process has multiple implications, including technical, social, and legal. In many cases, policies and laws may need to be modified to cost-effectively and equitably improve resilience. The process should consider ways of monitoring its effectiveness and implementing corrective actions, if necessary. Finally, the community resilience assessment process should promote continual improvement in how community leaders communicate planning decisions and actions to the members of their community. 
This Page Intentionally Left Blank 


\section{References}

Aguirre, B.E., Wenger, D., and Vigo, G. (1998). “A test of emergent norm theory of collective behavior,” Sociological Forum, 13, 301-320.

Ainsworth, M.D.S., and Bell, S.M. (1970). "Attachment, exploration and separation: Illustrated by the behavior of one-year-olds in a strange situation,” Child Development, 41: 49-67.

Aldrich, D.P. and Meyer, M.A. (2014). “Social capital and community resilience,” American Behavioral Scientist, October, pp. 1-16.

Association of Bay Area Governments Resilience Program (2015). "Stronger Housing, Safer Communities: Strategies for Seismic and Flood Risks,” Online:

http://resilience.abag.ca.gov/projects/stronger_housing_safer_communities_2015/

AWWA (2011), "Planning for an Emergency Drinking Water Supply Planning for an Emergency Drinking Water Supply,” American Water Works Association.

Baron, S, Field, J. and Schuller, T. (2000). Social Capital: Critical Perspectives, Oxford University Press.

Barron, M., B. Goldblatt, C. Ho, R. Hudson, D. Kaplan, E. Keberle, C. Naumoff, C. Perlmutter, Z. Suttile, C. Thorsteinson, D. Tsien, L. Wild, and M. Wilson (2010). "Understanding New York's food supply: a report prepared for New York city mayor's office of long-term planning and sustainability.”

Bourdieu, P. (1985). “The Forms of Capital” in J.G. Richardson (Ed.), Handbook of theory and research for the sociology of education, pp. 241-258, New York: Greenwood.

Bruneau, M., S. E. Chang, R. T. Eguchi, G. C. Lee, T. D. O'Rourke, A. M. Reinhorn, M. Shinozuka, K. Tierney, W. A. Wallace and D. von Winterfeldt (2003). "A framework to quantitatively assess and enhance the seismic resilience of communities,” Earthquake Spectra, 19(4): 733-752.

Campbell, A. F. (2014), “New Orleans' Post-Katrina Identity Crisis,” The Atlantic, Oct. 2014, http://www.theatlantic.com/politics/archive/2014/10/new-orleans-post-katrina-identity-crisis/431388/.

Accessed December 15, 2016.

Chang, S., T. McDaniels, and D.A. Reed (2005). "Mitigation of extreme events: electric power outage and infrastructure failure interactions," in The Economic Impacts of Terrorist Attacks, H.W. Richardson, P. Gordon, and J.E.M. II, Editors, Edward Elgar Publishing: Cheltenham, UK. p. 70-90.

Choguill, C. (1999). “Community Infrastructure for Low-Income Cities: The potential for Progressive Improvement,” Habitat International, 23(2): 289-301.

Code of Federal Regulations (CFR) (2015). "24 CFR Part 3280 - Manufactured Home Construction and Safety Standards - 24 CFR 3280.2 - Definitions.” Online: https://www.law.cornell.edu/cfr/text/24/3280.2. Accessed December 15, 2016.

Cohen, AK and Schuchter, JW (2013). "Revitalizing communities together: the shared values, goals, and work of education, urban planning, and public health,” Journal of Urban Health, 90(2):187-96. doi: 10.1007/s11524-012-9733-3. 
Comerio, M. C. (2014). “Disaster Recovery and Community Renewal: Housing Approaches” available from https://www.huduser.gov/portal/periodicals/cityscpe/vol16num2/ch3.pdf. Accessed December 15, 2016.

Cutter, S.L., Burton, C., and Emrich, C. (2010). "Disaster resilience indicators for benchmarking baseline conditions,” Journal of Homeland security and Emergency Management, 7, 1-22.

Cutter, S. L., L. Barnes, M. Berry, C. Burton, E. Evans, E. Tate and J. Webb (2008). “A place-based model for understanding community resilience to natural disasters.” Global environmental change 18(4): 598-606.

Daniel, P. A. and K. M. Morley (2011). "Postdisaster Water Supply: The Local-State-Federal Nexus and Recommendations for Speeding the Response,” Am. Water Work. Assoc. J., vol. 103, no. 8, pp. $24-27$.

Edt, P. M. (2014). “Preparedness Tools and Resources for Drinking Water and Wastewater.”

Edwards, Marc (2016). “Flint Water Study.” Online: http://flintwaterstudy.org/. Accessed: July 8, 2016.

Eisele-Dyrli, K. (2013). “Decade of Recovery: New Orleans Schools Show Progress,” District

Administration, September. Online: http://www.districtadministration.com/article/decade-recovery-neworleans-schools-show-progress. Accessed May 11, 2016.

EPA (2011). “Planning for an Emergency Drinking Water Supply,” U.S. Environmental Protection Agency. Online: https://www.epa.gov/sites/production/files/2015-

03/documents/planning for an emergency drinking water supply.pdf.

EPA (2013). “Incident Action Checklist - Volcanic Activity Impacts on Water and Wastewater Utilities,” pp. 1-8.

EPA (2015). “Conduct a Drinking Water or Wastewater Utility Risk Assessment,” Office of Water, U.S. Environmental Protection Agency Office of Ground Water, and U.S. EPA Office of Drinking Water, 2015. Online: https://www.epa.gov/waterriskassessment/conduct-drinking-water-or-wastewater-utilityrisk-assessment. Accessed: July 7, 2016.

EPA (2015a). “Incident Action Checklist - Tornado Impacts on Water and Wastewater Utilities,” U.S. Environmental Protection Agency.

EPA (2015b). “Incident Action Checklist - Earthquake Impacts on Water and Wastewater Utilities,” U.S. Environmental Protection Agency.

EPA (2015c). “Incident Action Checklist - Flooding Impacts on Water and Wastewater Utilities,” U.S. Environmental Protection Agency.

EPA (2015d). “Incident Action Checklist - Hurricane Impacts on Water and Wastewater Utilities,” U.S. Environmental Protection Agency.

EPA (2015e). “Climate Impacts on Water Resources,” 2016. U.S. Environmental Protection Agency, Climate Change Division, Online: https://www3.epa.gov/climatechange/impacts/water.html. Accessed: July 8, 2016. 
EPA (2015f). “Incident Action Checklist - Drought Impacts on Water and Wastewater Utilities,” U.S. Environmental Protection Agency.

EPA (2015g). “Incident Action Checklist - Wildfire Impacts on Water and Wastewater,” U.S. Environmental Protection Agency.

EPA (2015h). "Incident Action Checklist - Extreme Cold and Winter Storms Impacts on Water and Wastewater Utilities,” U.S. Environmental Protection Agency.

EPA (2015i). "Incident Action Checklist - Extreme Heat Extreme Heat Impacts on Water and Wastewater Utilities,” U.S. Environmental Protection Agency.

EPA (2015j). “Incident Action Checklist - Tsunami Impacts on Water and Wastewater Utilities,” U.S. Environmental Protection Agency.

EPA (2016). “Water Health and Economic Analysis Tool (WHEAT) 3.0,” U.S. EPA Office of Water, U.S. EPA Office of Ground Water, and U.S. EPA Office of Drinking Water. Online:

https://www.epa.gov/waterriskassessment/find-out-about-health-and-economic-impacts-water-utilityemergencies. Accessed: July 7, 2016.

FEMA (2014). “FEMA Disaster Declarations Summary,” Online: http://www.fema.gov/medialibrary/assets/documents/28318. Accessed May 25, 2016.

Fischer, H.W (2008) Response to Disaster: Fact vs Fiction and Its Perpetuation, University Press of America, Lanham, MD.

Flowers, M. B. and M. Buckley (2011). “USDA Foods Program Disaster Manual,” April, 2011.

Forgette, R. G., M. R. Hilliard, M. V. Van Boening, T. E. Combs, G. L. Easson and D. P. Vogt (2011). "Socio-economic resilience and dynamic micro-economic analysis for a large-scale catastrophe," U.S. Department of Homeland Security Southeast Regional Research Initiative, Report 80038-01, Oak Ridge, Tennessee, Oak Ridge International Laboratory.

Fried, M. (1963). “Grieving for a lost home,” in L. J. Duhl (Ed.), The Urban Condition: People and Policy in the Metropolis, New York: Simon \& Schuster.

Graham, S. (2000). “Introduction: cities and infrastructure,” International Journal of Urban and Regional Research, 24(1): 114-119.

Gwyther, G. (2005). Paradise planned: community formation and the master planned estate, Urban Policy and Research. Online:

http://ezproxy.uws.edu.au/login?url=https://doi.org/10.1080/0811114042000335304

Hanifan, L.J. (1916). "The rural school community center,” Annals of the American Academy of Political and Social Science. 67, pp.130-138.

Herrick, C., J. Pratt, R. Raucher, N. Kalas-Adams, J. Cotruvo, K. Darr-Bornstein, T. Gablehouse, J. Mencer, R. Moser, D. Newkirk, M. Schnack, and K. Westby (2006). "Emergency Response and Recovery Planning for Water Systems: A Kit of Tools,” Denver, CO, 2006. 
Herrman, H. (2012). “Promoting Mental Health and Resilience after a Disaster,” Journal of Experimental \& Clinical Medicine, 4(2): 82-87.

Hidalgo, M.C., and Hernandez, B. (2001) "Place attachment: Conceptual and empirical questions,” Journal of Environmental Psychology, 21: 273-281.

Hintz, K. (2013). "It Takes a Village to Start the School Year: A Community Rallies after a Natural Disaster,” Delta Kappa Gamma Bulletin 79(3): 6-12.

Homes, G. (2002). "Effect of extreme weather events on student test performance,” Natural Hazards Review, 3(3) 82-91.

Howe, M. and C. Avery (2011). “Texas WARN Boot Camps,” Am. Water Work. Assoc. J., vol. 103, no. 9, pp. 24-27.

Howitt, R., Havnen, O., \& Veland, S. (2011). "Natural and unnatural disasters: Responding with respect for indigenous rights,” Geographical Research, 50: 47-59.

HUD (2016), "Docket FR-5877-P-01 Manufactured Home Procedural and Enforcement Regulations; Revision of Exemption for Recreational Vehicles - HUD-2016-0013-0001.” U.S. Department of Housing and Urban Development, Federal Register - Proposed Rules, vol. 81, no. 26, February 9, 2016, pp. 6806 6810.

IOM (Institute of Medicine) (2015), "Healthy, resilient, and sustainable communities after disasters: Strategies, opportunities, and planning for recovery.” Washington, DC: The National Academies Press.

Jacob, B., Mawson, A., Payton, M., and Guignard, J.C. (2008). “Disaster mythology and fact: Hurricane Katrina and social attachment,” Viewpoint, 123, 555-566.

Jiang, W. and H. Schulzrinne (2000). "Modeling of packet loss and delay and their effect on real-time multimedia service quality,” Proceedings 10th International Workshop on Network and Operating System Support for Digital Audio, June, pp. 1-7.

Johannessen, Å., A. Rosemarin, F. Thomalla, Å. Gerger Swartling, T. Axel Stenström, and G. Vulturius (2014). "Strategies for building resilience to hazards in water, sanitation and hygiene (WASH) systems: The role of public private partnerships,” Int. J. Disaster Risk Reduct., vol. 10, no. PA, pp. 102-115.

Jorgensen, B.S., and Stedman, R.C. (2001). “Sense of place as an attitude: Lakeshore owners' attitudes toward their properties,” Journal of Environmental Psychology, 21, 233-248.

Joshi, A. and Aoki, M. (2014). "The role of social capital and public policy in disaster recovery: A case study of Tamil Nadu State, India,” International Journal of Disaster Risk Reduction March: 100-108.

Kano, M. and L.B. Bourque (2007). "Experiences with and Preparedness for Emergencies and Disasters among Public Schools in California,” NASSP Bulletin 91(3):201-218.

Kasarda, J. and Janowitz, M. (1974). “Community attachment in mass society,” American Sociological Review, 39, 328-339. 
Kwasinski, A., J. Trainor, B. Wolshon, and F. Lavelle (2016). A Conceptual Framework for Assessing Resilience at the Community Scale, NIST GCR 16-001, National Institute of Standards and Technology, Gaithersburg, MD. Online: https://doi.org/10.6028/NIST.GCR.16-001.

Lavelle, F.M., L.A. Ritchie, A. Kwasinski, and B. Wolshon (2015). Critical Assessment of Existing Methodologies for Measuring or Representing Community Resilience of Social and Physical Systems, NIST GCR 15-1010, National Institute of Standards and Technology, Gaithersburg, MD. Online: https://doi.org/10.6028/NIST.GCR.15-1010.

Lifelines Council (2014). “Lifelines Interdependency Study I Report,” April 17, 2014.

Loebach, P. and J. Stewart (2015). "Vital Linkages: A Study of the Role of Linking Social Capital in a Philippine Disaster Recovery and Rebuilding Effort,” Social Justice Research 28(3):339-362.

Long, M. H. (2016). “The J100 Standard : A Catalyst for an All-Hazards Vulnerability Assessment,” NEWEA 2016 Annual Conference. January 25, 2016.

Low, S.M., and Altman, I. (1992). “Place attachment: A conceptual inquiry,” In I. Altman, \& S.M. Low (Eds.), Place attachment (pp. 1-12). New York and London: Plenum Press.

Maslow, A.H. (1943). “A Theory of Human Motivation,” Psychological Review, 50 (4) 370-96.

Mawson, A. (2008). "Understanding mass panic and other collective responses to threat and disaster," Psychiatry, 68, 95-113.

Mayunga, J. S. (2009). "Measuring the measure: A multi-dimensional scale model to measure community disaster resilience in the U.S. Gulf Coast region,” Ph.D. dissertation, Texas A\&M University.

McKen, D. (2001). "When there is no normal: coping with a school disaster,” Principal Leadership (High School Ed.) 1 no. 8.

McLaughlin, J. W. (2010). “Going ‘all in’ on all hazards,” J. Am. Water Works Assoc., vol. 102, no. 1, pp. 33-35.

Mehan, III, T. and Kline, I. (2012). "Pricing as a demand side management tool: Implications for water policy and governance.” Journal AWWA, 104(2):61-66.

Mesch, G. S., and Talmud, I. (2010). "Internet connectivity, community participation, and place attachment: A longitudinal study,” American Behavioral Scientist.

Miles, S. B. (2014). “Theorizing community resilience to earthquakes,” Tenth U.S. National Conference on Earthquake Engineering. Anchorage, Alaska.

Morley, K.M. (2006) "Utilities Helping Utilities: an Action Plan for Mutual Aid And Assistance Networks for Water and Wastewater Utilities,” Denver, CO.

Morley, K. M. (2010). “Advancing the culture of security and preparedness in the water sector,” Am. Water Work. Assoc. J., vol. 102, no. 6, pp. 34-37. 
Morley, K. M. (2012). “Evaluating Resilience in the Water Sector: Application of the Utility Resilience Index,”

Morley, K. M. (2013). "Water Sector Security and Preparedness,” Am. Water Work. Assoc. J., vol. 105, no. 3, pp. 38-40.

Mutch, C. (2014). "The role of schools in disaster preparedness, response and recovery: what can we learn from the literature?” Pastoral Care in Education 32(1), 5-22, Online:

https://doi.org/10.1080/02643944.2014.880123.

NIST (2015). Community Resilience Planning Guide for Buildings and Infrastructure Systems,” NIST Special Publication 1190, National Institute of Standards and Technology, Gaithersburg, MD.

National Academies (2012). Disaster Resilience: A National Imperative, National Academies Press, Washington, D.C.

NRC (2011). Building Community Disaster Resilience Through Private-Public Collaboration, National Research Council, National Academies Press, Washington, D.C.

Norris, F. H., S. P. Stevens, B. Pfefferbaum, K. F. Wyche, and R. L. Pfefferbaum (2008). "Community resilience as a metaphor, theory, set of capacities, and strategy for disaster readiness,” American Journal of Community Psychology 41(1-2):127-150, doi:10.1007/s10464-007-9156-6.

Orrick, E. (2015) “Community-Wide Disaster Recovery: The Choices that Divide Us,” August 20, 2015. Online: http://www.slideshare.net/ElizabethOrrick/orrickcommunitywide-disaster-recovery-powerpoint3. Accessed December 15, 2016.

Osborne, S, Williamson, A and Beattie, R. 2010. “Community Involvement in Rural Regeneration Partnerships: Exploring the Rural Dimension,” Local Government Studies, 30(2): 156-188

Pane, J.; McCaffrey, D.; Kalra, N.; and Zhou, A. (2008). "Effects of Student Displacement in Louisiana During the First Academic Year after the Hurricanes of 2005. Rand Corporation,” Santa Monica, CA. Online: http://www.rand.org/pubs/reprints/RP1379.html. Accessed May 11, 2016.

Patterson, T. (2011), "Katrina evacuees shift Houston's identity.” Cable News Network (CNN), August, 2011 http://www.cnn.com/2011/US/08/12/katrina.houston/. Accessed December 15, 2016.

Perz, S. G., Shenkin, A., Barnes, G., Cabrera, L., Carvalho, L. A., and Castillo, J. (2012). “Connectivity and resilience: a multidimensional analysis of infrastructure impacts in the Southwestern Amazon," Social Indicators Research, 106(2): 259-285.

Peterson, D. (2015). “What is Adult Education?” About Education, Online: http://adulted.about.com/od/whatisadultlearning/p/whatisadulteducation.htm. Accessed August 23, 2016.

Philippa Williams \& Barbara Pocock (2010). "Building community for different stages of life: physical and social infrastructure in master planned communities,” Community, Work \& Family, 13(1): 71-87.

PPD-8 (2011). "Presidential Policy Directive/PPD-8: National Preparedness,” the White House, March 30, 2011. Online: https://www.dhs.gov/presidential-policy-directive-8-national-preparedness. 
PPD-21 (2013). Presidential Policy Directive/PPD-21, the White House, February 12, 2013. Online: http://www.whitehouse.gov/the-press-office/2013/02/12/presidential-policy-directive-critical-

infrastructure-security-and-resil.

Putnam, R. (1993). Bowling Alone: The Collapse and Revival of American Community, New York, NY: Simon and Schuster.

Quarantelli, E. L. (1982). “General and Particular Observations on Sheltering and Housing in American Disasters,” Disasters, vol. 6, no. 4, pp. 277-281.

Quarantelli, E. L. (1991). "Patterns of Sheltering and Housing in American Disasters,” University of Delaware Disaster Research Center Preliminary Paper \#170.

Reeves, J. P. (2013). “Observations from DC Water on EMAC Deployment,” American Water Works Association Annual Conference and Exposition 2013, Denver..

Renschler, C. S., A. Frazier, L. Arendt, G.-P. Cimellaro, A. M. Reinhorn and M. Bruneau (2010). “A framework for defining and measuring resilience at the community scale: The PEOPLES resilience framework,” Buffalo, NY, the Multidisciplinary Center for Earthquake Engineering Research (MCEER).

Rinaldi, S.M. (2001). "Modeling and simulating critical infrastructures and their interdependencies," $37^{\text {th }}$ Annual Hawaii International Conference on System Sciences.

Rinaldi, S. M., J. P. Peerenboom, and T. K. Kelly (2001). "Identifying, understanding, and analyzing critical infrastructure interdependencies,” IEEE Control Syst. Mag., vol. 21, no. 6, pp. 11-25.

Riordan, R. and J. Moyer (2007). "Mutual Aid and Assistance among Water Utilities: What is it? Where has it been? Where is it going?,” Am. Water Work. Assoc. J., vol. 99, no. 4, pp. 41-44.

Ritchie, L.A. and D.A. Gill (2011). "Considering Community Capitals in Disaster Recovery and Resilience,” PERI Scope, Public Entity Risk Institute, 14(2). Online:

https://www.riskinstitute.org/peri/component/option,com_deeppockets/task,catContShow/cat,86/id,1086/I temid,84/

RMC Water and Environment (2006). “Bay Area Integrated Regional Water Management Plan,” San Francisco, CA.

Saltman, K. (2007). “Capitalizing on Disaster: Taking and Breaking Public Schools,” Paradigm Publishers.

Scharfenaker, M. (2006). “Katrina stories highlight new realities of disaster planning,” Am. Water Work. Assoc. J., vol. 98, no. 6, pp. 16-30.

Schuster, M., Stein, B., Jaycox, L., Collins, R., Marshall, G., Elliott, M., Zhou, A., Kanouse, d., Morrison, J., \& Berry, S.H. (2001). “A national survey of stress reactions after the September 11, 2001, terrorist attacks,” The New England Journal of Medicine, 345(20), 1507-1512. 
Serrant, T.D. (2013). “Children, Learning and Chronic Natural Disasters: How Does the Government of Dominica Address Education during Low-Intensity Hurricanes?” Ph.D. dissertation, University of Pittsburgh.

Shaw, J.A., Applegate, B., \& Schorr, C. (1996). “Twenty-one month follow-up study of school-age children exposed to Hurricane Andrew,” Journal of the American Academy of Child and Adolescent Psychiatry, 35, 359-364.

Shaw, R., B. Razafindrabe, P. Gulshan, Y. Takeuchi and A. Surjan (2009). "Climate disaster resilience: Focus on coastal urban cities in Asia,” International Environment and Disaster Management (IEDM) Laboratory, Kyoto University.

Siegler, V. (2014). Measuring Social Capital, Office for National Statistics, UK.

Silva, J. d. and B. Morera (2014). “City Resilience Framework,” ARUP, London, UK.

Sime, J.D. (1983). “Affiliative behavior during escape to building exits,” Journal of Environmental Psychology, 3, 21-41.

Smilde-van den Doel, D. A., Smit, C., and Wolleswinkel-van den Bosch, J. H. (2006). "Before and after a disaster school performance and social-emotional behavior of primary school children,” Pediatrics, 118(5), 1311-1320.

Spence, S. D. and C. M. Tuozzoli (2011). “Gap Assessment for ASME-ITI/ AWWA J100-10 Standard and Leading Vulnerability Assessment Tools,” Water Research Foundation, Web Report \#4358.

Spence, S., J. Whitler, and C. Stormont (2011). "Lessons Learned From WARN Tabletop Exercises,” Am. Water Work. Assoc. J., vol. 103, no. 12, pp. 24-27.

Stokols, D., and Shumaker, S.A. (1981). "The psychological context of residential mobility and wellbeing,” Journal of Social Issues, 38, 149-171.

Sturgill, Kim (2008). "Obstacles post Katrina and the role of school leadership in one Mississippi school,” Ph.D. dissertation, Walden University.

Turner, A. (2015), “Ten years later, Katrina evacuees now part of Houston fabric,” Houston Chronicle, August, 2015. http://www.houstonchronicle.com/news/houston-texas/houston/article/Ten-years-laterKatrina-evacuees-now-part-of-6458412.php. Accessed December 15, 2016.

United States Department of Education (2004). “Building the Legacy: IDEA 2004,” Online: http://idea.ed.gov/explore/view/p/,root,regs,300,A,300\%252E39. Accessed August 23, 2016.

United States Department of Education (2015). "Education in the United States: A Brief Overview.” Online: http://www2.ed.gov/about/offices/list/ous/international/edus/index.html. Accessed July 8, 2016.

Uphoff, N. (2000). "Understanding social capital: Learning from the analysis and experience of participation” in Social Capital: A Multifaceted Perspective, Dasgupta, P and Serageldin, I (eds.) World Bank Washington, D.C. 
Verrucci, E., T. Rossetto, J. Twigg and B. Adams (2012). "Multi-disciplinary Indicators for evaluating the Seismic Resilience of Urban Areas,” $15^{\text {th }}$ World Conference on Earthquake Engineering, Lisbon, Portugal.

Vickerman, R.W. (1994). “Transportation Infrastructure and Region Building in the European Community,” Journal of Common Market Studies, 32(2).

Weist, MD, Sander, MA, Lever, NA, Rosner, LE, Pruitt, DB, Lowie, JA, Hill, S, Lombardo, S, Christodulu, KV (2002). “School Mental Health's Response to Terrorism and Disaster,” Journal of School Violence 1(4), 5-31.

Williams, P., and Pocock, B. (2009). Building Community for Different Stages of Life: Physical and Social infrastructure in Master Planned Communities.

Williams, R. (1973). The Country and the City, Oxford University Press. 